Linköping Studies in Science and Technology

Dissertation Thesis No. 2134

\title{
Functionalized \\ epitaxial graphene \\ as versatile platform \\ for air quality sensors
}

\section{Marius Rodner}



Linköping Studies in Science and Technology

Dissertation Thesis No. 2134

\title{
Functionalized epitaxial graphene as versatile platform for air quality sensors
}

\author{
Marius Rodner
}

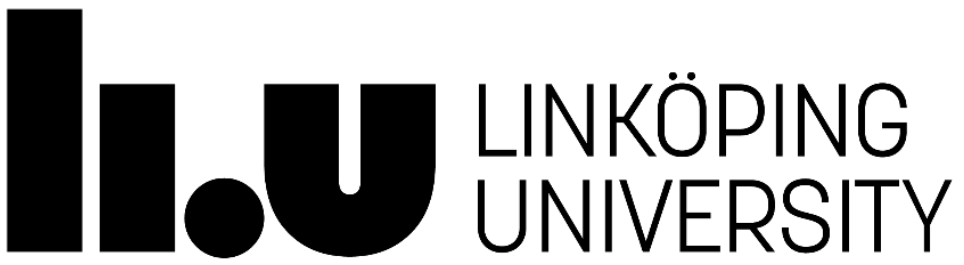

\footnotetext{
Applied Sensor Science Unit

Sensors and Actuators Division

Department of Physics, Chemistry and Biology

Linköping University

SE-581 83 Linköping

Sweden
}

Linköping 2021 
Cover art: Graphene layer with interacting gas molecules and environmental influences. Designed by graphic designer Paolo Quattrone.

(cc) EY-NG This work is licensed under a Creative Commons AttributionNonCommercial 4.0 International License.

https://creativecommons.org/licenses/by-nc/4.0/

(C) Marius Rodner

Printed by LiU-Tryck, Linköping, Sweden, 2021

ISBN: 978-91-7929-675-9

ISSN: 0345-7524 
Functionalized epitaxial graphene as versatile platform for air quality sensors

\author{
Dissertation \\ zur Erlangung des Grades \\ des Doktors der Ingenieurwissenschaften \\ der Naturwissenschaftlich-Technischen Fakultäten \\ der Universität des Saarlandes
}

von

Marius Rodner

Saarbrücken

2021 



\section{ABSTRACT}

The work presented in this thesis focuses on epitaxial graphene on $\mathrm{SiC}$ as a platform for air quality sensors. Several approaches have been tested and evaluated to increase the sensitivity, selectivity, speed of response and stability of the sensors. The graphene surfaces have been functionalized, for example, with different metal oxide nanoparticles and nanolayers using hollow-cathode sputtering and pulsed laser deposition. The modified surfaces were investigated towards topography, integrity and chemical composition with characterization methods such as atomic force microscopy and Raman spectroscopy. Interaction energies between several analytes and nanoparticle-graphene-combinations were calculated by density functional theory to find the optimal material for specific target gases, and to verify the usefulness of this approach. The impact of environmental influences such as operating temperature, relative humidity and UV irradiation on sensing properties was investigated as well. To further enhance sensor performances, the first-order time-derivative of the sensor's resistance was introduced to speed up sensor response and a temperature cycled operation mode was investigated towards selectivity.

Applying these methods in laboratory conditions, sensors with a quantitative readout of single ppb benzene and formaldehyde were developed. These results show promise to fill the existing gap of low-cost but highly sensitive and fast gas sensors for air quality monitoring. 



\section{ZUSAMMENFASSUNG}

Der Fokus dieser Thesis liegt auf der Erforschung von epitaxialem Graphen auf SiC als Plattform für Luftgütesensoren. Diverse Ansätze wurden untersucht, um die Sensitivität, Selektivität, Reaktionsgeschwindigkeit und Stabilität der Sensoren zu verbessern. Die Graphenoberfläche wurde unter anderem mit Metalloxid-Nanopartikeln oder nanometerdünnen Schichten funktionalisiert. Die funktionalisierten Sensorschichten wurden hinsichtlich ihrer Oberflächenbeschaffenheit, Unversehrtheit und chemischen Zusammensetzung mittels Rasterkraftmikroskopie und Raman Spektroskopie untersucht. Die Reaktionsenergien zwischen verschiedenen Analyten und Nanopartikel-Graphen-Kombinationen wurden mit Dichtefunktionaltheorie berechnet, um das optimale Material für spezifische Gase zu finden und um die Brauchbarkeit dieser Funktionalisierungsmethode zu verifizieren. Der Einfluss von äußeren Parametern wie Sensortemperatur, Luftfeuchte und UV-Einstrahlung auf die Sensoreigenschaften wurde ebenfalls untersucht. Um die Sensorleistung zu verbessern, wurde die erste zeitliche Ableitung des Sensorwiderstands als zusätzliches Signal eingeführt und ein temperaturzyklischer Betriebsmodus hinsichtlich seiner Eignung erforscht.

Durch die Anwendung dieser Methoden ist es möglich, einzelne ppbs Benzol und Formaldehyd unter Laborbedingungen zu detektieren. Diese Ergebnisse sind vielversprechend, um die bestehende Lücke der günstigen, aber sehr sensitiven Sensoren für Luftqualitätsüberwachung zu schließen. 



\section{SAMMANFATTNING}

Arbetet som presenteras i denna avhandling fokuserar på epitaxiell grafen på $\mathrm{SiC}$ som en plattform för luftkvalitetssensorer. Flera tillvägagångssätt har testats och utvärderats för att öka känsligheten, selektiviteten, responstiden, och stabiliteten hos sensorerna. Grafenytorna har modifierats till exempel med olika metalloxid-nanopartiklar och nanolager med användning av hålkatodsputtring och PLD. De modifierade ytorna undersöktes mot topografi, strukturell integritet och kemisk sammansättning med karakteriseringsmetoder som atomkraftsmikroskopi och Ramanspektroskopi. Interaktionsenergier mellan flera analyter och nanopartiklar-grafen-materialkombinationer beräknades med täthetsfunktionalteori för att hitta de optimala materialkombinationerna för specifika målgaser och för att verifiera användbarheten av ytmodifieringarna. Effekten av externa faktorer som arbetstemperatur, relativ fuktighet och UV-bestrålning på avkänningsegenskaper undersöktes också. För att ytterligare förbättra sensorprestanda introducerades första ordningens tidsderivat av sensorns resistans för att snabbare utvärdera sensorns respons, och ett temperaturcyklat driftläge i kombination med multivariat dataanalys undersöktes mot selektivitet.

Genom att använda dessa metoder under laboratorieförhållanden utvecklades sensorer med en kvantitativ avläsning av enstaka ppb bensen och formaldehyd. Dessa resultat visar på en möjlig lösning för att fylla det hålrum som finns i dagens sensorteknologier för luftkvalitetsövervakning, där flera relevanta gaser i dagsläget inte kan mätas med kostnadseffektiva men mycket känsliga och snabba gassensorer. 



\section{PoPULÄRVETENSKAPLIG}

\section{SAMMANFATTNING}

Förorenad luft är globalt den största enskilda orsaken till förtida dödsfall. Problemet är så allvarligt att världshälsoorganisationen, WHO, beskriver det som "den nya tobaken". Luftföroreningar medför enorma samhällskostnader. De tros bära ansvar för cirka åtta miljoner förtida dödsfall per år, och världsbanken har uppskattat att dålig utomhusluft årligen kostar det globala samhället mer än 5000 miljarder dollar i välfärdsbelastning.

Att övervaka hur giftiga luftföroreningar sprider sig lokalt i bebodda områden, framförallt storstäder där föroreningar är högre, är avgörande för att förmildra deras samhällspåverkan. Tyvärr kan inte dagens sensorteknologier mäta vissa föroreningar som är giftiga redan vid extremt låga koncentrationer med den noggrannhet som krävs för att garantera en säker levnadsmiljö.

Linköpings universitet har utvecklat sensorer i speciella sensormaterial som ligger i teknisk framkant vad gäller prestanda för de aktuella föroreningarna baserat på tester i labbmiljö. Sensorerna baseras på högkvalitativt grafen på kiselkarbid vars yta modifierats till exempel med nanostrukturer av metall eller metalloxid för att skräddarsy sensoregenskaperna. De modifierade ytorna undersöktes mot dess topografi, integritet och kemiska sammansättning med olika karakteriseringsmetoder. Flera sensorer testades för reaktion mot gasformiga föroreningar vid koncentrationer som är relevanta för övervakning av luftkvaliteten. Förutom välkända gaser som $\mathrm{CO}, \mathrm{NO}_{2}$ och $\mathrm{NH}_{3}$, har också giftigare gaser som bensen och formaldehyd (VOCs) undersökts. Dessutom applicerades olika nivåer av relativ fuktighet i omgivningen, sensortemperatur och ytterligare UV-bestrålning för att undersöka dessa effekter på sensorsvaret.

Som förväntat beror sensorernas prestanda på material/gas-kombination. Alla sensorer reagerade på $\mathrm{NO}_{2}$ and $\mathrm{NH}_{3}$, men endast ett fåtal visade respons för VOCs, vars svar ytterligare försvårades med fuktighet i omgivningen. Sensorsvarets magnitud varierar beroende på sensorernas ytstruktur och vilken gas de exponeras mot, men överlag erhålls störst reaktion gentemot $\mathrm{NO}_{2}$ och $\mathrm{NH}_{3}$. Trots detta är dessa sensorer lovande även för detektion av VOCs, då de sensorer som reagerade mot VOCs uppvisade svar för koncentrationer ner till låga miljarddelar, som är precis vad som 
behövs för luftkvalitetsövervakning. Detektion av så pass låga koncentrationer är möjlig tack vare den höga graden av uniformitet och låga mängden defekter i grafen på kiselkarbid, vilket i sin tur resulterar i ett material som karakteriseras av lågt brus och hög känslighet.

I nuläget kan vi inte detektera och samtidigt särskilja mellan alla gaser med bara en sensor. Vi tror att detta kommer bli möjligt i framtiden genom att använda flera sensorer samtidigt och/eller cyklade driftlägen, i kombination med smart analys av flerdimensionella data, ett koncept som ofta kallas elektronisk näsa. 


\section{Preface}

The present dissertation thesis is the result of my binational doctoral studies carried out between November 2016 and May 2021. The work was supervised by Dr. Jens Eriksson at the Sensors and Actuators Division at the Department of Physics, Chemistry and Biology (IFM), Linköping University, Sweden and Prof. Andreas Schütze at the Lab for Measurement Technology, Saarland University, Germany. It was performed in close collaboration with other divisions at IFM and the Department of Microtechnology and Nanoscience at Chalmers University of Technology, Sweden. Part of the contents of these chapters have been previously published in my Licentiate Thesis (No. 1851, Linköping Studies in Science and Technology, ISBN 978-91-7519-010-5). My research was financially supported by the Swedish Foundation for Strategic Research (SSF) through the grants GMT14-0077 and RMA15-024. During the course of research underlying this thesis, I was enrolled in Agora Materiae, a multidisciplinary doctoral program at Linköping University, Sweden. Research results are summarized, brought into context and then presented in the appended papers, preceded by an introduction to the scientific field and used research methods. For a better overview of my work, the latest unpublished results are included as well. However, to comply with regulations from both universities, only papers that have at least been accepted can be part of the formal evaluation.

Marius Rodner

Linköping, March 2021 



\section{APPENDED PAPERS}

Paper 1 M. Rodner, J. Bahonjic, M. Mathisen, R. Gunnarsson, S. Ekeroth, U. Helmersson, I. G. Ivanov, R. Yakimova, J. Eriksson, Performance tuning of gas sensors based on epitaxial graphene on silicon carbide, Materials and Design (2018)

Paper 2 M. Rodner, D. Puglisi, S. Ekeroth, U. Helmersson, I. Shtepliuk, R. Yakimova, A. Skallberg, K. Uvdal, A. Schütze, J. Eriksson, Graphene Decorated with Iron Oxide Nanoparticles for Highly Sensitive Interaction with Volatile Organic Compounds, Sensors (2019)

Paper 3 M. Rodner and J. Eriksson, First-order time-derivative readout of epitaxial graphene-based gas sensors for fast analyte determination, Sensors and Actuators Reports (2020)

Paper 4 M. Rodner, A. Icardi, M. Kodu, R. Jaaniso, A. Schütze, J. Eriksson, Metal Oxide Nanolayer-Decorated Epitaxial Graphene: A Gas Sensor Study, Nanomaterials (2020)

\section{Author's contribution to appended papers}

Paper 1 I evaluated and interpreted all measurement data and wrote the manuscript.

Paper 2 I designed and performed all gas and AFM measurements, evaluated and interpreted the data and wrote the main part of the manuscript.

Paper 3 I designed and performed all measurements, evaluated and interpreted the data and wrote the manuscript.

Paper 4 I designed and performed most of the measurements, evaluated and interpreted the data and wrote the main part of the manuscript.

Published articles have been reprinted with the permission of the copyright holders. 


\section{OTHER RELATED PUBLICATIONS}

Paper A M. Rodner, D. Puglisi, R. Yakimova, J. Eriksson, A Platform for Extremely Sensitive Gas Sensing: 2D Materials on Silicon Carbide, Tech Connect Briefs (2018)

Paper B M. Rodner, D. Puglisi, S. Ekeroth, U. Helmersson, I. G. Ivanov, R. Yakimova, K. Uvdal, A. Schütze, J. Eriksson, Iron Oxide Nanoparticle Decorated Graphene for Ultra-Sensitive Detection of Volatile Organic Compounds, Proceedings (2018)

Paper C P. Darshni Kaushik, M. Rodner, G. B. V. S. Lakshmi, I. G. Ivanov, G Greczynski, J. Palisaitis, J. Eriksson, P. Solanki, A. Aziz, A. M. Siddiqui, R. Yakimova, M. Syväjärvi, G. R. Yazdi, Surface functionalization of epitaxial graphene using ion implantation for sensing and optical applications, Carbon (2019)

Paper D K. H. Kim, H. He, M. Rodner, R. Yakimova, K. Larsson, M. Piantek, D. Serrate, A. Zakharov, S. Kubatkin, J. Eriksson, S. Lara-Avila, Chemical Sensing with Atomically Thin Platinum Templated by a 2D Insulator, Advanced Materials Interfaces (2020)

Paper E M. Rodner, A. Icardi, M. Kodu, R. Jaaniso, J. Eriksson, Metal Oxide Nanolayer Decorated Epitaxial Graphene Gas Sensors for Air Quality Monitoring, SMSI 2020 Conference - Sensor and Measurement Science International (2020)

Paper F G. Domènech-Gil, M. Rodner, J. Eriksson, D. Puglisi, Temperature Cycled Operation and Multivariate Statistics for Electronic-Nose Applications Using Field Effect Transistors, Proceedings (2020) 


\section{ACKNOWLEDGEMENTS}

First of all, I want to thank my supervisor Jens Eriksson for accepting me into his group and guiding me through this scientific journey on the search for the ultimate graphene gas sensor. I am grateful for your support with so many scientific questions and your patience, especially, when I come knocking again asking supposedly silly questions. Research is not all about science and, therefore, thank you for being a good friend also outside of work.

Moreover, I would like to thank all the former and current members of our small research group, Anette Andersson, Anita Lloyd Spetz, Donatella Puglisi, Maria Francesca Santangelo, Guillem Domènech Gil, Jasna Bahonjic, Lida Khajavizadeh, Manuel Bastuck, Mike Andersson, Peter Möller and Yuki Hasegawa. Even the most interesting project would not be any fun without a good work environment. So thank you all for all the Fikas, country dinners, work and non-work related trips around the world, group activities and of course a lot of scientific and non-scientific discussions. A special thanks to Donatella, who took care of me when I was new to this group and to Sweden. And also to Mike for his company in and outside of IFM and without whom our laboratory would not function at all. Moreover, I want to thank our current and former master students Adam Icardi, Alberto Zilli, Cecilia Gullström, Isac Cederquist and Marcus Mathisen for their contributions to this work.

For the opportunity to continue a collaboration with my old group at Saarland University, I want to thank especially Andreas Schütze for joining my doctorate as my supervisor on the German side. In general, I want to thank Andreas and the members of his Laboratory for Measurement Technology group for the hospitability throughout the years and the traditional "Fleischkäse-Freitage". A very special thanks to Manuel Bastuck, who was also a part time member of our group here in Linköping, when he was not pursuing his $\mathrm{PhD}$ in Germany. Thank you for taking care of me and my measurement needs when I came for visits to the old lab and all the help and discussions about our courses, papers, ongoing work, theses and life in general. A similar important thanks also to Caroline Schultealbert, Henrik Lensch and Tobias Baur, who helped me during and between my visits in Germany, making sure that everything from data acquisition over data handling and analysis to just having a good time went well. 
Furthermore, I want to thank my co-supervisor Kajsa Uvdal and my mentors Fredrik Karlsson and Jianwu Sun for all the fruitful discussions and helpful suggestions.

In general, I would also like to thank all the people I have collaborated with during this project and who supported me from sample preparations, over characterizations to evaluations and discussions. Thanks to Andreas Skallberg, Ivan G. Ivanov, Ivan Shtepliuk, Rickard Gunnarsson, Rositsa Yakimova, Sebastian Ekeroth and Ulf Helmersson from IFM at Linköping University, Hans He, Kyung Ho Kim, Samuel Lara-Avila, Sergey Kubatkin and Tomas Löfwander from the MC2 Lab at Chalmers University of Technology and Margus Kodu and Raivo Jaaniso from the Institute of Physics at University of Tartu.

Many thanks to my friends and colleagues from the Agora Materiae graduate school, the Agora Student Council of which I was a member of for longer than expected, and the former and current heads of Agora, PerOlof Holz, Fredrik Karlsson and Caroline Brommesson, for all the nice study trips, seminars, summer conferences and discussions.

I had also a very nice time being a member of the PhD Reference Group (now Doctoral Student Council - DoStuC) at IFM, thus getting involved in many interesting projects and boards throughout the whole university. It was a pleasure to work with you guys.

I would like to acknowledge the financial support from the Swedish Foundation for Strategic Research (SSF) through the grants GMT14-0077 and RMA15-024, and from the Centre in Nano science and technology (CeNano) through the "Graphene-nanoparticle hybrid gas sensor" projects. The research visits in Germany were financially supported by travel grants from the Hans Werthén Foundation and the Swedish Chapter of International Society of Indoor Air Quality and Climate (SWESIAQ).

$\mathrm{A} \mathrm{PhD} \mathrm{student} \mathrm{life} \mathrm{which} \mathrm{is} \mathrm{just} \mathrm{about} \mathrm{the} \mathrm{PhD}$ studies would be rather annoying and so I am glad to have made many new friends from all over the world during my time here. Thanks for the nice lunch group, my climbing buddies, tennis opponents, hiking comrades, techno-totem ravers, travel fellows and more. It was seldom boring (except during COVID-19 restrictions) and someone was always up for Fika, beers, dinners, concerts, parties, games, BBQs and so on. So thanks to Alex, Andreas, Arnaud, Claudia \& Mattias, Clio, Davide, Fredrik \& Matilda, Hassan \& Anna-Giulia, Judit \& Kevin, Johan \& Julia, Karina, Laurent, Nikos, Pernilla, Robin $\&$ Paula, Serge, Tim and Victor. In case I have forgotten anyone, I apologize. It was not on purpose, so thank you as well. 
Of course, I also want to thank my 'old' friends from Germany for their support and a special thanks to those who have even managed to visit me during my time here in Sweden.

Last and most important, I want to thank my family and my girlfriend Lisa. Thank you very much for so much support and motivation both from Germany and on site here in Linköping. This whole expedition would not have been possible without you. 



\section{Table of contents}

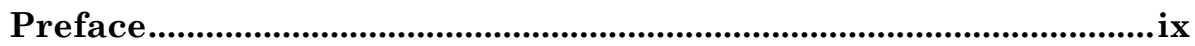

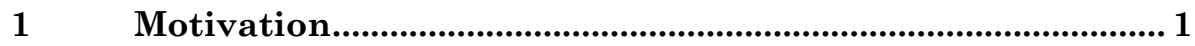

$2 \quad$ Theory and concepts ....................................................................... 5

$2.1 \quad$ Chemical gas sensors ................................................................ 5

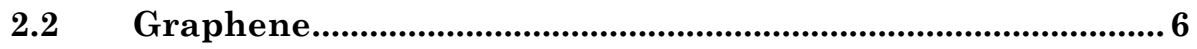

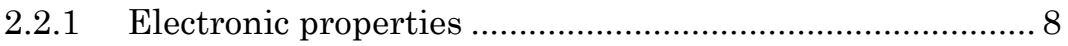

2.2.2 Epitaxial graphene on $\mathrm{SiC}$............................................. 10

$2.3 \quad$ Graphene as sensor platform.................................................... 11

2.3.1 Optimizing EG gas sensors .............................................. 12

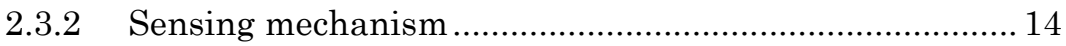

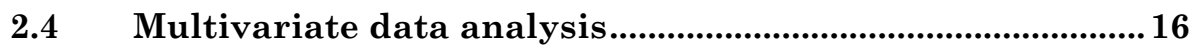

$3 \quad$ Experimental methods ............................................................. 19

3.1 Deposition techniques ..............................................................19

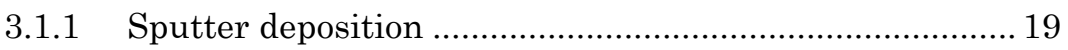

3.1.2 Pulsed laser deposition.................................................. 24

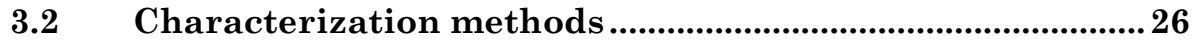

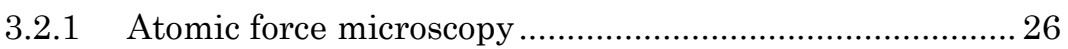

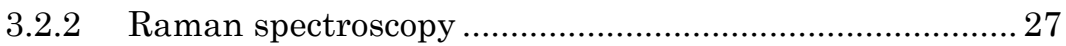

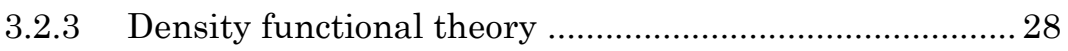

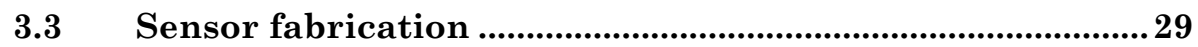

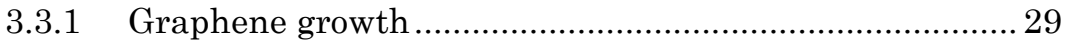

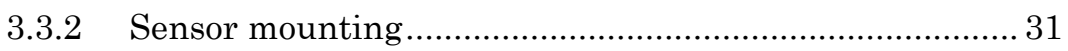

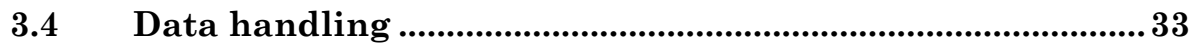

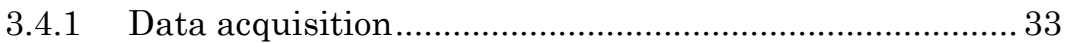

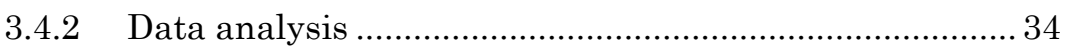

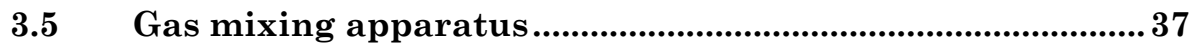

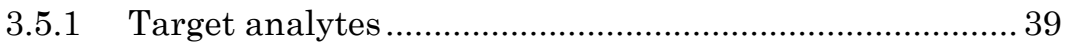

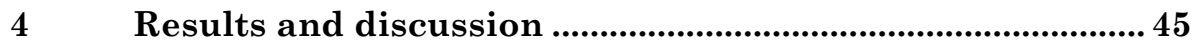

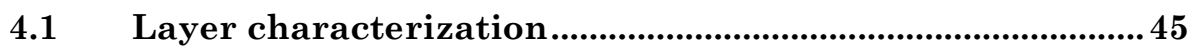


Table of contents

4.1.1 Topography ....................................................... 45

4.1.2 Structural integrity ............................................ 48

4.1.3 Theoretical considerations ....................................... 50

4.2 Gas measurements .............................................................. 51

4.2.1 Influence of temperature ...................................... 51

4.2.2 Influence of humidity ............................................. 53

4.2.3 Influence of UV irradiation....................................... 56

4.2.4 Influence of defects.............................................. 58

4.2.5 Target analyte detection ....................................... 60

4.3 Advanced data evaluation .................................................... 68

4.3.1 First-order time-derivative signal .............................. 68

4.3.2 Multivariate analysis ............................................ 74

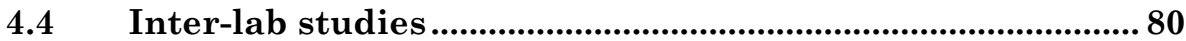

4.5 More EG sensor applications .............................................. 82

5 Conclusions and outlook ................................................ 85

References .............................................................................. 87

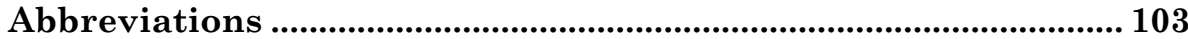




\section{Motivation}

According to the World Health Organization (WHO), several toxic air pollutants exceed the recommended exposure levels in more than $91 \%$ of the monitored urban areas [1, 2]. It is estimated that poor air quality is currently accountable for more than 8 million premature deaths per year with indoor air quality being the single largest environmental health risk factor worldwide [3]. With people in North America and Europe spending about $90 \%$ of their time indoors, a single short time exposure to most air pollutants is not dangerous, but reoccurring exposures over long periods of time can cause severe health risks and diseases referred to as "sick building syndrome" [4]. Poor air quality is also inflicting a yearly financial burden of about 5 trillion US dollars [5], with emissions from fossil fuels alone costing about $3.3 \%$ of global GDP, which is about 8 billion US dollars per day [6]. Therefore, a proper way of assessing air quality needs to be established.

The key is to be able to detect even trace amounts of hazardous gases. When it comes to the detection of carcinogenic volatile organic compounds (VOCs) like benzene $\left(\mathrm{C}_{6} \mathrm{H}_{6}\right)$ and formaldehyde $\left(\mathrm{CH}_{2} \mathrm{O}\right)$ at relevant levels, there are analytical instruments available which are, however, large, complex, and expensive. Small low-cost sensor systems, on the other hand, suffer from limited sensitivity, selectivity and stability [7, 8]. A portable low-cost sensor capable of rapid quantification of relevant VOCs at single digit parts per billion $\left(\mathrm{ppb}^{1}\right)$ or even lower would thus be a breakthrough in the field of air quality monitoring (AQM). Moreover, a current report from IDTechEx expects that the total market for environmental sensors will be over 3.8 billion US dollars by 2030 [9].

Two-dimensional materials like graphene exhibit several outstanding properties which enable the fabrication of sensor devices that can be used for quantification of very small gas concentrations as even a small change in the number of charge carriers results in a large change in the electronic state, which then can easily be measured as a change in resistance of the sensor surface $[10,11]$. In this work, epitaxial graphene on silicon carbide, which has been demonstrated to outperform standard CVD graphene if used as gas sensor [12], was studied as transducer or sensor material for AQM applications.

${ }^{1} \mathrm{ppb}$ refers here to the ratio in volume. Also known as ppb. 
One way to strongly increase the sensitivity and, potentially, selectivity of a gas sensor is the combination of different materials or the decoration of a sensitive transducer with a reaction-selective material, like metal oxides, combining their individual advantages [13]. For example, the combination of sensitive and more selective nanostructured metal oxides with very sensitive and low noise graphene leads to promising sensor hybrids. There, the gas reaction mainly takes place on the metal oxide nanostructure, and the graphene is used as a highly sensitive transducer [14, 15] leading to an increased sensitivity and selectivity to gases like nitrogen dioxide $\left(\mathrm{NO}_{2}\right)$, benzene and formaldehyde [16].

High sensitivity alone though is not sufficient to produce a useful gas sensor. Other properties such as stability, selectivity and fast time constants are also necessary. Especially for AQM, a sensor needs to be sensitive, selective, stable and it must have a high enough sampling rate to allow near-real-time monitoring with high time and concentration resolution $[17,18]$. To speed up the sensor response, usually the sensor is irradiated with a light source during the gas measurement [19] or operated at elevated temperatures [20]. A different method is the use of the sensor signal's first-order time-derivative which was shown to drastically decrease the detection time [21]. Improved stability, selectivity and sometimes even sensitivity can also be gained through a temperature cycled operation mode and multivariate data analysis [20, 22].

Here, epitaxial graphene on SiC-based gas sensors have been investigated regarding their capability of quickly detecting VOCs at concentrations of interest for AQM by combining several of the mentioned approaches. Evaluations performed at two independent laboratories verify the reliability of the obtained results.

This thesis summarizes and elaborates upon the work published in $\mathrm{Pa}$ pers 1-4. Additionally, unpublished content from latest research is included for a better overview.

Paper 1 discusses ways to improve the performance of gas sensors based on epitaxially grown graphene on silicon carbide with metal oxide nanoparticle decoration, UV irradiation and a smart sensor readout utilizing the first-order time-derivative of the sensor's resistance to evaluate them for AQM applications.

Paper 2 focuses on the surface decoration with iron oxide nanoparticles, and the implications for sensing properties to $\mathrm{C}_{6} \mathrm{H}_{6}$ and $\mathrm{CH}_{2} \mathrm{O}$ in the concentration range from parts per million down to single-digit parts per billion to create ultra-sensitive gas sensors for hazardous VOCs. 
Paper 3 investigates the utilization of the first-order time-derivative of the sensor's resistance as an additional sensor signal, its impact for time constants and its stability to external influences to enhance speed and stability of the sensor response to pulsed gas exposures.

Paper 4 studies the sensor properties of epitaxial graphene sensors decorated with several different metal oxide nanolayers, their response to various gases, the impact of environmental influences and an inter-lab comparison with measurements performed both at Linköping University and Saarland University. 



\section{Theory and concepts}

This chapter discusses the general properties of graphene and its peculiarities if grown on silicon carbide ( $\mathrm{SiC}$ ). It also gives a short introduction to chemical gas sensors and graphene sensors in general with a focus on possible surface modifications to tailor them for optimal gas detection.

\subsection{Chemical gas sensors}

In the context of this thesis, a chemical sensor is a sensor able to detect a chemical analyte, i.e., the presence of a specific gas. The sensing mechanism itself can be of physical, chemical or biological nature [23]. Focusing on gas sensors that rely on the analyte to adsorb to the sensor surface, the weakest possible interaction would be physisorption, where the analyte only binds through van der Waals forces. A chemisorption, usually in the form of ionic binding, is much stronger and can occur after the physisorption. Moreover, gas molecules can also dissociate and then react with reactive oxygen ions that are normally adsorbed on the sensor surface.

There are many different types of chemical gas sensors, but here, the focus is on resistive-type sensors, where a gas exposure leads to a change in the sensor's resistivity (or conductivity). The sensing layer is normally based on grainy, metal oxide semiconducting (MOS) materials such as tin dioxide $\left(\mathrm{SnO}_{2}\right)$, tungsten trioxide $\left(\mathrm{WO}_{3}\right)$ or zirconium dioxide $\left(\mathrm{ZrO}_{2}\right)$ [24-26]. Two neighboring grains of the sensing material form an energy barrier, which each electron contributing to the electric current has to overcome. The energy barrier depends on the depletion layer, which in turn depends on the surface states of each grain [27]. Oxygen adsorption on the sensor surface in the form of $\mathrm{O}^{2-}$ or $2 \mathrm{O}^{-}$can bind formerly free electrons, thus forming a depletion layer. Therefore, the energy barrier between two grains will increase and the conductivity will decrease [27]. Equation (2.1) describes the dependence of the conductivity $\kappa$ for an n-type sensor material:

$$
\kappa=\kappa_{B} \cdot \exp \left(-\frac{E_{B}}{k_{B} T}\right)
$$

where $\kappa_{B}$ is the conductivity of the bulk material, $k_{B}$ the Boltzmann constant, $T$ the temperature, and $E_{B}$ the energy barrier. The energy barrier is 
dependent on the surface charge density $Q_{S}$ and the density of donors $N_{D}$ according to the Schottky approximation as follows [27]:

$$
E_{B} \sim \frac{Q_{S}^{2}}{N_{D}}
$$

A reducing gas will bind and remove oxygen from the surface, decreasing the energy barrier between two grains and decreasing the resistivity. A more in-depth study on metal oxide semiconductor gas sensors can be found in [28].

\subsection{Graphene}

The existence of graphene was predicted already in 1947, but it took until 2004 to produce a free-standing, monoatomic layer of graphene that could be studied with regards to its special properties [29]. Since then, extensive research was conducted and graphene became the most studied two-dimensional material until now. Its two-dimensional structure consists of an arrangement of hexagonal covalently bound carbon atoms forming a honeycomb structure. The planar structure is due to $\mathrm{sp}^{2}$ hybridization of orbitals between carbon atoms. Three out of four valence electrons are involved in strong covalent $\sigma$-bonds (binding energy of $\sim 5.9 \mathrm{eV}$ ) with adjacent carbon atoms. These bonds are responsible for the flat structure of graphene and the exceptional structural strength. The solitary p-orbital, i.e., the fourth valence electron, forms an aromatic $\Pi$-bond with the adjacent carbon atoms [30]. These delocalized electrons construct the valence and conduction bands in graphene and give rise to the materials conductivity. A schematic depiction of the honeycomb lattice structure of graphene and its corresponding reciprocal counterpart is shown in Figure 2.1. The lattice vectors of the real space unit cell are described as

$$
a_{1}=\frac{3 a}{2} \hat{x}+\frac{\sqrt{3} a}{2} \hat{y} ; \quad a_{2}=\frac{3 a}{2} \hat{x}-\frac{\sqrt{3} a}{2} \hat{y}
$$

where $a$ is the distance between adjacent carbon atoms (1.42 $\AA$ ). The hexagonal lattice of graphene can be described as a combination of two triangular sublattices, A and B. The primitive cell contains two atoms in total, one from each sublattice. 
Direct lattice

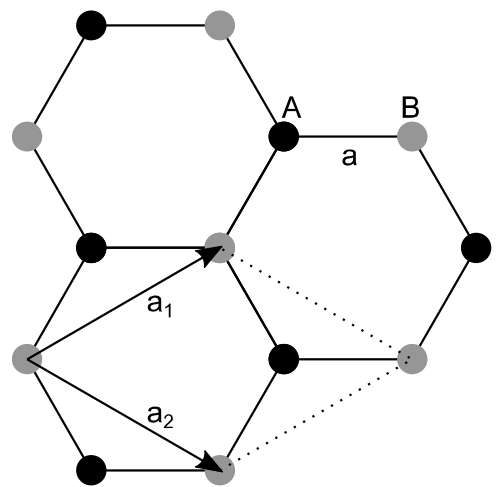

Reciprocal lattice

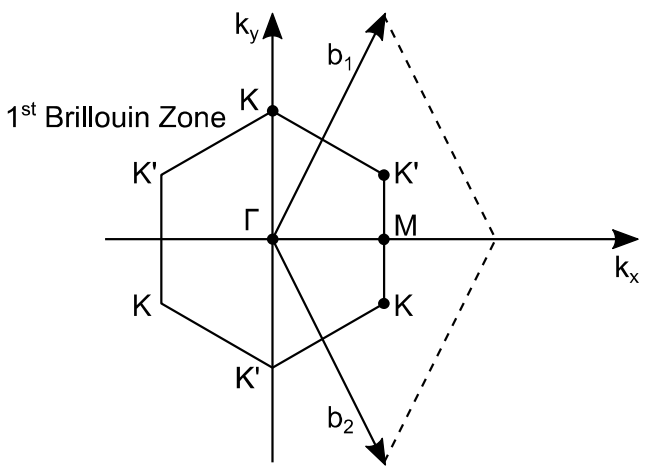

Figure 2.1: Left: Real space honeycomb lattice of graphene, consisting of two overlapping triangular sublattices A (black atoms) and B (grey atoms). The lattice vectors $\boldsymbol{a}_{\mathbf{1}}$ and $\boldsymbol{a}_{\mathbf{2}}$ form the primitive cell together with the dotted lines. Right: Reciprocal lattice with the first Brillouin zone. Adapted from [31].

The first Brillouin zone (BZ) is represented in the reciprocal lattice, which is defined by the reciprocal lattice vectors $b_{1}$ and $b_{2}$. The corners of the hexagonal first BZ are marked by six points, with only two non-equivalent points $K$ and $K^{\prime}$, due to the two sublattices A and B. These six points are called Dirac points. The reciprocal vectors and the Dirac points can be calculated using

$$
b_{i} a_{j}=2 \pi \delta_{i j}
$$

where $\delta_{i j}$ is the Kronecker delta, leading to

$$
\begin{gathered}
b_{1}=\frac{2 \pi}{3 a} \hat{x}+\frac{2 \pi}{\sqrt{3} a} \hat{y} ; \quad b_{2}=\frac{2 \pi}{3 a} \hat{x}-\frac{2 \pi}{\sqrt{3} a} \hat{y} \\
K=\frac{2 \pi}{3 a} \hat{x}+\frac{2 \pi}{\sqrt{3} \cdot 3 a} \hat{y} ; \quad K^{\prime}=\frac{2 \pi}{3 a} \hat{x}-\frac{2 \pi}{\sqrt{3} \cdot 3 a} \hat{y}
\end{gathered}
$$

A monolayer graphene can also be the starting point for other interesting carbon allotropes (see Figure 2.2). It can be wrapped into $0 \mathrm{D}$ fullerenes (also referred to as 'Buckyballs'), rolled into 1D nanotubes (also referred to as 'CNTs') or stacked into 3D graphite (also referred to as 'multilayer graphene' if containing only a low number of layers). Each structure, with its specific properties, is used in different fields of research and applications. 


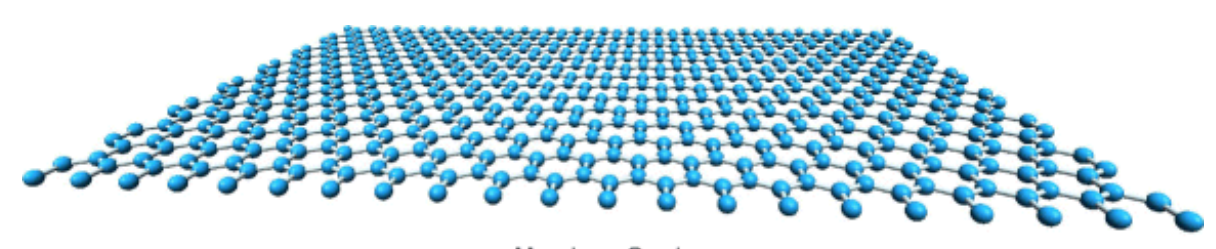

Monolayer Graphene

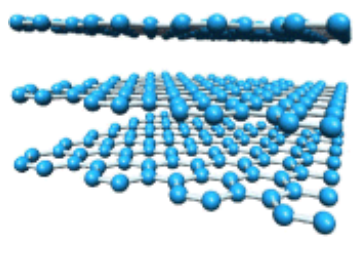

Multilayer Graphene

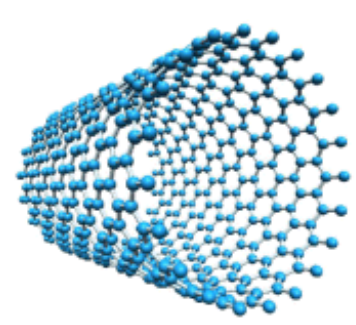

Carbon Nanotube

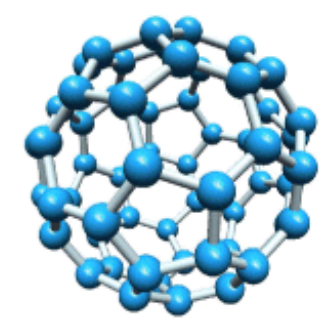

Buckyball

Figure 2.2: $\quad$ Different structures formed out of graphene. Reprinted with permission from Springer Nature, Journal of Infrared, Millimeter and Terahertz Waves: A Review of the Terahertz Conductivity of Bulk and Nano-Materials by James Lloyd-Hughes et al. (2012) [32].

\subsubsection{Electronic properties}

Graphene has some outstanding properties like high electrical conductivity $\left(\sim 10^{8} \mathrm{~S} \mathrm{~m}^{-1}\right)$, a high melting point $(4510 \mathrm{~K})$, high thermal conductivity (up to $5000 \mathrm{~W} \mathrm{~m}^{-1} \mathrm{~K}^{-1}$ ), a high maximum current density $\left(\sim 1.6 \cdot 10^{9} \mathrm{~A} \mathrm{~cm}^{-2}\right.$ ) and a high electron mobility $\left(2 \cdot 10^{5} \mathrm{~cm}^{2} \mathrm{~V}^{-1} \mathrm{~s}^{-1}\right.$ at an electron density of $\sim 2 \cdot 10^{11} \mathrm{~cm}^{-2}$ ) [33]. Figure 2.3 shows the low energy band structure of graphene with the six Dirac points. At the Dirac points, valence and conduction band meet in the reciprocal space. Since the energy dispersion is linear close to the Dirac points at low energies $|E|<3 \mathrm{eV}$ and the effective mass is equal to the second derivative of the energy versus momentum relations, charge carriers in graphene behave as ultra-relativistic particles with zero rest mass, hence like photons. Therefore, the Schrödinger equation reduces to the 2D Dirac equation which is used to describe the behavior of massless Dirac fermions. This is also the reason why the $K$ and $K^{\prime}$ points are called Dirac points. The linear dispersion creates a conical shape in reciprocal space, the so-called Dirac cone. The density of states DOS can then be calculated as

$$
\operatorname{DOS}(E)=\frac{2|E|}{\pi\left(\hbar v_{F}\right)^{2}}
$$


where $\hbar$ is the so-called reduced Planck constant and $v_{F}$ is the Fermi velocity. Electron hopping is the dominating charge transfer mechanism in graphene and therefore the charge carriers move at the Fermi velocity $\left(\sim 10^{6} \mathrm{~m} / \mathrm{s}\right)$ [31]. The DOS is linear with energy and vanishes at the Dirac points. In theory this means that, at absolute zero, graphene is electrically insulating with infinite resistance at the Dirac points. Since there is no band gap, graphene is often referred to as a zero-bandgap semi-metal. In practice, there are other factors such as spatial charge disorder which complicate this relation though. Experiments show a very high, instead of infinite, resistance at the Dirac points, with the maximum resistance of graphene being controversial with different theories predicting varying values [34].

It is important to note that multilayer graphene can grow in the $\mathrm{AB}$ (Bernal) or the AA stacked form depending on the substrate. In the AA stacked form, all layers are perfectly aligned, whereas in the AB stacked form, half of the atoms lie directly over the center of a hexagon in the lower graphene sheet, and half of the atoms lie over an atom. The stacking mode is very important for the electrical properties of the resulting graphene sheets [31]. The binding energy between AB stacked layers is higher compared to AA stacked layers, leading to a more stable structure [35].

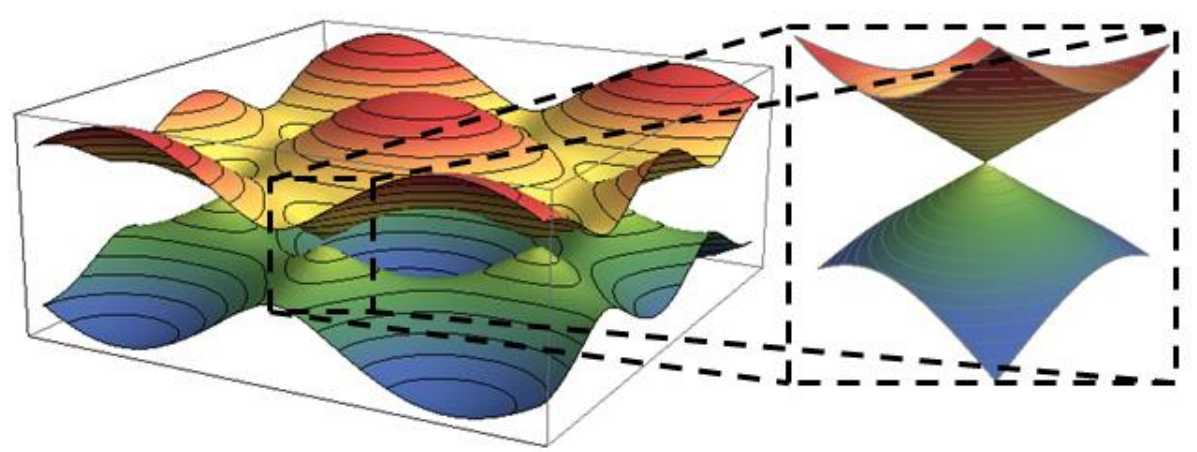

Figure 2.3: Dirac points in graphene with the electronic dispersion of the honeycomb lattice in terms of (zoomed in) the energy spectrum of finite values. Reprinted under the CC BY-SA 3.0 license, Yomach (2014) [36]. 


\subsubsection{Epitaxial graphene on SiC}

$\mathrm{SiC}$ is a binary crystal comprising $\mathrm{Si}$ and $\mathrm{C}$ atoms in a 1:1 distribution. $\mathrm{SiC}$ can crystallize in about 250 different configurations that are chemically identical but have different electronic properties. The crystal structure, called polytype, is determined by the stacking sequence of the SiC tetrahedron during growth. The most commonly used polytypes of $\mathrm{SiC}$ for graphene growth are $4 \mathrm{H}-\mathrm{SiC}$ and $6 \mathrm{H}-\mathrm{SiC}$. In theory $3 \mathrm{C}-\mathrm{SiC}$ is better as it has a uniform step decomposition velocity, thus no step-bunching [37], and also no spontaneous polarization, which therefore should result in less charge transfer to graphene compared to $4 \mathrm{H}-$ and $6 \mathrm{H}-\mathrm{SiC}$. However, the latter two are the only stable hexagonal polytypes [38], and since they are of high interest in the field of power semiconductor devices to replace Si in high-end power electronics applications to reduce device-related energy losses, their growth has been optimized to the point where $4 \mathrm{H}$ - and $6 \mathrm{H} \mathrm{SiC}$ wafers of very high quality are available at costs that would have seemed impossible a decade ago. The letter $\mathrm{H}$ indicates the hexagonal crystal structure and the numbers 6 and 4 define the number of Si-C pairs stacked per unit cell. SiC wafers cut along the c-axis (0001) have two different surface terminations: Si-face ( $\mathrm{Si}$ atoms) or C-face (C atoms). For the growth of monolayer graphene, the Si-terminated surface (0001) is normally used, as it exhibits a slower and more controlled Bernal stack growth process [39]. C-terminated $\mathrm{SiC}(000 \overline{1})$ leads to a multi-layered and more inhomogeneous growth instead [40]. Therefore, the Si-face is used for applications where high quality graphene is needed, such as Quantum Hall Effect (QHE) devices [41, 42] or gas sensors [43].

If $\mathrm{SiC}$ is heated to sufficiently high temperatures, $\mathrm{Si}$-atoms sublimate and leave a carbon-rich layer beneath, which eventually forms graphene. The growth is explained in more detail in section 3.3.1. The very first layer of graphene forms the so-called buffer layer, which is a $(6 \sqrt{3} \times 6 \sqrt{3}) \mathrm{R} 30^{\circ}$ reconstruction of the $\mathrm{SiC}$ surface [40]. In the buffer layer, about $30 \%$ of the carbon atoms are covalently bound to the $\mathrm{SiC}$ bulk, turning it into an insulating layer. It is often also referred to as zero-layer graphene. The second layer then forms the conducting monolayer of graphene. Figure 2.4 represents a schematic of the grown graphene lattice on top of $\mathrm{SiC}$ with the buffer layer in between. 


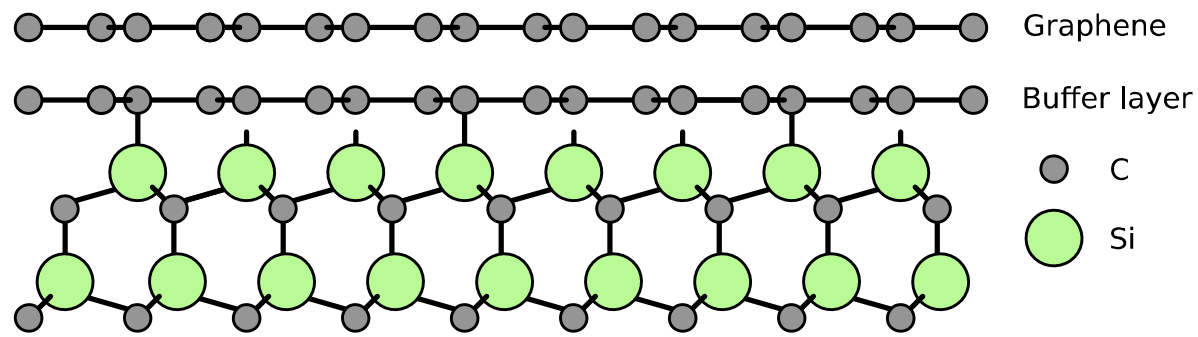

Figure 2.4: $\quad$ Schematic of epitaxial graphene on SiC.

The graphene layer is influenced electrically by the buffer layer and the $\mathrm{SiC}$ bulk. The buffer layer has a distance of $\sim 3.24 \AA$ to the graphene layer [44] and acts as a mediator for charge transfer between the $\mathrm{SiC}$ bulk and the graphene leading to intrinsic n-doping in the order of $10^{13} \mathrm{~cm}^{-2}$ [45]. As a result, the graphene lattice has a high density of states. The SiC bulk also affects the doping of graphene in the same direction as the buffer layer [46]. The buffer layer reduces the mobility in epitaxial graphene (EG) compared to exfoliated graphene due to the introduction of charges and scattering centers [47]. To eliminate the influence of the buffer layer, the covalent bonds between buffer and $\mathrm{SiC}$ can be removed through the intercalation of, for example, hydrogen which will decouple the buffer layer into a freestanding graphene layer [46]. To produce monolayer graphene in this manner it is necessary to perform the intercalation step on $\mathrm{SiC}$ that has been processed to have just the buffer layer with no graphene on top.

\subsection{Graphene as sensor platform}

Besides the already mentioned properties, graphene's exceptionally low electronic noise makes it very promising for a large variety of sensing applications. Only few crystal defects occur leading to low Johnson [48] and thermal switching noise [49], which in turn lead to a high signal-to-noiseratio (SNR). Graphene sensors are currently being studied by the scientific community to investigate among others mechanical, electro-magnetic or bio-/chemical properties with, e.g., strain, Hall or gas sensors, respectively $[33,42,50]$. Fluctuations due to thermal motion of charges and defects lead to intrinsic noise, limiting the detection resolution of gas sensors. Due to the low density of states near the Dirac point even a minimal charge transfer yields a significant change in the electronic state, leading to a high 
sensor response even to low analyte concentrations. Schedin et al. demonstrated already in 2007 that graphene can be used to detect single atoms/molecules [51], albeit under optimized laboratory and rather unrealistic ambient conditions. Adsorbates can attach to a graphene surface, alter the local carrier concentration and, thus, change the resistivity accordingly. Since then, a lot of research has been conducted to utilize graphene as 'the ultimate gas sensor'. It was found that when using graphene as a sensitive layer, the number of layers greatly affects the sensor performance [10]. This is especially true for EG on $\mathrm{SiC}$, as the sensitivity depends on the band structure which in turn depends on the number of layers, as SiC exhibits Bernal stacking of graphene layers. Furthermore, graphene has been found to be very sensitive to some gases like ammonia $\left(\mathrm{NH}_{3}\right)$ or $\mathrm{NO}_{2}$, but needs functionalization to fully exploit its potential [52]. Due to its high sensitivity to many gases, graphene suffers from poor selectivity. At the same time, graphene exhibits poor interaction with several gases of interests in AQM such as VOCs and also slow adsorption and desorption processes, leading to long response and recovery times. Moreover, its low number of dangling bonds on the surface limits the chemisorption of target gases, thus limiting the sensitivity [53].

\subsubsection{Optimizing EG gas sensors}

There are many different ways to overcome the limitations of pristine graphene gas sensors. Graphene can be functionalized via additional doping or defects, decoration or intercalation with other functional materials, combined into a compound material or controlling the sensing environment.

The most common and extensively studied approach is to work with graphene itself and turn it into a hybrid structure together with metal oxides $[14,15]$. Metal oxides are very well studied in the gas sensor community and are dominating in industrial applications due to their advantages like low cost and controlled production [13]. Having the optimal metal oxide and target gas combination already leads to a very good sensor performance. The sensitivity to most analytes can drastically be increased by increasing the surface-to-volume ratio of the sensing layer as a larger detection area per unit volume results in a higher adsorption of gas molecules per volume, thus leading to more material/gas interaction. Therefore, nano-sized structures are often used in combination with highly sensitive materials [13]. Combining the advantages of sensitive metal oxides with 
low-noise graphene can lead to very promising new sensor hybrids where the surface chemistry is controlled by the metal oxide nanostructure and the graphene acts as a highly sensitive transducer [14, 15]. Moreover, graphene can be turned into graphene oxide or wrapped into CNTs, which are then again used as a transducer and functionalized with different sensitive materials. In this work, graphene was decorated with different metal oxide nanoparticles (NPs) and nanolayers (NLs).

The intercalation of atomic species into the graphene lattice is another method of changing the surface properties. This is especially interesting when doing so with epitaxial graphene on $\mathrm{SiC}$ where the buffer layer can be turned into the topmost quasi-free-standing epitaxial graphene (QFSEG) layer or the existing monolayer graphene into a bilayer graphene sample. This intercalation has been done with several different species ranging from salts over metals to gases [54]. Here, only hydrogen intercalated sensors were investigated as it is the most common intercalation method.

The controlled introduction of defects, vacancies or doping impurities into the graphene lattice can also lead to an increased sensitivity [55, 56]. However, this procedure normally entails a higher noise level, due to local disruptions of the $\mathrm{sp}^{2}$ hybridization, which could be detrimental for the detection limit. In this work, defects were introduced into graphene with $\mathrm{Ag}$ - ion irradiation [Paper C].

A rather drastic idea is to use the known substrates on which graphene can be grown and substitute the graphene lattice with another material like two-dimensional platinum and use it as sensor or transducer instead [Paper D].

The enhancement of sensitivity and decrease of time constants using additional UV irradiation during the gas exposure was shown for many different material/gas combinations [19]. The irradiation with light allows energized photons to interact with the target gas or sensing material. This interaction highly depends on the possibility to adsorb photons at the given photon energy. Thus, the photon energy level has to be compatible both with the sensing material and the target analyte. This in turn means that the interaction depends on the wavelength of the irradiation source and might be enhanced for a specific wavelength but has no effect for longer wavelengths. The photon interaction can help to split up gas molecules into detectable atoms or it can help to clean the sensor surface from the adsorbed gas and activate adsorption sites. For example, it was reported that UV irradiation can be attributed to cleaning of the graphene surface, 
thus freeing active sites for target gas adsorption [57]. Unfortunately, this method does not work for all material/gas combinations, making it a useful, but not very versatile add-on.

One option where no actual functionalization is needed is the use of transient or secondary data, generated during the measurement. A common approach, usually applied for MOS or field effect transistor (FET) devices, is the operating mode called temperature cycled operation (TCO) $[22,58]$. In general, a relatively high operation temperature is often desirable, as it accelerates reactions on the sensor like ad-and desorption, influences speed and repeatability, and can change the catalytic activity of the sensor surface. Even more information can be gained by quickly cycling between different temperatures to create non-equilibrium states that can be used to enhance sensitivity and selectivity [59]. If the sensor does not support high temperatures or the system should exhibit a low power consumption, other methods like cycling the gate bias [60] or utilizing a pulsed UV irradiation [61] are possible alternatives. To substantially decrease the sensor's time constants at a constant temperature, the first-order timederivative of the signal can be calculated and used as well [21]. This approach focuses on the change in signal during ad-and desorption phases and can be extracted from almost any pulsed sensor signal.

\subsubsection{Sensing mechanism}

A change in the sensor's resistivity follows from a change in charge carrier concentration or mobility. The resistivity $\rho$ is inversely proportional to the product of the charge carrier concentration and the mobility [62].

$$
\rho=\frac{1}{n e \mu_{e}+p e \mu_{h}}
$$

$e$ is the elementary charge, $n$ and $p$ are the electron and hole concentrations, and $\mu_{e}$ and $\mu_{h}$ are their respective mobilities.

Adsorption of molecules on the graphene lattice can result in a charge transfer between the surface and the adsorbed molecule, thus changing the measured resistance. The adsorbent acts as chemical dopant, changing the Fermi level EF [63]. If electron-accepting molecules adsorb, i.e., an oxidizing gas, extra holes are introduced, resulting in p-type doping, shifting the Fermi level down and increasing the resistivity for n-doped graphene, such as EG on SiC [10]. Adsorption of electron-donating molecules, i.e., a reducing gas, on the other hand, results in extra electrons, leading to 


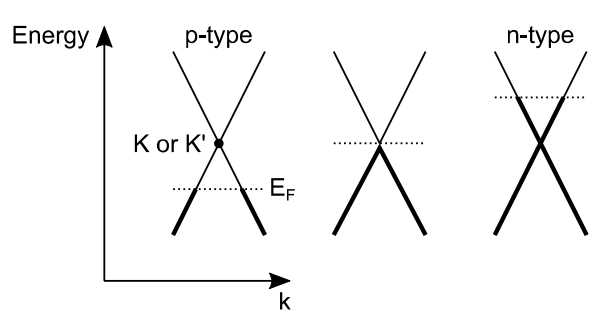

Figure 2.5: Schematic of Fermi level $\left(\mathrm{E}_{\mathrm{F}}\right)$ dependence on doping in graphene.

n-type doping, shifting the Fermi level up and decreasing the resistivity. For the Fermi level and thus the sensor resistance to change, a physisorption can already be enough. The effects of doping on the Fermi level are displayed in Figure 2.5.

In free-standing graphene, the Fermi level is located at the charge neutrality point, the Dirac point. In as-grown epitaxial graphene, the Fermi level is shifted to approximately $0.4 \mathrm{eV}$ above the Dirac point, due to the n-type doping from the buffer layer and the SiC substrate [64].

The sensing mechanism of graphene decorated with metal oxide NPs or NLs can be modeled by a receptor and a transducer process. Physisorption and chemisorption occur mainly at the metal oxide surface, forming the receptor process. The transport of electrons between metal oxide and graphene as well as establishing the electrical signal belongs to the transducer process [15]. It is believed that the change in resistivity is due to trapping of electrons by adsorbed molecules and additional scattering points induced by such. For example, adsorbed oxygen $\left(\mathrm{O}_{2}\right)$ on the sensing material withdraws electrons from the metal oxide NPs as shown in Equation (2.9).

$$
\mathrm{O}_{2}+e^{-} \rightarrow \mathrm{O}_{2}^{-} \text {(ads) }
$$

Note that this simplification is only true up to about $150{ }^{\circ} \mathrm{C}$ as above this temperature ionic oxygen species dominate [65]. The negatively charged, adsorbed oxygen molecules cause a depletion area at the interface between the metal oxide and the graphene lattice, lowering the resistivity of the graphene lattice [15]. Reactions with oxidizing molecules will further increase the depletion region, whereas reactions with reducing molecules result in the trapped electrons being returned to the metal oxide, thus increasing the resistivity of the graphene lattice again [66]. The mentioned mechanisms are described disregarding the dissociation of more complex 
molecules. This can, of course, happen as well, depending on the active sensing sites and might lead to a more complex sensing mechanism.

\subsection{Multivariate data analysis}

A raw sensor signal, e.g., resistance, is usually not the desired output of a sensor device, especially if the user expects an easily interpretable reading. To convert this signal into the property of interest, e.g., gas concentration in ppb, models are normally used instead. As mentioned in section 2.3.1, models can also help to improve the sensing performance if done properly. To fully exploit a sensor's potential, more information than just the raw signal can be created by looking also at other or alternating properties, e.g., cycled operating temperature, which is then evaluated with multivariate data analysis methods [58]. Therefore, sensor devices usually contain sensor arrays. These are either physical arrays, i.e., sensors with, for example, different sensing materials, or one sensor that is operated in a way resulting in a virtual array, e.g., cycled operating temperature or bias. The resulting signal patterns often contain more information than a single sensor, hence enabling the classification or quantification of individual gases even in rather complex gas mixtures. However, since chemical reactions strongly depend on the material/gas combination, each sensor device needs to be calibrated with individual models for the desired application. Good overviews together with more in-depth discussions about multivariate data analysis can be found in [67, 68].

Before a model is created, the recorded set of data usually undergoes a so-called preprocessing or data cleaning step to remove obvious imperfections, noise or sensor drift. For example, baseline drift of MOS sensors in TCO mode can be compensated by dividing each measurement cycle by its own mean value [69].

The next steps are feature selection and dimensionality reduction. Features refer to a specific data value over all observations, e.g., last point of the temperature plateau in TCO, or the method of how the value is extracted, e.g., the mean value of the temperature plateau in TCO. Target values contain the predefined label of each observation, such as gas type or concentration and are sometimes also referred to as target, target classes or groups, while one observation could for example be one TCO cycle. Each feature can be seen as an additional dimension, which might contain useful information. Too many features, however, lead to negative effects 
with the model not performing as well as it could [70]. Therefore, and to make the calculations manageable, the dimensionality of the given dataset needs to be reduced as much as possible while not losing too much information. There are several different methods on how this reduction can be obtained like feature extraction, feature selection or multivariate statistics [68]. Features can be extracted based on the shape of the signal, e.g., mean value or slope of the sensor signal, mathematically, e.g., with Fourier analysis or wavelet transform, or as a combination. The most common approaches based on multivariate statistical methods are linear discriminant analysis (LDA) ${ }^{2}$ and principal component analysis (PCA). Both project the data into a new subspace with the aim of retaining as much information as possible while reducing the dimensionality down to usually 1-3 for easier visual representation [71]. The original LDA algorithm, was described already in 1936 [72] for two-dimensional data, but is today also used for multi-dimensional problems. LDA is a so-called supervised method. This means that the target values are known and used for modelbuilding, projecting the data into separated clusters corresponding to the target values. LDA searches for a set of axes that maximize the variance between points, minimizing the distance within a group of points corresponding to a particular gas, and maximize the distance between different groups or gases. PCA, on the other hand, is unsupervised, which means that the target values are not known while the model tries to project the data into a new, orthogonal space, where the first axis points along the direction of highest variance and the last axis to the direction with the lowest variance.

Classification or quantification of unknown observations is the ultimate goal of any model. A classification assigns a predefined target to each observation, e.g., if the exposed gas is reducing or oxidizing. Examples for common classification models are knn (k nearest neighbors) or again LDA. To determine, for example, gas concentrations, a regression model would be the better option with PLSR (partial least squares regression) being the most common one for chemical gas sensors [70].

After the model has been built, which is often called training of the model, it has to be validated and tested. During training, the model parameters are determined as, e.g., linear combinations of the features. The

\footnotetext{
${ }^{2}$ LDA is often also referred to as canonical discriminant analysis (CDA) if used for dimensionality reduction.
} 
validation step then determines the model's hyperparameters, i.e., dimensions, and finally, the performance of the model is tested with new data, thus giving feedback on how close predicted values are compared to the known real values of the dataset. To obtain the optimal model, the validation and testing should be done with a new, independent dataset. However, parts of the same dataset can also be used for training, validation and testing of the model. For this, the most common method is k-fold, which randomly divides the dataset into $\mathrm{k}$ parts, using $\mathrm{k}-1$ parts to train the model and the remaining part for validation or testing. This is performed $\mathrm{k}$ times until each part had been left out once. The final outcome is then the average of all validation or testing folds. 


\section{Experimental methods}

The research and development from idea to realization of a novel sensing material involves several different fabrication and characterization techniques and systems. This chapter gives an overview of what is needed to end up with a functioning and functionalized EG gas sensor. It starts with the different deposition techniques and material characterization methods. Thereafter, the process of sensor fabrication itself and handling of the obtained data is addressed and, finally, the gas mixing systems with the utilized test gases are described.

\subsection{Deposition techniques}

Depending on the application in mind, several different deposition techniques may be used to grow a thin film on an already existing substrate. One distinguishes usually between physical vapor deposition (PVD) and chemical vapor deposition (CVD) techniques. In the case of CVD, a liquid or gaseous precursor undergoes a chemical change at a solid surface, resulting in the growth of a new solid film on top. PVD, on the other hand, uses thermal, mechanical or electromechanical processes to produce a thin solid film on top of a substrate. All techniques applied in this work belong to the family of PVD and are described in the following sections. Sputter deposition was used to deposit contact pads on the sensor surface or decorate it with nanoparticles. Continuous nanolayers were deposited utilizing pulsed laser deposition.

\subsubsection{Sputter deposition}

Sputter deposition techniques are usually divided into non-reactive and reactive sputtering. For non-reactive sputtering, the background ambient consists only of an inert gas like argon (Ar), whereas for the reactive sputtering a more reactive gas like oxygen is present as well, which then reacts with the ejected target atoms to form oxides. The main principle though is similar for both techniques: A sputter gas, normally argon, is ionized with a high energy source and directed to the so-called sputter target where it bombards the surface and ejects target atoms from the bulk [73]. Depending on the atomic weight of the sputter atom, the ejection mechanisms 


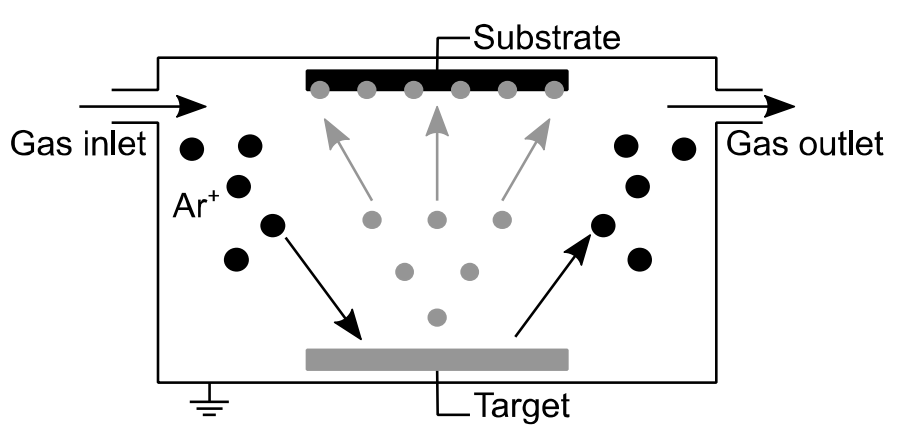

Figure 3.1: $\quad$ Schematic of sputter process.

differ. If heavy sputter atoms hit the surface, they transfer their energy into the surface, which generates a cascade of collisions and eventually ejects atoms out of the surface. If a rather light atom hits the surface, it does not produce a cascade of collisions. Instead, those ions are reflected inside the surface layer and eject surface atoms by hitting them from the bulk side. For argon with its intermediate mass, both mechanisms contribute to the sputter yield [74]. The sputter yield, defined as the ratio between ejected target atoms and incoming ions, is highly dependent on the angle, mass and kinetic energy of the incoming ion as well as the target material. The ejected atoms move to the opposing substrate and grow into a film on it. Figure 3.1 presents a schematic of the general sputter process. Besides the ejection of target atoms, also secondary electrons are ejected. Accelerating these free electrons close to the target surface will further increase the rate of ionization, eventually leading to the formation of a plasma with its origin on the target surface. In this work, only "soft" deposition techniques were used with a rather low kinetic energy of the incoming target atoms to maintain the integrity of the graphene lattice and to not induce structural damage to it.

\subsubsection{Magnetron sputtering}

As the name suggests, in a magnetron sputter system a magnet is utilized to confine the sputter electrons close to the target. The magnetic field bends the electrons' trajectory back to the target surface. This locally increases the plasma density through ionizing collisions with neutral atoms [75]. Figure 3.2 (a) shows an image of the deposition process with the plasma occurring in the top left and particles depositing over the whole 


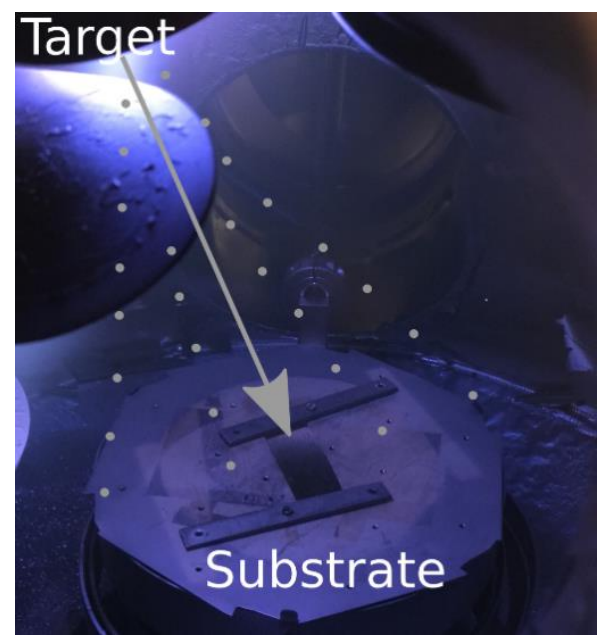

(a)

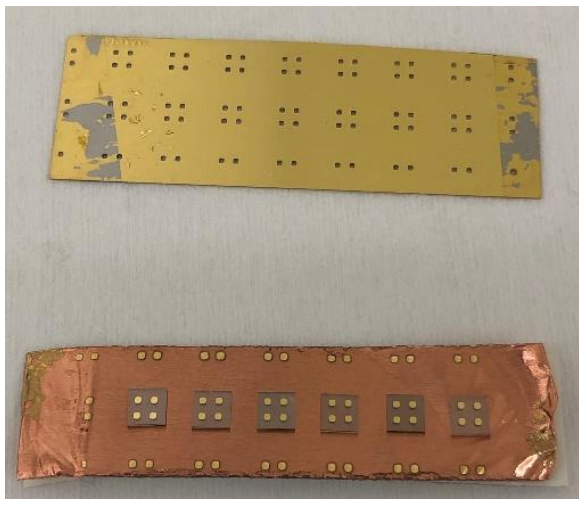

(b)

Figure 3.2: $\quad$ (a) Overlay of schematic with real image of the magnetron sputter process with the occurring plasma plume within the vacuum chamber and (b) sensor chips with deposited contacts.

chamber including the substrate on the substrate holder as the target shutter is open.

A custom-built magnetron sputter system was used to deposit contacts (Ti/Au or Cr/Au with 2/200 nm) on top of the sensor chips. Titanium and chromium have been used, depending on availability of the target material, as a binding layer between the graphene surface and the gold layer. For titanium, the base pressure was 1.5 mTorr with a voltage of $350 \mathrm{~V}$ and a current of $300 \mathrm{~mA}$, for chromium the base pressure was $1.7 \mathrm{~m}$ Torr with $300 \mathrm{~V}$ and $360 \mathrm{~mA}$, and for gold the values were $1.9 \mathrm{mTorr}, 400 \mathrm{~V}$ and $200 \mathrm{~mA}$, respectively. Depositions were performed with an argon flow of $25 \mathrm{ml} / \mathrm{min}$ for all materials. Sensor chips with deposited contacts can be seen in Figure 3.2 (b) together with the used mask. The chips are fixated on copper tape for better stability during the deposition. Note that a few early sensors had contacts deposited via thermal evaporation, but since sputter deposition did not damage the graphene lattice, produces better quality layers and was more easily available, sputter deposition was used for almost all sensors. 


\subsubsection{Pulsed plasma hollow cathode sputtering}

A hollow cathode sputter system traps the electrons inside the cathode cylinder where they are accelerated and repelled by the opposing cathode sheaths. This leads to an oscillation of electrons inside the cathode and collisions of gas atoms with these highly energized electrons form a plasma with a high degree of ionization. High power pulses are applied similar to high power impulse magnetron sputtering, to substantially enhance the ionization of the sputtered species as compared to direct current magnetron sputtering. A schematic view of the experimental arrangement is given in Figure 3.3. In this work, the technique has been leveraged for fabrication and deposition of metal oxide NPs on graphene substrates.

One of the main advantages of hollow cathode sputtering is the control of size, shape and dispersion of the deposited nanoparticles, as well as minimizing agglomeration on the substrate surface by alternating pulse amplitude, length and frequency [76, 77]. The NPs are formed in the gas phase of the sputter vapor and their growth undergoes three main stages: In the first stage, a dimer is formed by nucleation during a three-body collision. This dimer then grows into a small cluster through the addition of more individual metal atoms/ions. If the cluster is large enough, it gets negatively charged in the second stage as the electron mobility becomes higher as the mobility of positive ions. This leads to coagulation. When the coagulated cluster reaches sizes of $>10 \mathrm{~nm}$, the built-up negative charge prevents it from further coagulation. In the third stage, the particle grows only due to slow addition of metal atoms/ions [76].

Here, titanium dioxide $\left(\mathrm{TiO}_{2}\right)$, magnetite $\left(\mathrm{Fe}_{3} \mathrm{O}_{4}\right)$ and platinum $(\mathrm{Pt}) \mathrm{NPs}$ were deposited on top of graphene using this technique. The substrates were placed outside the dense plasma region, preventing energetic species from reaching and damaging the graphene lattice. The discharge parameters for the $\mathrm{Fe}_{3} \mathrm{O}_{4} \mathrm{NPs}$ were: a pulse frequency of $1200 \mathrm{~Hz}$, a pulse width of $80 \mu \mathrm{s}$ and an average power of $90 \mathrm{~W}$. A substrate bias can be used to attract the particles to the substrate surface. For the $\mathrm{Fe}_{3} \mathrm{O}_{4}$ particles no bias was applied, referred to as floating ${ }^{3}$, and the substrates were exposed to NP deposition ranging from 0.5 to 4 minutes. Pt NPs were deposited with similar parameters, only the average power was lower $(30 \mathrm{~W})$ and the deposition time was 3 min. For the $\mathrm{TiO}_{2} \mathrm{NPs}_{\mathrm{s}}$ the deposition time was $15 \mathrm{~s}$

${ }^{3}$ Floating means that the samples were not connected to the electrical circuit, which, therefore, is different from $0 \mathrm{~V}$. 
and the bias was $+10 \mathrm{~V}$. Other process parameters are given in reference [77]. Important deposition parameters are summarized in Table 1. The main results are only based on $\mathrm{Fe}_{3} \mathrm{O}_{4} \mathrm{NP}$ decorated sensors, in particular the ones with deposition times of 2 and 4 minutes, respectively, as they show comparable surface coverage (compare Table 5) and sensor response (compare section 4.2.5). $\mathrm{TiO}_{2} \mathrm{NP}$ decorated sensors were mainly investigated prior to and at the very beginning of this project. Investigations regarding Pt NP decorated sensors are still ongoing and are not published yet.

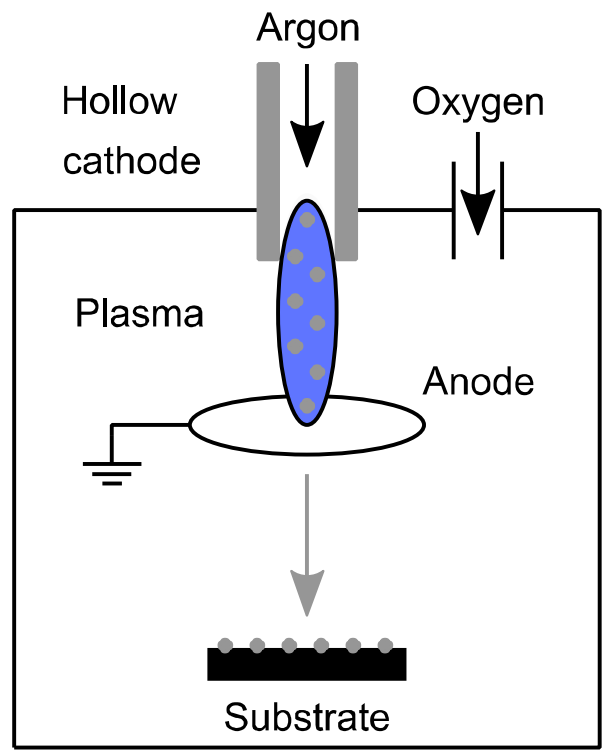

Figure 3.3: $\quad$ Schematic of hollow cathode sputter process based on [77]. 
3 Experimental methods

Table 1: Hollow cathode targets and their deposition parameters.

\begin{tabular}{lcc}
$\begin{array}{l}\text { Sputter } \\
\text { material }\end{array}$ & $\begin{array}{c}\text { Deposition } \\
\text { time (min) }\end{array}$ & $\begin{array}{c}\text { Substrate } \\
\text { bias (V) }\end{array}$ \\
\hline $\mathrm{Fe}_{3} \mathrm{O}_{4}$ & 0.50 & floating \\
$\mathrm{Fe}_{3} \mathrm{O}_{4}$ & 1.00 & floating \\
$\mathrm{Fe}_{3} \mathrm{O}_{4}$ & 2.00 & floating \\
$\mathrm{Fe}_{3} \mathrm{O}_{4}$ & 4.00 & floating \\
$\mathrm{Pt}^{\mathrm{TiO}}$ & 3.00 & floating \\
& 0.25 & +10
\end{tabular}

\subsubsection{Pulsed laser deposition}

Pulsed laser deposition (PLD) uses a coupling of photonic energy to a bulk target material through electronic processes for growing a layer on a substrate opposite of the target. Both target and substrate are positioned within a vacuum chamber with an optical quartz glass window and usually with several in- and outlets for gases. A high energy laser pulse is focused onto the rotating target and is partially absorbed near its surface. Exceeding the ablation threshold of the target, a plasma plume occurs with particles moving perpendicular to the target. The material within the plasma plume can collide and react with background or inlet gases or ion sources. Eventually, it will recondense on the substrate and grow into a layer. A schematic of the general principle is presented in Figure 3.4.

The detailed PLD process used here is described in [12]. Different target materials were ablated using a krypton fluoride $(\mathrm{KrF})$ excimer laser at a wavelength of $248 \mathrm{~nm}$. The oxygen partial pressure was kept at either 0.1 or 0.05 mbar. The laser pulses were adjusted to keep a layer thickness of $\sim 0.5-1 \mathrm{~nm}$. The sensor substrates were kept at room temperature during deposition. Copper oxide $(\mathrm{CuO})$, magnetite $\left(\mathrm{Fe}_{3} \mathrm{O}_{4}\right)$, vanadium pentoxide $\left(\mathrm{V}_{2} \mathrm{O}_{5}\right)$ and zirconium dioxide $\left(\mathrm{ZrO}_{2}\right)$ have been used as target materials. Their process properties are summarized in Table 2. Unfortunately, the $\mathrm{ZrO}_{2}$ sample processed at 0.05 mbar was not available for measurements and the $\mathrm{V}_{2} \mathrm{O}_{5}(0.1 \mathrm{mbar})$ sample physically broke during the project. 


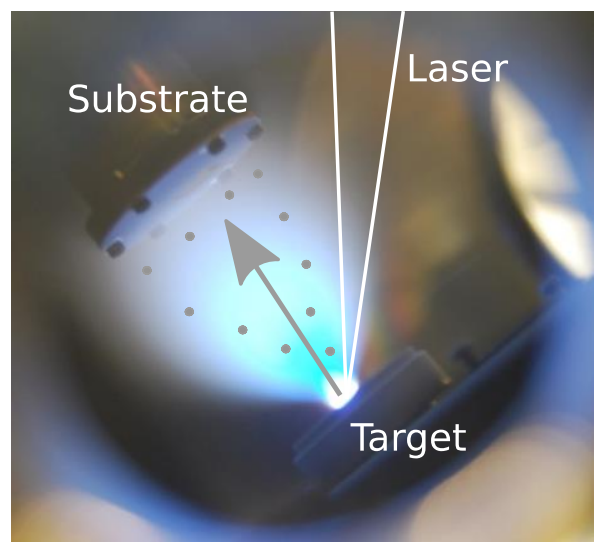

Figure 3.4: Overlay of schematic with real image of the PLD process and the occurring plasma plume within the vacuum chamber. Adapted from [78].

As the sensors with the same deposition material showed very similar sensor responses, only one of each is discussed here for the sake of readability. Included are $\mathrm{CuO}$ (0.1 mbar), $\mathrm{Fe}_{3} \mathrm{O}_{4}(0.1 \mathrm{mbar}), \mathrm{V}_{2} \mathrm{O}_{5}$ (0.05 mbar) and $\mathrm{ZrO}_{2}$ (0.1 mbar) NL DEG sensors, which are also the ones [Paper 4] is based on.

Table 2: PLD targets and their deposition parameters.

\begin{tabular}{lccc}
$\begin{array}{l}\mathrm{PLD} \\
\text { material }\end{array}$ & $\begin{array}{c}\mathrm{O}_{2} \text { pressure } \\
(\text { mbar })\end{array}$ & $\begin{array}{c}\text { Laser fluence } \\
\left(\mathrm{J} / \mathrm{cm}^{2}\right)\end{array}$ & $\begin{array}{c}\text { Number of } \\
\text { laser pulses }\end{array}$ \\
\hline $\mathrm{CuO}$ & 0.05 & 5 & 120 \\
$\mathrm{CuO}$ & 0.10 & 5 & 180 \\
$\mathrm{Fe}_{3} \mathrm{O}_{4}$ & 0.05 & 7 & 150 \\
$\mathrm{Fe}_{3} \mathrm{O}_{4}$ & 0.10 & 7 & 200 \\
$\mathrm{~V}_{2} \mathrm{O}_{5}$ & 0.05 & 5 & 120 \\
$\mathrm{~V}_{2} \mathrm{O}_{5}$ & 0.10 & 3 & 200 \\
$\mathrm{ZrO}_{2}$ & 0.10 & 3 & 220
\end{tabular}




\subsection{Characterization methods}

To gain information about the purity, thickness uniformity and integrity of the used graphene samples, they were analyzed using atomic force microscopy (AFM) and Raman spectroscopy before and after the applied surface modifications. AFM gives information about the topography, while Raman spectroscopy is used to acquire information about structural properties of the graphene lattice. Density functional theory (DFT) calculations were used to theoretically investigate the binding energies between the sensor surface and a specific analyte, thus possibly predicting the sensor response.

\subsubsection{Atomic force microscopy}

Using a very sharp needle attached to a micro-cantilever, the AFM scans the surface of a specimen. Different scanning modes are possible: contact mode, non-contact mode and tapping mode. Here, only the tapping mode was used, where the cantilever oscillates close to its resonance frequency in z-direction while scanning the whole surface in an x-y raster scan. Depending on the topography, van der Waals forces change the oscillation amplitude of the cantilever, which is detected by reflecting a laser beam of the back of the cantilever and onto a position-sensitive photodiode. Resolutions down to an atomic level can be achieved in height, which provides an opportunity to gain topographical information of very flat samples such as graphene. In addition to the amplitude, also the phase difference between the excitation signal of the cantilever and its actual oscillation is recorded. The phase provides an insight into mechanical properties and the viscoelasticity of the studied sample as it responds to energy loss. For example, for $\mathrm{EG}$ on $\mathrm{SiC}$ it can reveal whether the surface consists of different graphene domains as different graphene thicknesses, i.e., monolayer, bilayer or multilayer, exhibit different Young's moduli. Besides topographical measurements, AFM measurements can also be adapted to measure, e.g., the work function (Kelvin Probe Microscopy) or conductivity using a conductive tip.

In this work, a Dimension 3100 (Veeco Instruments Inc., New York, USA), with a Nanoscope IVa controller was used with silicon tips (PPPNCHR-50 from Nanosensors, Neuchatel, Switzerland) with a tip radius of curvature below $7 \mathrm{~nm}$ exclusively in tapping mode. 
The overall roughness is calculated as the deviation of the root mean square $R_{q}$ :

$$
R_{q}=\sqrt{\frac{\sum_{i=1}^{N}\left(Z_{i}-Z_{\text {average }}\right)^{2}}{N}}
$$

where $N$ is the total number of measurement points, $Z_{i}$ is the height at measurement point $i$ and $Z_{\text {average }}$ is the average height. Note that the roughness in height is calculated for an arbitrary area within the AFM measurement and should only be utilized to compare similar samples with each other.

\subsubsection{Raman spectroscopy}

With Raman spectroscopy, incoming monochromatic light gets scattered inelastically on the sample surface due to interactions with molecular vibrations or excitations. This inelastic scattering leads to a characteristic energy shift of the outgoing laser light, the so-called Raman effect. Raman scattering can be separated into Stokes scattering and Anti-Stokes scattering. The incident radiation has a higher frequency than the scattered radiation for Stoke scattering and vice versa for Anti-Stoke scattering [79]. Narrow optical filters shield the detector from reflected, non-scattered light coming from the laser.

The quality and especially the integrity of graphene surfaces can easily be verified using Raman spectroscopy. A typical Raman spectrum of EG on $\mathrm{SiC}$ is shown in Figure 3.5. The important modes are $\mathrm{D}$ at $1350 \mathrm{~cm}^{-1}, \mathrm{G}$ at $1582 \mathrm{~cm}^{-1}, \mathrm{D}^{\prime}$ at $1620 \mathrm{~cm}^{-1}$ (not present here) and 2D (also referred to as $\mathrm{G}^{\prime}$ ) at $2700 \mathrm{~cm}^{-1}$ [80]. The $\mathrm{G}$ and $2 \mathrm{D}$ peaks, specifically their intensity ratio and the full width at half maximum of the $2 \mathrm{D}$ peak, can be used to determine the quality of the graphene while the D peak arises only when disorder or lattice defects are present. Furthermore, the whole sample surface can be mapped giving information about spatial distribution of graphene features, such as peak ratios and FWHM (full width at half maximum) values [81, 82].

A micro-Raman setup was used to perform Raman spectroscopy and reflectance measurements. A CCD (charge-coupled device) camera coupled to a monochromator (HR460) was utilized along with a $100 \times$ magnification objective. The samples were excited using a $532 \mathrm{~nm}$ diode-pumped solidstate laser, with a power of $17 \mathrm{~mW}$ for pristine EG (PEG) and $<1 \mathrm{~mW}$ for 


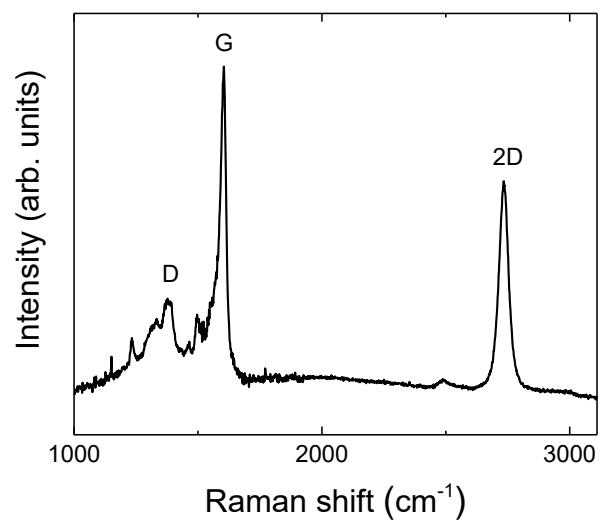

Figure 3.5: Typical Raman spectra of EG on $\mathrm{SiC}$ with important modes. Adapted from [Paper 1].

surface decorated EG (DEG) samples, respectively. The lower laser powers were used as a safety procedure, to make sure that the decorated metal oxide nanostructures do not burn. The focused spot size had a diameter of $\sim 0.9 \mu \mathrm{m}$ on the sample and a system spectral resolution of approximately $5 \mathrm{~cm}^{-1}$ could be achieved. The Raman spectra of Si-face graphene were obtained by subtracting a reference spectrum of $4 \mathrm{H}-\mathrm{SiC}$ (0001). A more detailed description of this setup can be found in [81].

\subsubsection{Density functional theory}

DFT is used to calculate and predict material behavior. It is based on quantum mechanical models which in turn are based on the Hohenberg-Kohn theorems [83]. DFT is often put to use in material science to investigate the electronic structure of many-body systems. Here, the adsorption of gas molecules on PEG and metal oxide NP DEG was investigated. The calculations are based on hybrid gas-phase DFT and executed with the Gaussian 16 Rev. B.01 program package [84]. PEG has been modeled as one $4 \times 5$ graphene layer on top of a $4 \times 5$ buffer layer, which is covalently bound to the $4 \times 4$ Si-face surface of hexagonal $4 \mathrm{H}$-SiC. DEG was simulated by full geometrical optimization of $\mathrm{Fe}_{3} \mathrm{O}_{4}$ and $\mathrm{TiO}_{2}$ located on $\mathrm{PEG}$, where all dangling bonds are passivated by hydrogen atoms. M06-2X level theory with consideration of a split basis set was used for all calculations [85]. The dispersion-corrected DFT functional M06-2X implicitly includes modified parameters associated with the Hartree-Fock exchange interaction, allowing the prediction of weak van der Waals interactions [86]. A LANL2DZ 
(Los Alamos National Laboratory 2 Double-Zeta) basis set was applied for iron $(\mathrm{Fe})$ and titanium (Ti) atoms, and a 6-31G basis set for carbon, silicon, oxygen and hydrogen species [87]. All atoms were allowed to fully relax during geometrical optimization and no symmetry restrictions have been applied. The adsorption energy of gas molecules $\left(E_{a d s}\right)$ was calculated as

$$
E_{\mathrm{ads}}=\left(E_{\mathrm{tot}}^{\mathrm{PEG} / \mathrm{DEG}}+E_{\mathrm{tot}}^{\mathrm{gas}}\right)-E_{\mathrm{tot}}^{\mathrm{gas} @ \mathrm{PEG} / \mathrm{DEG}}
$$

where $E_{\mathrm{tot}}^{\mathrm{PEG} / \mathrm{DEG}}$ and $E_{\mathrm{tot}}^{\mathrm{gas}}$ are the total energies of isolated PEG or DEG templates and gas molecules, respectively. The total energy of PEG or DEG after the reaction with gas molecules is defined as $E_{\text {tot }}^{\text {gas } @ P E G / D E G}$. A compensating correction for basis set superposition error (BSSE) was applied for a more accurate prediction of the adsorption energies [88].

\subsection{Sensor fabrication}

In this section, all processes involved in the fabrication of the studied sensors are discussed. It starts with the growth of graphene on $\mathrm{SiC}$ and then elaborates on how this chip is mounted to become a stand-alone sensor unit.

\subsubsection{Graphene growth}

Since it was first experimentally produced in 2004, scientific advances and technology development in graphene have virtually exploded. As such, also the definition of graphene has been expanded to include materials that are not strictly only monoatomic carbon, but also chemically reduced graphene oxide, composite materials comprising of micrometer-sized graphene flakes, and multilayer graphene. Clearly, these different types of graphene will have different mechanical, optical, and electrical properties, where the choice of material should depend on the intended application. The type of graphene depends on how it is synthesized, and there are many well-established methods for graphene growth [89]. The most common method for production of large area monolayer graphene relies on chemical vapor deposition, where a carbon-rich precursor gas is used to grow graphene on a metallic catalyst substrate [90]. This approach is highly scalable and can produce high quality graphene [91]. However, the necessary transfer of the graphene to an insulating substrate - for electronic devices - ads an addi- 
tional step which can lead to a degradation or contamination of the graphene surface [89]. Another, rather hands-on method is mechanical exfoliation. This method produces the highest quality graphene and is mainly used in fundamental research, but the process is very slow and not scalable [89]. The method employed to grow graphene in this work was epitaxial growth of graphene through thermal decomposition of a $\mathrm{SiC}$ substrate. Figure 3.6 demonstrates a simplified growth process of EG on SiC.

At elevated temperatures sublimation of silicon occurs at a much faster rate compared to carbon atoms due to its higher vapor pressure[92]. The underlying Si-terminated $\mathrm{SiC}$ substrate reconstructs in a supercell of the gained buffer layer, on which the graphene is grown, which matches quite well with the graphene lattice. Usually, an overpressure of argon is applied to enhance the uniformity of the EG layer. Monocrystalline graphene can be grown over an entire wafer with very high quality on insulating or semiconducting $\mathrm{SiC}$, thus allowing the direct fabrication of electronic devices [89].

In this work, growth was performed on $7 \times 7 \mathrm{~mm}$ hexagonal polytype $4 \mathrm{H}$-SiC (0001) on-axis Si-terminated substrates. $4 \mathrm{H}-\mathrm{SiC}$ is, with a bandgap of $3.26 \mathrm{eV}$, a wide bandgap semiconductor that is either semiconducting or semi-insulating depending on the doping. Here, only semi-insulating $\mathrm{SiC}$ was used. EG was prepared by sublimation of $\mathrm{SiC}$ and subsequent graphene formation at $2000{ }^{\circ} \mathrm{C}$ in argon at a pressure of 1 atm [93]. The graphene layer forms on top of a monoatomic carbon buffer layer, which is still partially covalently bound to the SiC substrate [40]. As a result, and sensor basis, EG with a monolayer ratio of about $98 \%$ (2\% bilayer) was achieved. Depending on the wanted outcome, the growth can also be stopped after the buffer layer has formed. In this case, argon is introduced to the chamber at $1400{ }^{\circ} \mathrm{C}$ and the buffer growth is completed already at $1700^{\circ} \mathrm{C}$. A high-quality buffer layer is especially important for the $\mathrm{H}_{2}$-intercalation (here referred to as intercalated EG or IEG) and graphene-substitution samples. The exact growth processes for those two latter samples are explained in [94] and [Paper D], respectively. Note that results obtained with the IEG sensor are not published yet.

Due to better accessibility, EG was also acquired as a 4" wafer from Graphensic AB, Stockholm, Sweden, and diced into the desired geometries at a later stage of the PhD work (includes Pt NP DEG and several PEG sensors). The graphene was grown on a $\mathrm{SiC}$ wafer with similar settings in a comparable reactor. 


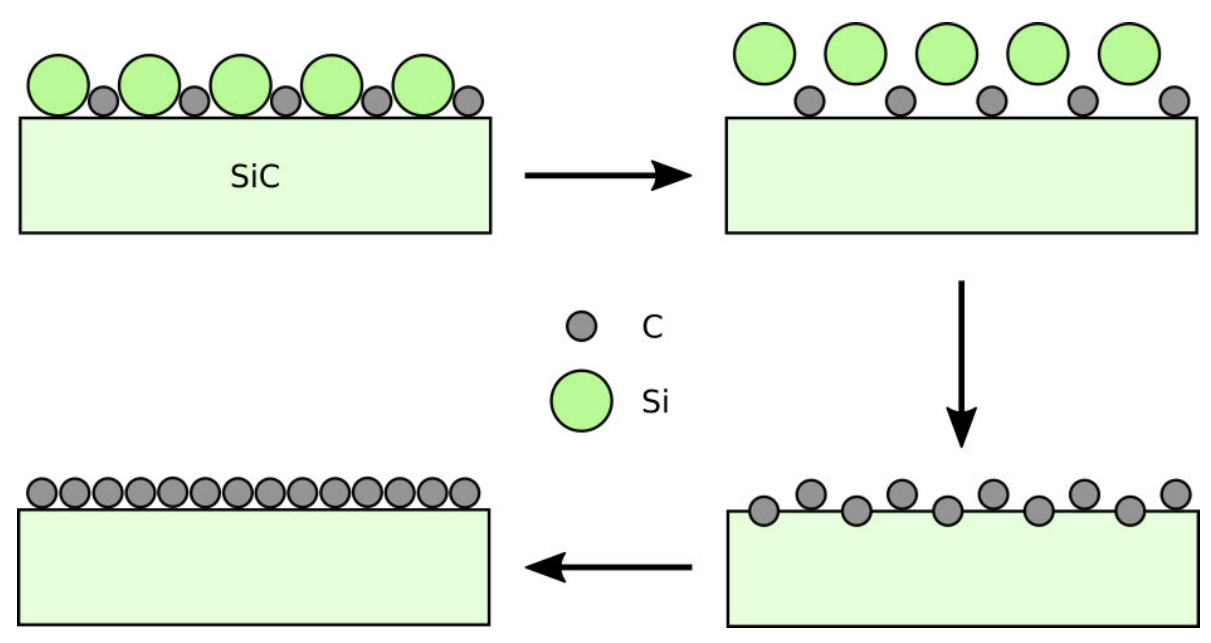

Figure 3.6: Schematic of EG growth on SiC.

\subsubsection{Sensor mounting}

To dice the chips, a $30 \mu \mathrm{m}$ thin diamond blade is used with an automatic dicing saw (DAD321 from DISCO, Tokyo, Japan) and deionized water cooling during the cutting process. The resulting cut has a width of about $50 \mu \mathrm{m}$. To ensure no contamination is added to the graphene surface, a protective layer of positive photoresist (SU1818) was applied beforehand. The photoresist was applied via spin coating for $30 \mathrm{~s}$ at $4000 \mathrm{rpm}$ with an acceleration speed of $2000 \mathrm{rpm} / \mathrm{s}$. The sample was then baked for $20 \mathrm{~min}$ at $100{ }^{\circ} \mathrm{C}$ in an oven in ambient air for curing. The backside of each fully transparent chip was marked with a diamond pen to prevent using the wrong side. To remove the photoresist after cutting, the chip was put into pure acetone, then into pure ethanol, blow-dried using a handheld nitrogen gun and finally baked at $100{ }^{\circ} \mathrm{C}$ for $10 \mathrm{~min}$. After successful growth and dicing of the chips, the high quality of the graphene surface was verified for each applied functionalization method via AFM and Raman spectroscopy (compare section 4.1).

As a first step of transforming the $\mathrm{EG}$ on $\mathrm{SiC}$ chip into a graphene gas sensor, electrodes were deposited on top. The contacts were deposited mainly through sputter deposition ${ }^{4}$ of titanium $(2 \mathrm{~nm})$ or chromium $(2 \mathrm{~nm})$ and gold $(200 \mathrm{~nm})$ sequentially. The arrangement of electrodes varies,

${ }^{4}$ Some early samples had contacts deposited via thermal evaporation (compare section 3.1.1). 
thus influencing the baseline resistance measured between two electrodes. In this work, all tested gas sensors had several, i.e., at least two, square contacts with either $0.5 \mathrm{~mm}$ width (PEG and NP DEG sensors) or $2 \mathrm{~mm}$ width (NL DEG and IEG sensors) with a $1 \mathrm{~mm}$ gap in between. To enable a closed-loop temperature control, each sensor chip was glued on top of a ceramic heater substrate (Heraeus $\mathrm{GmbH}$, Hanau, Germany) with an additional Pt-100 temperature sensor (Heraeus GmbH, Hanau, Germany) using Ceramabond 571 (Aremco, Valley Cottage, New York, USA). This whole device was mounted on top of a TO8-socket and connected to its pins using gold-wire bonding and silver glue (Epotek E3081 from Epoxy Technology, Inc., Billerica, Massachusetts, USA). The silver glue is necessary as the deposited gold contacts have only a weak adhesion to the graphene lattice and would be destroyed or even lift off with conventional ball- or wedge-bonding techniques. This setup limits the working temperature to $300{ }^{\circ} \mathrm{C}$, wherefore measurements were only performed up to $200^{\circ} \mathrm{C}$ as a safety measure. Figure 3.7 shows a mounted sensor with all necessary parts.

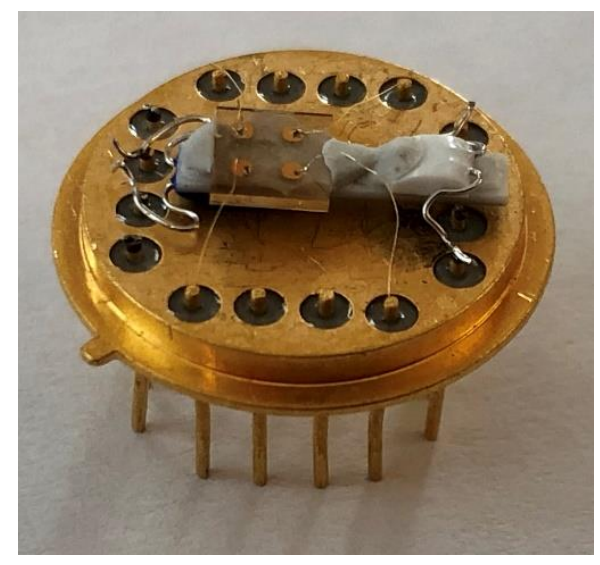

Figure 3.7: Photograph of mounted sensor device. Here Pt NP DEG. 


\subsection{Data handling}

As the sensor signal, the resistance is recorded over time and then evaluated. How this was performed is described in detail in the following sections.

\subsubsection{Data acquisition}

The resistance of the graphene layer between the deposited contacts, i.e., two-point resistance, was measured over time and used as the sensor signal. As mentioned in section 2.3.2, the charge carrier density will change due to gas interaction, thus altering the sensor's resistance. A schematic of this is demonstrated in Figure 3.8. The resistance was measured with a Sourcemeter (Keithley 2601 from Tektronix Inc., Solon, Ohio, USA) and transferred to a custom-made computer program with a sampling rate of 1 or $5 \mathrm{~Hz}$. The resistance was calculated from the current measured at 1 or $3 \mathrm{~V}$. For sensors with lower baseline resistance values, the measurement voltage was decreased to stay approximately below $1 \mathrm{~mA}$ of measured current. This small variation, i.e., 1-3 V, is not expected to have a notable impact on the sensor performance and the only sensors measured at $1 \mathrm{~V}$ are Pt NP DEG and IEG. Some measurements were performed using a specialized board from $3 \mathrm{~S} \mathrm{GmbH}$ (Saarbrücken, Germany) instead. The measurement voltage, however, was kept the same. More information about this system can be found in [95]. Either a custom-made temperature controller or a 3S-board was used to monitor and adjust the sensor operating temperature. The controller can be programmed to keep the sensor at a given temperature or change it over time to create ramps or plateaus. The ceramic heater heats the sensor and the Pt-100 reads back the actual temperature. 
3 Experimental methods
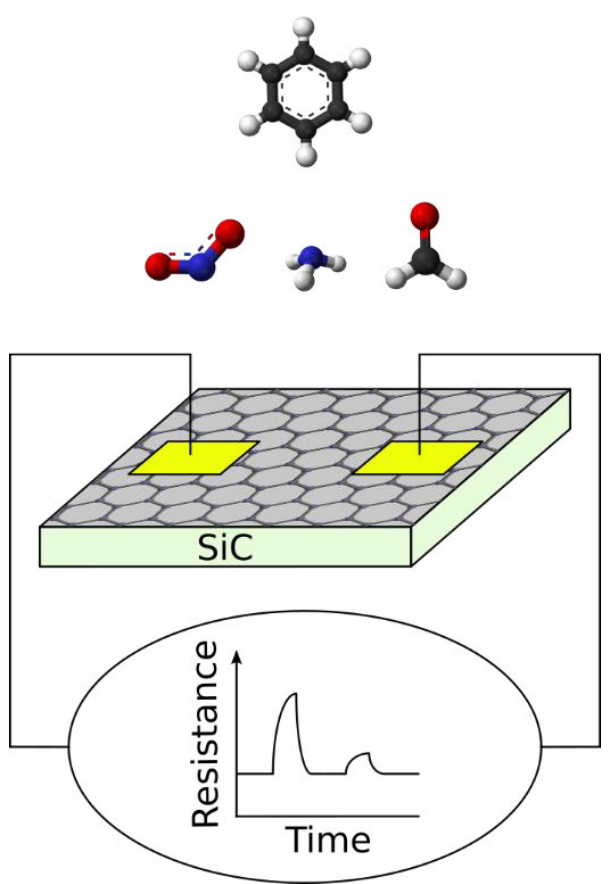

Figure 3.8: $\quad$ Schematic of graphene sensor readout.

\subsubsection{Data analysis}

To facilitate a better understanding of the presented results, the most common sensor properties are defined here. An exemplary response is presented in Figure 3.9, where a $\mathrm{Fe}_{3} \mathrm{O}_{4} \mathrm{NP}$ DEG sensor was exposed to $30 \mathrm{~min}$ pulses of $\mathrm{CH}_{2} \mathrm{O}$ at concentrations between 5 and $0.1 \mathrm{ppm}$ at $150{ }^{\circ} \mathrm{C}$ at $0 \%$ relative humidity $(\mathrm{RH})$. If applicable, the sensor properties were calculated for this example and are stated alongside their definition.

Response: The (relative) response $r$ is calculated as the maximum difference in resistance, i.e., with and without gas exposure, in relation to its baseline.

$$
r=\frac{R-R_{0}}{R_{0}} \cdot 100 \%
$$

$R$ is either the equilibrated resistance signal or the absolute maximum value of resistance before the gas exposure is switched back to background gas and $R_{0}$ corresponds to the baseline resistance before the gas exposure. 


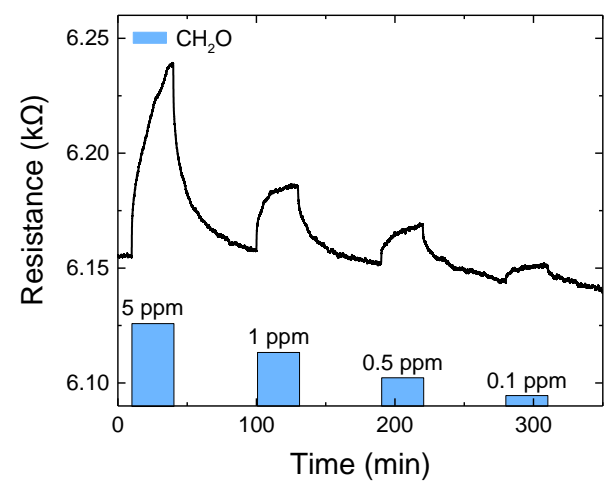

Figure 3.9: Resistance over time of $\mathrm{Fe}_{3} \mathrm{O}_{4}$ NP DEG for $\mathrm{CH}_{2} \mathrm{O}$ exposures at $150{ }^{\circ} \mathrm{C}$ at $0 \% \mathrm{RH}$. Adapted from [Paper 2].

In this example (compare Figure 3.9), the relative response is $0.45 \%$ for 1 ppm $\mathrm{CH}_{2} \mathrm{O}$.

Sensitivity: The sensitivity is defined as the derivative in output signal (response) by the input variation (gas concentration) and has therefore the unit \%/ppb.

Cross-sensitivity: In case the sensor reacts to several analytes in a gas mixture or additional influences, the sensor is cross-sensitive and the sensor response depends on more than just one gas reaction.

Selectivity: Selectivity is the ability to respond to only the target analyte or to be able to distinguish between the responses to several analytes or influences.

Stability: If the sensor exhibits a non-changing baseline (resistance) over a certain period of time at the same operating conditions, it can be called stable. If there is a clear trend of a baseline shift instead, this change is called drift.

Repeatability: If the sensor exhibits the same response to the same measurement at different points in time, the measured response is repeatable.

Reproducibility: Reproducibility is the ability to generate the same relative sensor response with different sensors of the exact same kind.

Speed of response: The speed of response of a sensor is usually expressed by the time constant and is calculated either as $\tau_{90}$ as $\tau_{63}$. Here, only $\tau 63$ values, defined as when $63 \%$ of the change has happened, are stated and simply referred to as $\tau$. An exponential fit is applied to the gas response as 
3 Experimental methods

$$
y=A_{1} e^{-x / \tau}+y_{0}
$$

where $\mathrm{A}_{1}, \tau$ and $\mathrm{y}_{0}$ are the optimized fitting parameters, whereof $\tau$ corresponds to $\tau_{63}$. In this example (compare Figure 3.9), $\tau$ is about $300 \mathrm{~s}$ for 1 ppm $\mathrm{CH}_{2} \mathrm{O}$.

Signal-to-noise-ratio: The signal-to-noise-ratio (SNR) in decibel (dB) is a good value to compare sensor properties and is calculated as

$$
\mathrm{SNR}_{\mathrm{dB}}=20 \log _{10}\left(\frac{A_{\text {signal }}}{A_{\text {noise }}}\right)
$$

where $A_{\text {signal }}$ is the maximum absolute response, i.e., difference between $R$ and $R_{0}$, at a given concentration and $A_{\text {noise }}$ is calculated as three times the standard deviation of the baseline noise (also referred to as $3 \sigma^{5}$ ). For the absolute response to $1 \mathrm{ppm} \mathrm{CH}_{2} \mathrm{O}(28 \Omega)$ shown in Figure 3.9, the standard deviation is $0.32 \Omega$ and the SNR is $29 \mathrm{~dB}$.

Detection limit: The detection limit (or limit of detection, LOD) is the smallest concentration possible to detect reliably, i.e., a response smaller than $A_{\text {noise }}$ cannot be counted as it could be a noise artifact. Here, it is calculated assuming a linear correlation of response over concentration, which results in the worst case LOD scenario, and a detectable response larger than $3 \sigma$.

If multivariate data analysis was performed, it was either carried out using DAV ${ }^{3} \mathrm{E}$ [96], which is a MATLAB toolbox developed by the Lab for Measurement Technology at Saarland University, or a custom-made MATLAB script (compare results in section 4.3.2). LDA and PCA were evaluated for classification, and PLSR for quantification. For baseline and/or sensor drift correction, the measured cycles were either normalized or standardized, respectively [95]. For normalization, each cycle was divided by its own mean and for standardization, the mean of each cycle was subtracted from the cycle itself and then divided by the standard deviation of all cycles.

\footnotetext{
${ }^{5} 3 \sigma$ is the standard confidence interval used in analytical chemistry [162].
} 


\subsection{Gas mixing apparatus}

To perform gas measurements with well-defined gas flows and concentrations over the sensor, a gas mixing apparatus (GMA) was used. The GMA can provide different gases whose flows are regulated by mass flow controllers (MFCs). Known gas mixtures, usually from a gas cylinder, are connected to MFCs. Each mass flow controller has a fixed maximum flow of which a range between 5 and $100 \%$ can be set reliably. Zero air out of a zero air generator or pure nitrogen $\left(\mathrm{N}_{2}\right)$ was used as the background or carrier gas with the possibility of varying humidity and oxygen partial pressure. A humid gas flow is produced by splitting the dry ${ }^{6}$ carrier gas into two streams, one of which goes through a water bottle, the so-called "bubbler", which can be assumed having $100 \% \mathrm{RH}$. After this, both streams are unified, hence the humidity can be adjusted by varying the split ratio. If not especially mentioned, a total flow of either 100 or $200 \mathrm{ml} / \mathrm{min}$ was applied for all experiments. Test gases are provided via a gas bottle or via a permeation oven. The sensors were inserted in a flow chamber with a volume of $3 \mathrm{ml}$. Using specially designed flow chambers, either one sensor, two sensors, or one sensor with a UV-LED (light emitting diode) on the opposite side of the sensor can be used during a measurement. Figure 3.10 gives a simplified overview of how such a gas mixing system can look like.

For the system at Linköping University (LiU), the background and purging gas was applied through two MFCs giving a mixture of $80 \% \mathrm{ni}$ trogen and $20 \%$ oxygen. The test gas was added through an additional MFC into the same line. In total, up to six different test gases can be applied during a single measurement session. The whole gas flow enters a four-way valve which can direct the flow either through the sensor chamber or directly to waste. To maintain a constant flow and background, a second branch with only nitrogen and oxygen MFCs is connected to the four-way valve. When the valve switches, one gas flow goes to the waste line and the other is automatically led through the sensor chamber. This system enables sharp switching steps and time for a new gas mixture to settle. The MFCs had maximum flow rates of 20,50 or $100 \mathrm{ml} / \mathrm{min}$. Nitrogen MFCs had a maximum flow of $100 \mathrm{ml} / \mathrm{min}$ whereas all other MFCs

${ }^{6} 0 \% \mathrm{RH}:<5 \mathrm{ppm} \mathrm{H}_{2} \mathrm{O}$ for gas from gas cylinders with purity 6.0 and $<63.2 \mathrm{ppm}$ for gas from the zero air generator. 


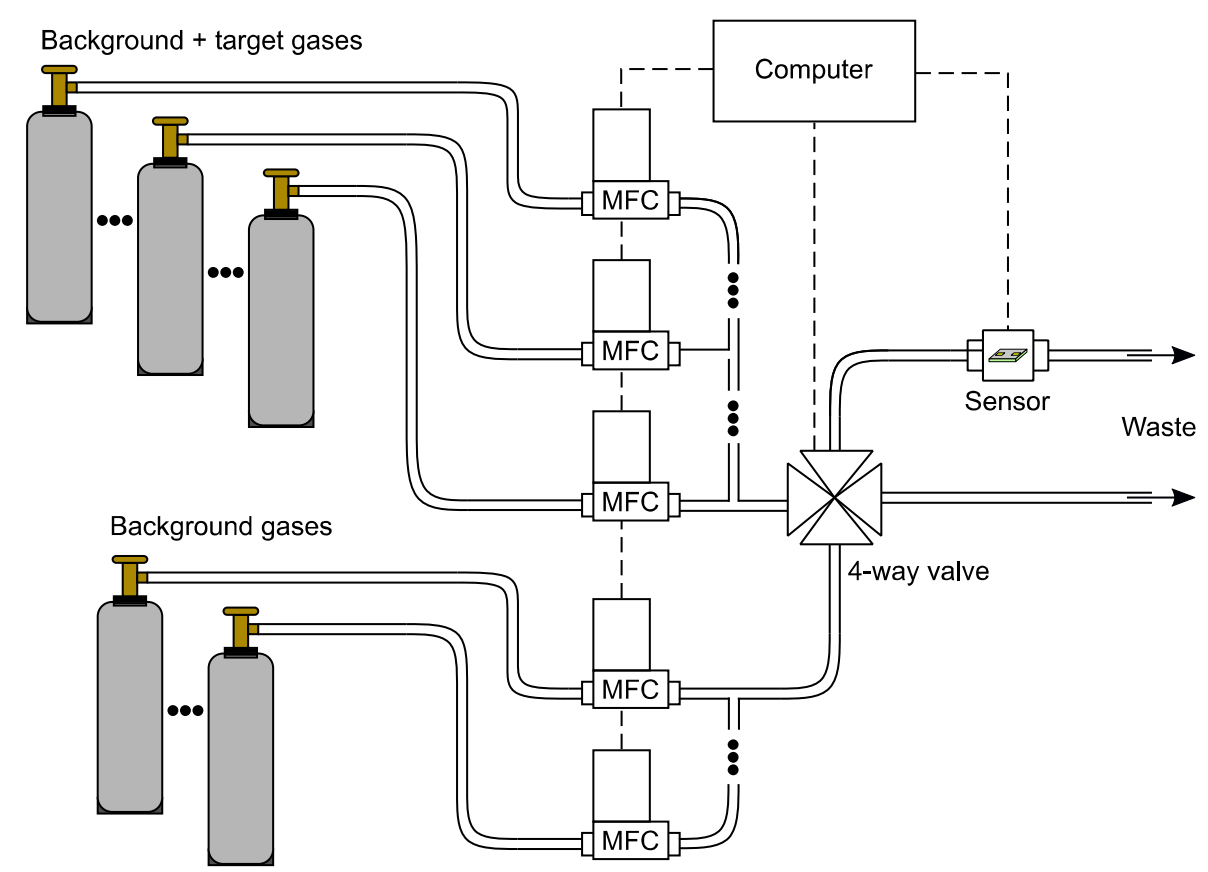

Figure 3.10: Simplified schematic of a gas mixing apparatus similar to what is used at LiU.

had $50 \mathrm{ml} / \mathrm{min}$ except for the $\mathrm{NH}_{3} \mathrm{MFC}(20 \mathrm{ml} / \mathrm{min})$. To ensure that no humidity could leak into the system when performing measurements under dry conditions, the bubbler line was disconnected in this case. A more detailed description of the system can be found in [97].

Measurements performed at Saarland University (UdS) used zero air generated by a GT Plus ultra-zero air generator (VICI AG International, Schenkon, Switzerland) as background gas instead with an approximate mixture of $79 \% \mathrm{~N}_{2}$ and $21 \% \mathrm{O}_{2}$. To enable measurements with lower concentrations than what is possible with the standard procedure of injecting the test gas with one MFC, an additional flow line can be connected to predilute the test gas. In this case, two additional MFCs $(500 \mathrm{ml} / \mathrm{min}$ for carrier gas and 10 or $20 \mathrm{ml} / \mathrm{min}$ for test gas) are added to predilute the test gas before the gas mixture is injected into the main gas stream. With this procedure, a dynamic dilution over more than four orders of magnitude can be achieved [98]. This allows the dilution of $100 \mathrm{ppm}$ gas bottles down to one-digit ppb concentrations over the sensor. Another option to prepare rather low concentrations in the gas flow is the use of a permeation oven. 
Here, a permeation tube is placed in a heated and sealed oven chamber. The permeation tube contains the pure test substance which slowly diffuses through the tube walls made of perfluoroalkoxy alkane (PFA). The rate of diffusion is highly dependent on the oven temperature which therefore needs to be kept constant. The outflow is connected to the main gas flow via an MFC so that the permeation oven is conceptually similar to a gas bottle with a variable test gas concentration. Permeation tubes do not only enable low concentrations but can also be used for gases with very high vapor pressure, which cannot be kept in gaseous form in pressurized gas bottles. More details about the system can be found in [68, 99].

If UV irradiation of the sensor is desired during a measurement, a special sensor chamber was used where the UV-LED was placed opposite of the sensor. Two different LEDs with wavelengths of $265 \mathrm{~nm}$ (s-T39B-F1265-01-1-050 from Sensor Electronic Technology Inc., Columbia, South Carolina, USA) and $355 \mathrm{~nm}$ (XSL-355-3E-R6 from Roithner Lasertechnik $\mathrm{GmbH}$, Vienna, Austria) have been used.

\subsubsection{Target analytes}

In this section, all test gases are briefly defined and characterized through their chemical composition, appearance and pollutant guidelines. The World Health Organization [100] as well as the European Parliament [101] have guidelines for pollutant acceptance levels for indoor-air quality and these references are used if not specified otherwise.

Ammonia $\left(\mathrm{NH}_{3}\right)$ is only toxic to humans at comparably high concentrations and has a 8-hour exposure limit of $20 \mathrm{ppm}$ [102]. Nevertheless, it is one of the most produced inorganic chemicals with a wide use in the production of pharmaceuticals, explosives, cleaning products and as a precursor for fertilizers, with the latter alone being responsible for $80 \%$ of the total $\mathrm{NH}_{3}$ production [103]. Furthermore, $\mathrm{NH}_{3}$ can be related to the formation of secondary particulate matter by reacting with acidic species, like $\mathrm{NO}_{\mathrm{x}}$ or sulfur dioxide $\left(\mathrm{SO}_{2}\right)$, to form ammonium-containing aerosols, which constitute the major fraction of $\mathrm{PM}_{2.5}$ aerosols in the atmosphere [104].

Carbon monoxide (CO) is toxic under exposure of high concentrations and listed with an acceptance level of $8.7 \mathrm{ppm}$ for 8 hours of exposure. It is mainly produced in combustion processes, whenever there is not enough oxygen to oxidize the carbon fully to carbon dioxide and through breathing and photochemical reactions in the troposphere. 
Hydrogen was tested as well but not due to its toxicity, but rather as it is a very common gas in the ambient and can be used as a marker for human presence [105]. Moreover, many known sensor principles show a cross-sensitivity to changes in hydrogen concentration [106]. Hydrogen can also become explosive if more than $4 \mathrm{vol} \%$ are present in air and should therefore not exceed this threshold.

Nitrogen dioxide $\left(\mathrm{NO}_{2}\right)$ can cause respiratory symptoms and has an acceptance level of $21 \mathrm{ppb}$ annual average. It is mostly produced in internal combustion engines, accountable for around 40.5\% of $\mathrm{NO}_{\mathrm{x}}$ emissions in Europe, followed by energy production (22.5\%) [107].

Volatile organic compounds (VOCs) have, unfortunately, no universal definition. They are defined via boiling points [108], vapor pressures [109], or their participation in atmospheric photochemical reactions [110]. Although some of them are hazardous to humans even at very low concentrations, they are widely put to use in industry and everyday products as solvents. For example, VOCs are still a big problem for the air quality of nail salons, as the main product is based on such solvents [111]. Additionally to the safety levels, also the chronic reference exposure levels (REL) for an 8-hour exposure are given [112]. In this work, benzene and formaldehyde are used as model VOCs:

Benzene $\left(\mathrm{C}_{6} \mathrm{H}_{6}\right)$ is a genotoxic aromatic compound, especially associated with leukemia, and has therefore very low acceptance levels and a REL value of $9.4 \mathrm{ppb}$. At the time of writing, France has the lowest acceptance level with $0.6 \mathrm{ppb}$ [113]. According to the latest published WHO recommendations and a directive of the European Parliament, however, there is no safe level for benzene. It is mostly produced as a byproduct of traffic and is, additionally, often used as a component of solvents in cleaning agents or paint [114].

Formaldehyde $\left(\mathrm{CH}_{2} \mathrm{O}\right)$ has an acceptance level of $80 \mathrm{ppb}$, a $\mathrm{REL}$ value of $7.3 \mathrm{ppb}$ and is genotoxic. France limits short-term exposures towards $\mathrm{CH}_{2} \mathrm{O}$ to $24 \mathrm{ppb}$ over a $2 \mathrm{~h}$ period [113]. In low concentrations, $\mathrm{CH}_{2} \mathrm{O}$ usually does not pass beyond the respiratory system which limits direct cause to portal-of-entry effects like nasal cancer and sensory irritation. It is produced in combustion processes and is often used in its aqueous solution as disinfectant or conservative in everyday products as well as in the production of plastics [115].

All gases come with a purity level of at least 5.0. Nitrogen, generated from a liquid source has a purity of 6.0 in gaseous form. 5.0 and 6.0 purity level means that either $99.999 \%$ or $99.9999 \%$ of the gas volume belong to 
the desired species with $10 \mathrm{ppm}$ or $1 \mathrm{ppm}$ of unknown molecules, respectively. All test gases used at LiU had nitrogen as their carrier gas within the gas bottle, whereas all test gas bottles used at UdS had zero air as carrier. Only $\mathrm{CH}_{2} \mathrm{O}$ had also nitrogen as carrier gas at $\mathrm{UdS}^{7}$, hence an addition of $\mathrm{CH}_{2} \mathrm{O}$ to the gas stream slightly changed the oxygen concentration as well. The maximum change in oxygen concentration is $0.4 \%$ for $1 \mathrm{ppm}$ of $\mathrm{CH}_{2} \mathrm{O}$ and only $0.003 \%$ for $1 \mathrm{ppb}$. Exemplarily, the $\mathrm{Fe}_{3} \mathrm{O}_{4} \mathrm{NP}$ DEG sensor was exposed to a varying oxygen concentration and the response towards a change from 20 to $15 \% \mathrm{O}_{2}$ was $0.08 \%$. Comparing this to the maximum occurring difference of $0.4 \%$ change in $\mathrm{O}_{2}$ level, the relative response should be approximately one order of magnitude lower and is then no longer of interest when comparing the gas responses.

Table 3 gives an overview of the gases and their specifications for measurements performed at LiU and UdS, respectively. Each gas and other environmental sensor influence has its own color code used throughout the whole thesis. They are summarized in Table $4^{8}$.

${ }^{7}$ Formaldehyde tends to polymerize in air over time and is more stable in an inert ambient like $\mathrm{N}_{2}$.

8 The colors were chosen from a color palette for color blind people. 
3 Experimental methods

Table 3: Test gases and their system properties.

\begin{tabular}{lcc} 
& LiU & UdS \\
\hline Test gas & $\begin{array}{c}\text { Bottle concentration } \\
(\mathrm{ppm})\end{array}$ & $\begin{array}{c}\text { Bottle concentration } \\
(\mathrm{ppm})\end{array}$ \\
\hline Zero air ${ }^{9}$ & $/$ & $100 \%$ \\
Nitrogen & $100 \% 10$ & $100 \%$ \\
Oxygen & $100 \%$ & $/$ \\
Ammonia & 2,500 & 2900 \\
Benzene & 0.5 & $0.111,100$ \\
Carbon monoxide & $/$ & 1000,4000 \\
Formaldehyde & 4,6 & $48,50,57$ \\
Hydrogen & $/$ & 100 \\
Nitrogen dioxide & 1,5 & 10
\end{tabular}

${ }_{9}$ Zero air is generated using a GT Plus ultra-zero air generator (VICI AG International, Schenkon, Switzerland) and is not retrieved from a gas cylinder.

10 Nitrogen is generated from a liquid source and is not retrieved from a gas cylinder.

$110.1 \mathrm{ppm}$ source concentration from permeation tube at $80^{\circ} \mathrm{C}$. 
Table 4: Color codes of used gases and environmental influences.

\begin{tabular}{|c|c|c|}
\hline Test gas/ influence & Color & RGB values \\
\hline Ammonia & & 000146146 \\
\hline Benzene & & 209109000 \\
\hline Carbon monoxide & & 000000000 \\
\hline Formaldehyde & & 109182255 \\
\hline Hydrogen & & 000073073 \\
\hline Nitrogen dioxide & & 255109182 \\
\hline Oxygen & & 036255036 \\
\hline $\mathrm{dR} / \mathrm{dt}$ & & 146073000 \\
\hline Humidity & & 000109219 \\
\hline Temperature & & 146000000 \\
\hline UV (265 nm) & & 182109255 \\
\hline UV (355 nm) & & 073000146 \\
\hline
\end{tabular}





\section{Results and discussion}

This chapter presents and discusses the experimental results of the work. The first section describes integrity studies performed on the graphene samples before and after functionalization. Then the gas measurements of the different sensors with different gases and environmental influences are discussed. The last section deals with advanced data treatment to further improve the sensing properties.

\subsection{Layer characterization}

Before using a pristine or functionalized graphene layer for the production of a sensor device, its topography and structural integrity was analyzed.

\subsubsection{Topography}

To make sure that graphene formed a continuous layer over the SiC substrate and was free from contaminations, the topography was measured using AFM. A typical topography of the grown pristine graphene layer is shown in Figure 4.1 (a). The steps from the $\mathrm{SiC}$ step bunching that occurs during the high temperature growth have a height of typically $0.5-1.5 \mathrm{~nm}$ and form terraces [92]. The low height difference can be seen in the inset of Figure 4.1 (a), which presents the horizontal height profile for a $2 \mu \mathrm{m}$ line scan across the surface. The surface roughness $R_{q}$ within such a terrace is very small $(\sim 0.25 \mathrm{~nm})$. The corresponding phase image (Figure 4.1 (b)) exhibits a very continuous reading with the only exceptions being the step edges and a bi- or multilayer graphene patch in the lower left corner. This is an additional indicator for a high-quality monolayer graphene lattice. Figure 4.1 (c) shows the C-terminated backside surface of such a chip. It is still very flat but exhibits a completely different crystalline structure pattern with presumably several layers of graphene grown on it.

The samples were analyzed again after surface decorations. Figure 4.2 (a) represents an AFM image of the $\mathrm{Fe}_{3} \mathrm{O}_{4} \mathrm{NL}$ DEG sample. The surface does not differ much from PEG, as a very thin ( 0.5-1 nm), continuous layer is deposited onto the graphene surface. The dominating features are still the step edges formed by the $\mathrm{SiC}$ chip. After the decoration with $\mathrm{Fe}_{3} \mathrm{O}_{4}$ 


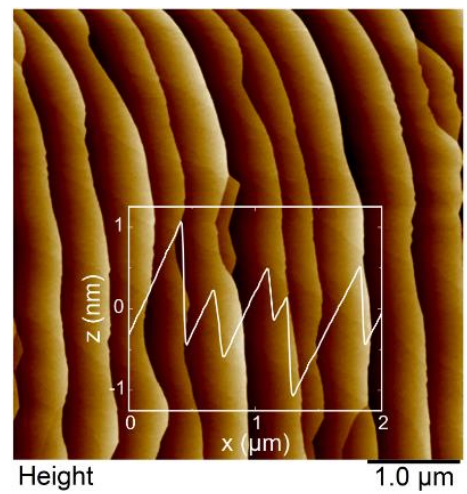

(a)

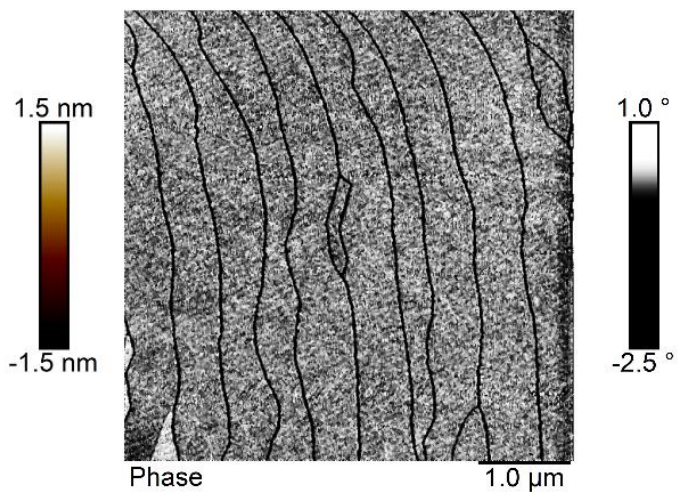

(b)

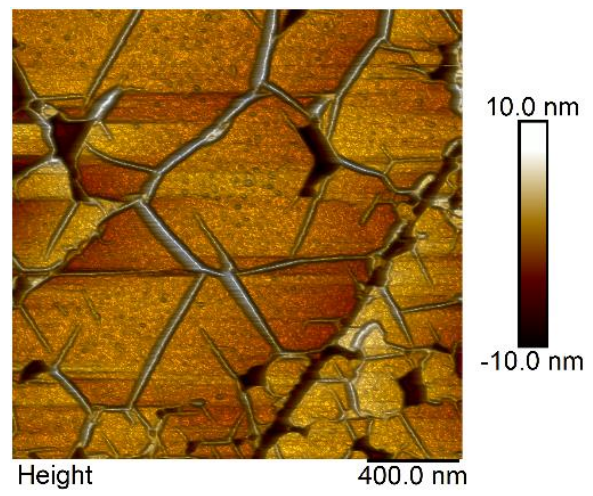

(c)

Figure 4.1: $\quad$ AFM images of (a) pristine graphene on Si-terminated $4 \mathrm{H}-\mathrm{SiC}$ with height profile as inset, (b) its corresponding phase image and (c) backside (C-face) of a $\mathrm{SiC}$ chip.

NPs, the graphene surface looks completely different (Figure 4.2 (b), here 0.5 min deposition time). The NPs are now dominating the surface roughness and the step-like plateaus with their small differences in height can hardly be resolved with the set z-scale. The particle coverages and average particle diameters of the NP DEG samples investigated in this work are summarized in Table 5. The particle size was calculated after evaluating at least 100 single particles and agglomerates per sample. For the $\mathrm{Fe}_{3} \mathrm{O}_{4}$ samples with different deposition times, the single particle size should stay approximately constant, as no other deposition parameters have been 


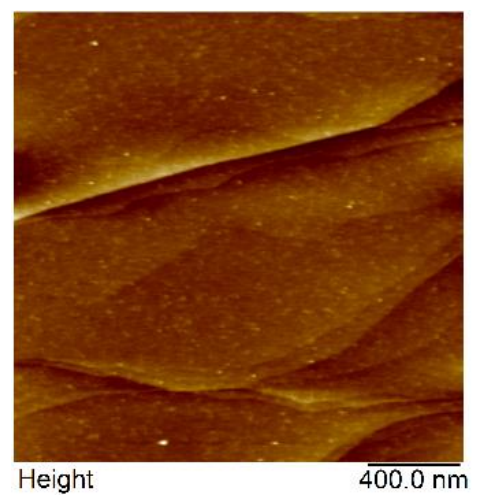

(a)

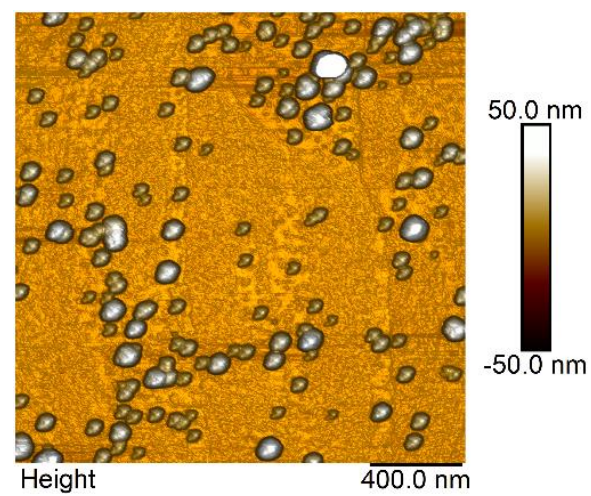

(b)

Figure 4.2: $\quad$ AFM image of (a) $\mathrm{Fe}_{3} \mathrm{O}_{4} \mathrm{NL}$ and (b) NP DEG.

modified. This is true to a large extent for single particles, but with a longer deposition time, more agglomerates are formed. An exemplary histogram of the particle size distribution is discussed in [Paper 2]. The Pt NPs are the smallest of all with a diameter of only approximately $25 \mathrm{~nm}$. The particle size itself can have an impact on the sensor's sensitivity and selectivity and thus is another parameter that can be optimized for sensor performance tuning [16]. This was, however, not investigated in this work. With an increase in deposition time, the coverage should increase. This can be seen for most of the $\mathrm{Fe}_{3} \mathrm{O}_{4}$ NP DEG surfaces. Only the sample deposited for 2 min resulted in a slightly higher coverage than the one deposited for $4 \mathrm{~min}$. However, the coverage percentages are within the margin of error, so they could have roughly the same coverage, which still would not be desired, but leads to comparable sensors in this case. Regarding AFM images, all graphene samples are very clean, except for the deposited functionalization material. This is also demonstrates that the addition and eventual removal of the used photoresist does not leave residues, which could be a problem otherwise [116, 117].

AFM images regarding IEG samples and the 2D Pt sensors are not shown here, but their quality was evaluated in other publications [47, 118]. 
Table 5: Resulting coverages and particle sizes after the decoration with NPs.

\begin{tabular}{lccc}
$\begin{array}{l}\text { Sputter } \\
\text { material }\end{array}$ & $\begin{array}{c}\text { Deposition } \\
\text { time (min) }\end{array}$ & $\begin{array}{c}\text { Avg. particle } \\
\text { size (nm) }\end{array}$ & $\begin{array}{c}\text { Coverage } \\
(\%)\end{array}$ \\
\hline $\mathrm{Fe}_{3} \mathrm{O}_{4}$ & 0.50 & $80 \pm 10$ & $15 \pm 5$ \\
$\mathrm{Fe}_{3} \mathrm{O}_{4}$ & 1.00 & $80 \pm 10$ & $25 \pm 5$ \\
$\mathrm{Fe}_{3} \mathrm{O}_{4}$ & 2.00 & $80 \pm 10$ & $55 \pm 5$ \\
$\mathrm{Fe}_{3} \mathrm{O}_{4}$ & 4.00 & $80 \pm 10$ & $45 \pm 5$ \\
$\mathrm{Pt}$ & 3.00 & $25 \pm 10$ & $20 \pm 5$ \\
$\mathrm{TiO}_{2}$ & 0.25 & $90 \pm 10$ & $15 \pm 5$
\end{tabular}

\subsubsection{Structural integrity}

Raman measurements were performed by Ivan G. Ivanov at Linköping University to verify that the integrity of the graphene layer was maintained after the decoration with NPs or NLs. The comparison between PEG, $\mathrm{Fe}_{3} \mathrm{O}_{4}$ NP DEG and $\mathrm{Fe}_{3} \mathrm{O}_{4} \mathrm{NL}$ DEG is shown in Figure 4.3. For a better comparison, all spectra were normalized to the $\mathrm{G}$ peak. The lower line belongs to the PEG reference which has distinct $G$ and $2 D$ peaks, typical for sp $\mathrm{sp}^{2}$-hybridized carbon, around $1600 \mathrm{~cm}^{-1}$ and $2737 \mathrm{~cm}^{-1}$, respectively [119]. The rather small FWHM value of $35 \mathrm{~cm}^{-1}$ at the $2 \mathrm{D}$ peak is indicative of uniform monolayer graphene within the irradiated spot [120]. The features above $1280 \mathrm{~cm}^{-1}$ and extending into the $\mathrm{G}$ peak are related to the interfacial buffer layer between the graphene and the $\mathrm{SiC}$ substrate [119]. Although they overlap with the position of the D peak at $1350 \mathrm{~cm}^{-1}$, they are not related to defects. If damage is induced into the graphene lattice, the D peak would rise. It can be clearly seen that the spectra after decoration are almost the same as the reference, indicating that no damage was introduced. The position of the $2 \mathrm{D}$ peak is the same for all samples, but the $\mathrm{G}$ peak varies slightly $\left( \pm 10 \mathrm{~cm}^{-1}\right)$. This is most likely due to different levels of strain in the graphene lattices [121] or possibly a result of different doping in the graphene due to charge transfer between graphene and decoration material. Moreover, the 2D peak broadens for the NL DEG sample which could be related to the inclusion of bi- or multilayer 


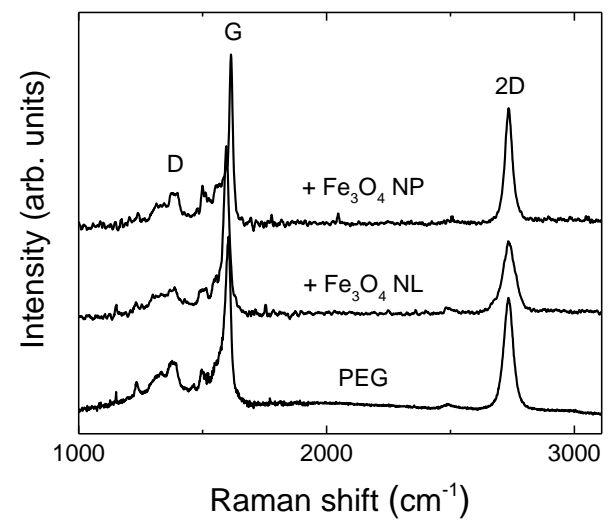

Figure 4.3: Raman spectra of $\mathrm{PEG}, \mathrm{Fe}_{3} \mathrm{O}_{4} \mathrm{NL}$ and NP DEG. Adapted from [Paper 1,4].

graphene in the measured spot. The lower G/2D peak ratio is another indication for this [81].

Figure 4.4 shows the Raman spectra of damaged graphene surfaces, i.e., hydrogen intercalated graphene and $\mathrm{Ag}$ - ion irradiated graphene, along with PEG as reference. The peaks corresponding to the graphene lattice are still distinct and if the graphene framework would be disrupted completely, the Raman features would change drastically (compare [Paper $\mathrm{C}]$ ). However, the rising $\mathrm{D}$ peak is a clear indication of significant amounts of defects in the graphene lattice. For example, the ratio between the intensity of the $\mathrm{D}$ and $\mathrm{G}$ peak is approximately 1.8 for the $5 \times 10^{12}$ ions $/ \mathrm{cm}^{2}$ irradiated sample which hints to a dominance of vacancy defects compared to the dominating $\mathrm{sp}^{3}$ defects for IEG with a ratio below 1, i.e., 0.6 [122]. The occurring red shift of the $2 \mathrm{D}$ peak, i.e., moving to lower values, of the defective graphene layers compared to PEG can be associated with relaxation of the compressive strain by defect creation [123]. Furthermore, the FWHM of the 2D peak increases for both treated samples to 48 and $56 \mathrm{~cm}^{-1}$ for IEG and ion irradiated EG, respectively, which is another indication for a defective graphene layer. The peaks D' and D+D' arising around 1200 and $2960 \mathrm{~cm}^{-1}$ also indicate rising defect levels. The D' peak can only be properly seen for the IEG sample whereas for the ion irradiated EG, it becomes part of the broader G peak. 


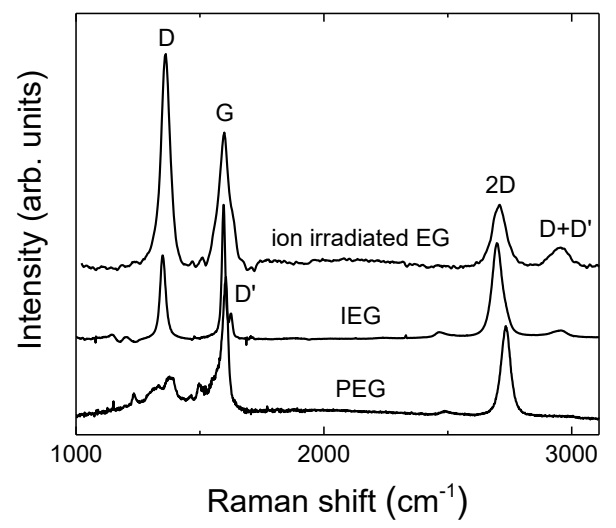

Figure 4.4: Raman spectra of PEG, IEG and $5 \times 10^{12}$ ions $/ \mathrm{cm}^{2}$ irradiated EG. Adapted from [Paper 1, C].

\subsubsection{Theoretical considerations}

DFT calculations have been performed by Ivan Shtepliuk at Linköping University to investigate the different adsorption energies between $\mathrm{C}_{6} \mathrm{H}_{6}$ and $\mathrm{CH}_{2} \mathrm{O}$, and PEG and NP DEG, i.e., $\mathrm{Fe}_{3} \mathrm{O}_{4}$ and $\mathrm{TiO}_{2}$, respectively, to theoretically verify that the NP decoration increases the gas sensitivity. The adsorption energy for $\mathrm{C}_{6} \mathrm{H}_{6}$ on $\mathrm{Fe}_{3} \mathrm{O}_{4}$ NP DEG is $E_{\text {ads }}=1.795 \mathrm{eV}$, whereas the adsorption energy on PEG is significantly lower with $E_{\text {ads }}=0.284 \mathrm{eV}$. For $\mathrm{TiO}_{2}$ NP DEG, the adsorption energy is also higher compared to PEG, but about $0.4 \mathrm{eV}$ lower compared to $\mathrm{Fe}_{3} \mathrm{O}_{4} \mathrm{NP}$ DEG. Therefore, further optimizations and gas measurements have not been performed with the $\mathrm{TiO}_{2}$ NP DEG sample. Figure 4.5 shows the energetically favored adsorption configurations of the gas molecules on PEG and $\mathrm{Fe}_{3} \mathrm{O}_{4}$ NP DEG. In the absence of the $\mathrm{Fe}_{3} \mathrm{O}_{4} \mathrm{NPs}$, the $\mathrm{C}_{6} \mathrm{H}_{6}$ molecule adsorbs parallel to the surface in a flat geometry. In this case, the center of the $\mathrm{C}_{6} \mathrm{H}_{6}$ ring lays on top of a carbon atom belonging to the graphene. With $\mathrm{Fe}_{3} \mathrm{O}_{4} \mathrm{NPs}$ being present, the formation of a strong chemical bond between the $\mathrm{C}_{6} \mathrm{H}_{6}$ ring and one of the Fe atoms is facilitated, leading to a tilted $\mathrm{C}_{6} \mathrm{H}_{6}$ adsorption.

The $\mathrm{CH}_{2} \mathrm{O}$ molecule behaves similarly with adsorption energies of $0.149 \mathrm{eV}$ and $1.870 \mathrm{eV}$ for the adsorption on PEG and $\mathrm{Fe}_{3} \mathrm{O}_{4} \mathrm{NP}$ DEG, respectively (compare [Paper 2]). In conclusion, weak physisorption of $\mathrm{C}_{6} \mathrm{H}_{6}$ and $\mathrm{CH}_{2} \mathrm{O}$ on PEG can be altered to strong chemisorption with the presence of $\mathrm{NPs}$. Therefore, $\mathrm{Fe}_{3} \mathrm{O}_{4}$ DEG graphene should exhibit an enhanced 


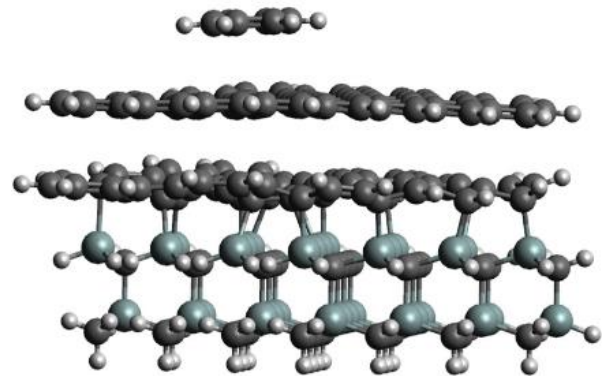

(a)

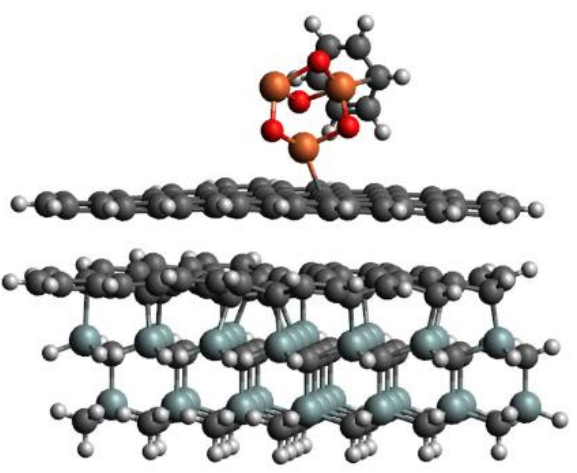

(b)

Figure 4.5: Optimized adsorption configurations of $\mathrm{C}_{6} \mathrm{H}_{6}$ on (a) $\mathrm{PEG}$ and (b) $\mathrm{Fe}_{3} \mathrm{O}_{4}$ NP DEG [Paper 2].

sensor reaction to the exposure of $\mathrm{C}_{6} \mathrm{H}_{6}$ and $\mathrm{CH}_{2} \mathrm{O}$ compared to $\mathrm{TiO}_{2} \mathrm{NP}$ DEG and PEG, with a slightly higher estimated interaction with $\mathrm{CH}_{2} \mathrm{O}$.

\subsection{Gas measurements}

To evaluate the performance of the prepared EG-based gas sensors and their applicability in AQM, measurements with several test gases under varying operating conditions have been performed and their results are discussed in the following subsections.

\subsubsection{Influence of temperature}

The sensor temperature plays an important role for the performance of gas sensors. To ensure adsorption and reaction of gases at the sensor surface and thus a sensor response, a specific activation energy has to be overcome [27]. This leads to different reaction times caused by different rate constants for specific gases [20]. As already mentioned, the current sensor setup limits the operating temperature to about $300{ }^{\circ} \mathrm{C}$ and no measurements above $200{ }^{\circ} \mathrm{C}$ were performed as a precaution. To be able to work at higher temperatures, sensors are usually annealed at an even higher temperature, which was not done here.

The influence of the operating temperature is shown exemplarily in Figure 4.6. Figure 4.6 (a) represents a measurement with the $\mathrm{V}_{2} \mathrm{O}_{5} \mathrm{NL}$ DEG sensor over a temperature range from 50 to $125^{\circ} \mathrm{C}$ and $30 \mathrm{~min} \mathrm{NH}_{3}$ 


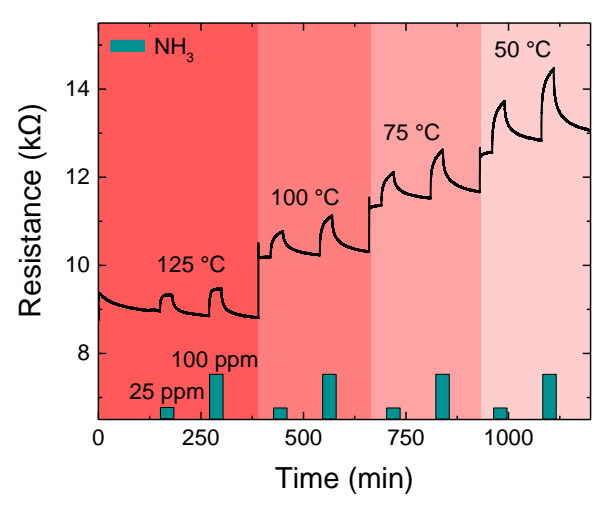

(a)

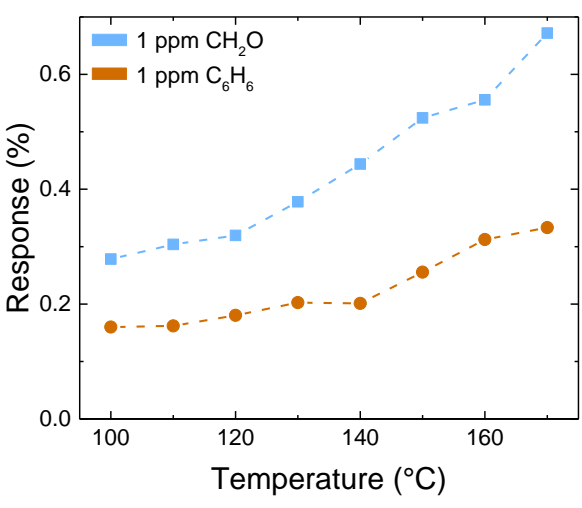

(b)

Figure 4.6: (a) Resistance over time of $\mathrm{V}_{2} \mathrm{O}_{5}$ NL DEG for $\mathrm{NH}_{3}$ exposures at different temperatures at $50 \% \mathrm{RH}$ based on [Paper 4] and (b) response of $\mathrm{Fe}_{3} \mathrm{O}_{4}$ NP DEG for $\mathrm{CH}_{2} \mathrm{O}$ and $\mathrm{C}_{6} \mathrm{H}_{6}$ exposures at different temperatures at $0 \% \mathrm{RH}$.

exposures at $50 \% \mathrm{RH}$. The measurement clearly shows that the baseline resistance decreases with increasing temperature. A higher operating temperature results in a faster equilibration of the resistance, but does not automatically lead to a larger absolute response. $\tau$ decreases from approximately $550 \mathrm{~s}$ at $50{ }^{\circ} \mathrm{C}$ down to $150 \mathrm{~s}$ at $125^{\circ} \mathrm{C}$. Moreover, at lower temperatures, the sensor is not always able to relax back to its baseline after 90 min. More results with all four NL DEG sensors are discussed in [Paper 4]. Figure 4.6 (b) shows the response of a $\mathrm{Fe}_{3} \mathrm{O}_{4}$ NP DEG sensor for 30 min of 1 ppm $\mathrm{CH}_{2} \mathrm{O}$ and $\mathrm{C}_{6} \mathrm{H}_{6}$ exposures at temperatures ranging from $100{ }^{\circ} \mathrm{C}$ up to $170{ }^{\circ} \mathrm{C}$ in steps of $10^{\circ} \mathrm{C}$ at $0 \% \mathrm{RH}$. In this case, a higher operating temperature leads to a higher sensor response, e.g., the response to $1 \mathrm{ppm} \mathrm{CH}_{2} \mathrm{O}$ increases from $0.28 \%$ at $100{ }^{\circ} \mathrm{C}$ to $0.67 \%$ at $170{ }^{\circ} \mathrm{C}$.

A compromise between level of response, speed of response and stability of the baseline has to be established. Therefore, and for better comparability between the different sensors, most measurements presented in this work have been performed at $150^{\circ} \mathrm{C}$. To make the most use of the different performances at varying temperatures, the operating temperature can also be cycled within a gas measurement. This so-called TCO approach will be discussed in section 4.3.2. 


\subsubsection{Influence of humidity}

Perhaps even more critical for the sensor response than the operating temperature is the influence of relative humidity in the ambient. Many metal oxides have been found to exhibit a cross-sensitivity to $\mathrm{RH}$ and for most materials, a higher level of RH means a lower sensitivity to other gases as they must compete with water for available adsorption sites [26, 28]. Adsorption of water molecules on graphene can provide additional Coulomb and impurity scattering centers decreasing the free charge carrier mobility, thus decreasing the possible sensor response [124].

Not only the sensitivity, but also the baseline resistance of a sensor can strongly be affected by a humid ambient as additional water molecules act as p-dopants. Most measurements were performed in a dry environment for optimal sensitivity. Nevertheless, the effect of RH was explored separately with different samples, gases and operating temperatures.

Figure 4.7 (a) shows the response of PEG as the difference between the baseline resistances at two different humidity levels $\mathrm{x}$ and $\mathrm{y}$, written as $\mathrm{x}-\mathrm{y} \% \mathrm{RH}$. The humidity was varied from $0 \% \mathrm{RH}$ up to $40 \% \mathrm{RH}$ while the sensor was kept at $150{ }^{\circ} \mathrm{C}$ in a constant flow of zero air. The resistance decreases with an increase in $\mathrm{RH}$, thus exhibiting typical p-type behavior as additional $\mathrm{H}_{2} \mathrm{O}$ molecules act as p-dopants [124]. However, the used $\mathrm{PEG}$ is an $\mathrm{n}$-type material and, therefore, the change in resistance should occur in the opposite direction. As the sensor is operated at $150{ }^{\circ} \mathrm{C}$, hence no water film should form on the sensor surface, and ionic oxygen species are already present, p-doping by water is not the sole answer for the change in resistance. Water vapor forms hydroxyl groups which can react with surface oxygen forming rooted hydroxyl groups acting as electron donors and also a dissociated neutral hydrogen atom can react with surface oxygen, resulting in an oxygen vacancy, which is also an electron donor, thus reversing the expected p-type doping from the water molecule alone [125]. It can be clearly seen that for a change from any level of relative humidity to one that is not zero, the change in baseline resistance is rather small while a change from or to $0 \% \mathrm{RH}$ has a rather large impact on the baseline resistance. The observed logarithmically decreasing sensor response is typical for exposures towards decreasing gas concentrations, which also would suggest that the relative humidity rather acts as a target gas and not as a surface poisoning substance forming a passivating water film on the sensor surface. This would fit the observation that the sensors react to changes in relative humidity even if operated well above $100{ }^{\circ} \mathrm{C}$. 


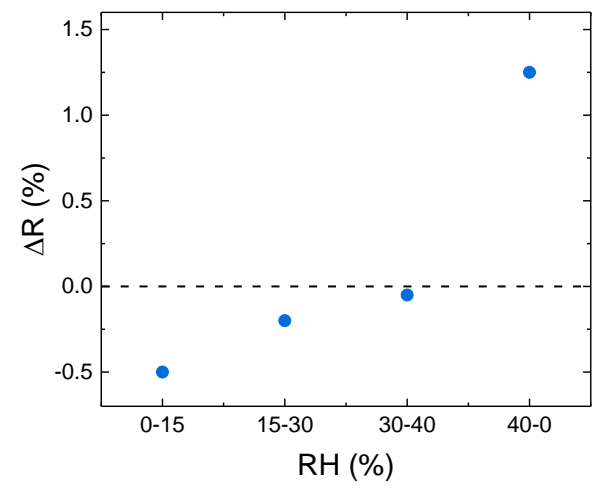

(a)

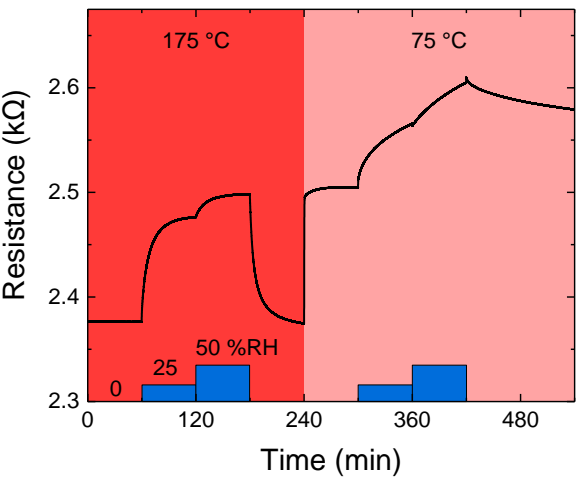

(b)

Figure 4.7: (a) Changes of baseline resistance of $\mathrm{PEG}$ at $150{ }^{\circ} \mathrm{C}$ at different $\mathrm{RH}$ and (b) resistance over time of IEG for $\mathrm{RH}$ variations at 175 and $75^{\circ} \mathrm{C}$, respectively.

To support this, the change in $\mathrm{RH}$ was investigated for several different temperatures. This is exemplarily shown for the IEG sensor in Figure 4.7 (b), which shows the response to changes in relative humidity first at $175{ }^{\circ} \mathrm{C}$ and then at $75^{\circ} \mathrm{C}$ operating temperature. Note that the resistance increases with increasing relative humidity, which is opposite the reaction of PEG, but expected as the IEG sensor reacts as a p-type sensor instead. It can be clearly seen that the change in resistance is completely reversible to an zero air exposure with and without $\mathrm{RH}$ at $175^{\circ} \mathrm{C}$ and occurs rather fast, whereas the sensor resistance changes very slowly at $75^{\circ} \mathrm{C}$ when $25 \% \mathrm{RH}$ are introduced the first time. Furthermore, when changing back from 50 to $0 \% \mathrm{RH}$ at $75{ }^{\circ} \mathrm{C}$, the baseline does not fully recover, which hints at the formation of a water film on the sensor surface, not possible at elevated temperatures. Moreover, when comparing the relative responses to changes in $\mathrm{RH}$, it decreased slightly with increasing temperature for temperatures between 125 and $175{ }^{\circ} \mathrm{C}$. For example from -3.4 to $-2.8 \%$ for PEG and from 5.7 to $5.2 \%$ for IEG, respectively.

Figure 4.8 (a) shows the response of $\mathrm{Fe}_{3} \mathrm{O}_{4}$ NP DEG to 1.6 and $0.8 \mathrm{ppm}$ of $\mathrm{CH}_{2} \mathrm{O}$, and 100 and $200 \mathrm{ppb}$ of $\mathrm{C}_{6} \mathrm{H}_{6}$ for $30 \mathrm{~min}$ at $150{ }^{\circ} \mathrm{C}$ for 50,25 and $0 \% \mathrm{RH}$. No response is observed for humidity levels above zero for both gases. Similarly, NL DEG sensors only respond to $\mathrm{C}_{6} \mathrm{H}_{6}, \mathrm{CH}_{2} \mathrm{O}$ and $\mathrm{CO}$ in a dry ambient (compare [Paper 4]). This means that the complete sensor system for AQM would need to run in a dry environment, which is a draw- 


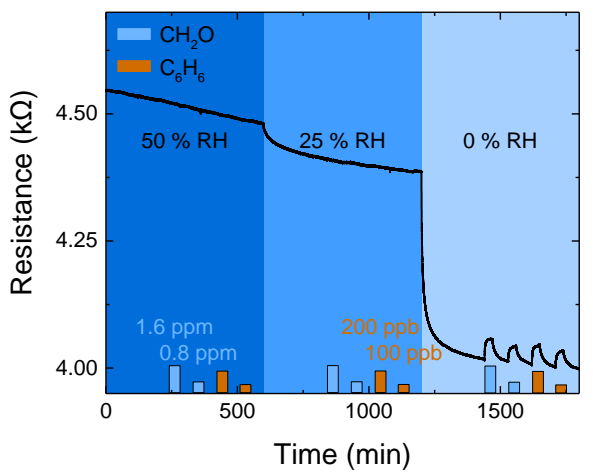

(a)

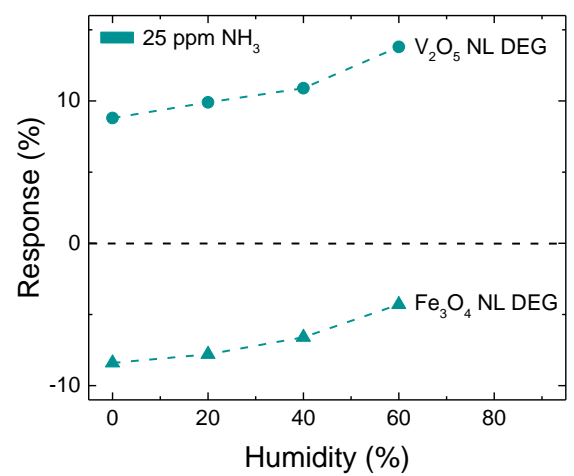

(b)

Figure 4.8: (a) Resistance over time of $\mathrm{Fe}_{3} \mathrm{O}_{4}$ NP DEG for $\mathrm{CH}_{2} \mathrm{O}$ and $\mathrm{C}_{6} \mathrm{H}_{6}$ exposures at $150{ }^{\circ} \mathrm{C}$ at different $\mathrm{RH}$ and (b) responses of $\mathrm{Fe}_{3} \mathrm{O}_{4}$ and $\mathrm{V}_{2} \mathrm{O}_{5}$ NL DEG sensors for $25 \mathrm{ppm} \mathrm{NH}_{3}$ exposures at $75^{\circ} \mathrm{C}$ at different RH. (b) is based on [Paper 4].

back, but technologically possible. However, other sensors, i.e., IEG and Pt NP DEG, are still able to detect both VOCs with humidity present, which would make the overall AQM system much simpler (compare section 4.2.5).

For other material/gas combinations, a humid ambient can boost the sensor response compared to the corresponding performance in a dry ambient. This is exemplarily demonstrated in Figure 4.8 (b), where the response of $\mathrm{Fe}_{3} \mathrm{O}_{4}$ and $\mathrm{V}_{2} \mathrm{O}_{5} \mathrm{NL}$ DEG to $30 \mathrm{~min}$ of $25 \mathrm{ppm} \mathrm{NH}_{3}$ exposure at $75^{\circ} \mathrm{C}$ and various $\mathrm{RH}$ is shown. While the response of the $\mathrm{Fe}_{3} \mathrm{O}_{4} \mathrm{NL}$ DEG sensor decreases with increasing $\mathrm{RH}$, the response of the $\mathrm{V}_{2} \mathrm{O}_{5} \mathrm{NL}$ DEG sensors increases from initially $8.8 \%$ up to $13.8 \%$ at 0 and $60 \% \mathrm{RH}$, respectively. It is interesting that an increase in humidity increases the response, even exceeding the response at zero humidity. Especially when measuring $\mathrm{NH}_{3}$, this increase could be due to the reaction with $\mathrm{OH}^{-}$groups or of products of reactions from $\mathrm{OH}$ groups and $\mathrm{NH}_{3}$ instead. This phenomenon was found to occur for metal oxide gas sensors when operating them at relatively low temperatures in a humid environment [65, 126]. Similarly, also $\mathrm{V}_{2} \mathrm{O}_{5}$ NL DEG, Pt NP DEG and the IEG sensors exhibit an increase in response to $\mathrm{NO}_{2}$ with increasing $\mathrm{RH}$ in the ambient even when measured at $150{ }^{\circ} \mathrm{C}$ (compare for example [Paper 4]). One possible explanation for the IEG sensor could be that $\mathrm{NO}_{2}$ mostly changes, i.e., enhances, the mobility but not the carrier density. In such a case, graphene with low 
doping introduced to $\mathrm{NO}_{2}$ would show only a small change in resistance, because there are only a few charge carriers with their mobility being enhanced. When graphene is strongly doped (e.g., by ambient humidity), $\mathrm{NO}_{2}$ gas enhances the mobility of the charge carriers, resulting in a stronger change in resistance [127].

\subsubsection{Influence of UV irradiation}

As mentioned before, the sensor performance can be enhanced by additional UV irradiation. It is known that if the band gap is below the wavelength energy (4.48 eV for $265 \mathrm{~nm}$ and $3.49 \mathrm{eV}$ for $355 \mathrm{~nm}$ ), there will be charge excitation changing the charge density in the exposed surface material, i.e., the decorated nanostructures and/or the graphene lattice. This could increase or counteract the effect of the gas response depending on the material/gas combination and should be more pronounced for thicker layers, where the net charge excitation is higher.

Figure 4.9 shows the response of a $\mathrm{TiO}_{2} \mathrm{NP}$ DEG sensor to varying oxygen percentages without and with UV irradiation. The UV LED has a wavelength of $265 \mathrm{~nm}$ and an optical output power of $0.8 \mathrm{~mW}$. The operating temperature was $100{ }^{\circ} \mathrm{C}$ and oxygen was varied from a baseline of $20 \%$ to values ranging between 16 and $1 \%$. It can be clearly seen that the measurement without UV irradiation shows changes in resistance when varying the oxygen concentration, but they are not distinct and cannot be related to the specific concentrations. Introducing the UV irradiation, the baseline resistance drops by about $270 \Omega$. Moreover, the changes in oxygen concentration can now be distinctively observed as the resistance exhibits the typical shape of a gas sensor response. Unfortunately, the exposure time of 10 min was not enough to arrive at an equilibrated response level. The desorption process is enhanced under the irradiation as well, decreasing the time needed for the sensor to return to its baseline after the gas exposure, making it faster and more efficient [19]. The low response without UV is likely due to an oxygen saturated surface in the background of $20 \% \mathrm{O}_{2}$. UV irradiation promotes oxygen desorption, leading to an increased dynamic range for oxygen detection [57]. 


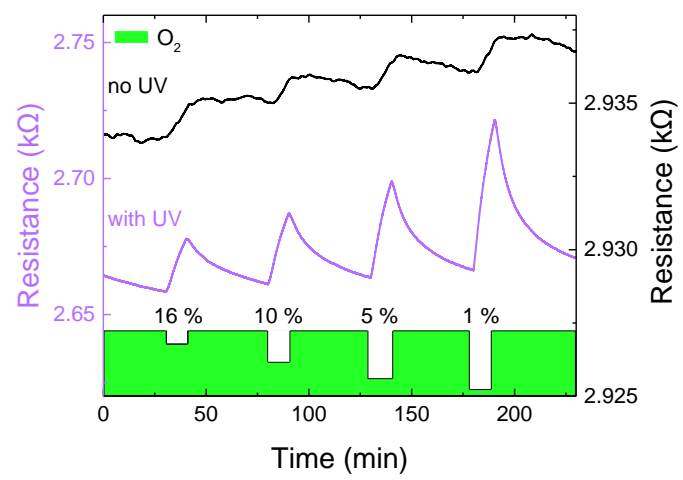

Figure 4.9: Resistance over time of $\mathrm{TiO}_{2}$ NP DEG to a variation of oxygen changing from a background of $20 \%$ without and with UV irradiation at $100{ }^{\circ} \mathrm{C}$ at $0 \% \mathrm{RH}$. Adapted from [Paper 1].

Depending on the material/gas combination, additional UV irradiation can have no or only a rather small impact on the sensor properties. This is exemplarily shown in Figure 4.10. $\mathrm{V}_{2} \mathrm{O}_{5}$ and $\mathrm{ZrO}_{2} \mathrm{NL}$ DEG sensors were exposed to $30 \mathrm{~min}$ of $25 \mathrm{ppm} \mathrm{NH}_{3}$ with and without additional UV irradiation. Both UV wavelengths increase the sensor response for $\mathrm{V}_{2} \mathrm{O}_{5}$, while the response for $\mathrm{ZrO}_{2}$ is almost constant for all measurements. This is expected as $\mathrm{ZrO}_{2}$ has a comparably large bandgap ( $>5 \mathrm{eV}$ ), while $\mathrm{V}_{2} \mathrm{O}_{5}$ with $\sim 2.4 \mathrm{eV}$ has a bandgap smaller than the used photon energies (e.g., $3.49 \mathrm{eV}$ for $355 \mathrm{~nm}$ ). UV irradiation can also have a positive effect on the time constants. For example, $\tau$ decreases for $\mathrm{V}_{2} \mathrm{O}_{5}$ from approximately $500 \mathrm{~s}$ without irradiation down to $400 \mathrm{~s}$ at $265 \mathrm{~nm} \mathrm{UV}$ irradiation. An irradiation with $355 \mathrm{~nm}$ does decrease $\tau$ as well, but not as much as $265 \mathrm{~nm}$ UV irradiation. This could be due to the higher energy at shorter wavelength. The same trend could be expected for the response as well, i.e., higher energy due to the shorter wavelength would lead to an increased response, but for all three NL DEG, where the response increased with UV, the maximum was reached with $355 \mathrm{~nm}$ irradiation. This could be due to the fact that energetically higher irradiation does not only facilitate stronger surface reactions, but also better molecule desorption, thus two competing mechanisms occur at the same time as mentioned in [57].

In general, additional UV irradiation is often used for graphene when $\mathrm{NH}_{3}$ or $\mathrm{NO}_{\mathrm{x}}$ should be detected (see also [Paper 4, C] and [128]) and can even be used in pulsed mode to generate transient data [61]. 


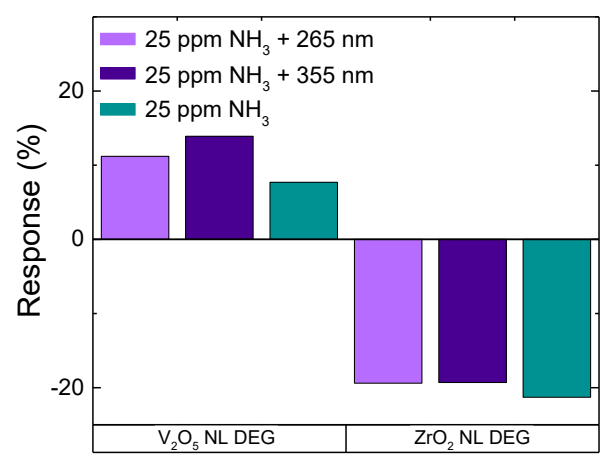

Figure 4.10: Responses of $\mathrm{V}_{2} \mathrm{O}_{5}$ and $\mathrm{ZrO}_{2} \mathrm{NL}$ DEG for $25 \mathrm{ppm} \mathrm{NH}_{3}$ exposures at $75^{\circ} \mathrm{C}$ and $125^{\circ} \mathrm{C}$, respectively at $50 \% \mathrm{RH}$ without and with UV irradiation. Adapted from [Paper 4].

\subsubsection{Influence of defects}

Another way to tailor the sensing properties of graphene is by introducing structural defects or impurities. Assuming that the gas sensing takes place at graphene's ח-electrons, which are directly exposed to adsorbed molecules, more available $\Pi$-electrons would lead to an increase in sensor response. Thus, it was reported that dopants and defects can increase the sensing capabilities of graphene [56]. In general, carbon atoms on a defective graphene surface hold higher dipole moments compared to PEG, which can result in a stronger bond formation with foreign molecules. Here, defects were introduced using low energy ion beam implantation (30 keV) with Ag- ions.

Figure 4.11 summarizes the responses for PEG and ion irradiated EG sensors to $50 \mathrm{ppb} \mathrm{NO}_{2}$ and $\mathrm{NH}_{3}$ exposures at $150{ }^{\circ} \mathrm{C}$ at $0 \% \mathrm{RH}$. Without any ion treatment, the PEG sensor exhibits typical $n$-type behavior with a positive response to $\mathrm{NO}_{2}$ and a negative response to $\mathrm{NH}_{3}$. With increasing ion irradiation fluence, the sensor response first increases in magnitude before it inverts its behavior just below a fluence of $5 \times 10^{13}$ ions $/ \mathrm{cm}^{2}$, with a decrease in response and a change in response direction for both gases. This means that there is not only an optimal defect density achieving the absolute highest sensor response, but also that doping by defect introduction can change the sensing behavior from initial n-type EG to p-type EG on $\mathrm{SiC}$. Moreover, the corresponding response and recovery time constants are inversely correlated with the ion irradiation, i.e., first decreasing with ion irradiation fluence and then increasing again (compare [Paper C]). 


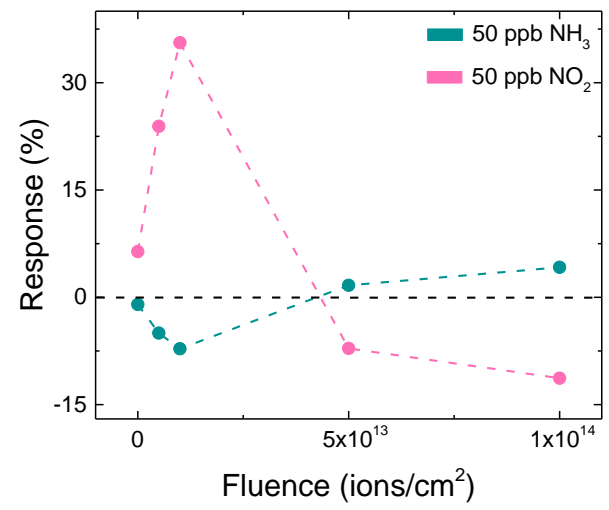

Figure 4.11: Response of $\mathrm{EG}$ for $50 \mathrm{ppb} \mathrm{NH}_{3}$ and $\mathrm{NO}_{2}$ exposures at $150{ }^{\circ} \mathrm{C}$ at $0 \% \mathrm{RH}$ over increase in $\mathrm{Ag}$ - ion irradiation. Based on [Paper $\mathrm{C}$ ].

The initial increase in sensor response observed for low fluences could be explained with an increased interaction between $\mathrm{NO}_{2}$ molecules and defective graphene compared to PEG [56] (compare section 4.1.2). Furthermore, additional adsorption sites are available on defective graphene compared to PEG and defects increase the charge transfer between graphene and $\mathrm{NO}_{2}$ molecules, both leading to an increased sensor response [129]. The higher the irradiation fluence, the more carbon vacancies and dangling bonds are produced. These dangling bonds correlate with $\mathrm{sp}^{3}$ defects, which also represent $\mathrm{C}-\mathrm{OH}$ and $\mathrm{C}-\mathrm{O}-\mathrm{C}$ bonds. These carbon bonds are electron acceptors, i.e., p-type dopants, which could explain the change from $\mathrm{n}$ - to $\mathrm{p}$-type behavior. Similar explanations can be given for the observed differences in sensor response for increasing defect density when exposed to $\mathrm{NH}_{3}$ as well [130]. An in-depth study of the defect generation can be found in [Paper C].

This change in response behavior, i.e., from n- to p-type, can also be achieved with a sufficiently high concentration of a strongly oxidizing gas. This is shown in Figure 4.12, where a PEG and an ion irradiated sensor (5x1012 ions/cm $\mathrm{cm}^{2}$ fluence) were exposed to $\mathrm{NO}_{2}$ at $150{ }^{\circ} \mathrm{C}$ at $0 \% \mathrm{RH}$. While the PEG sensor exhibited an n-type behavior for the whole tested concentration range, i.e., from $50 \mathrm{ppb}$ to $50 \mathrm{ppm}$, the irradiated sensor inverts its response direction when ppm concentrations were provided. This is most probably due to a doping effect corresponding to the gas species, which increases with an increase in concentration. This doping changes the 


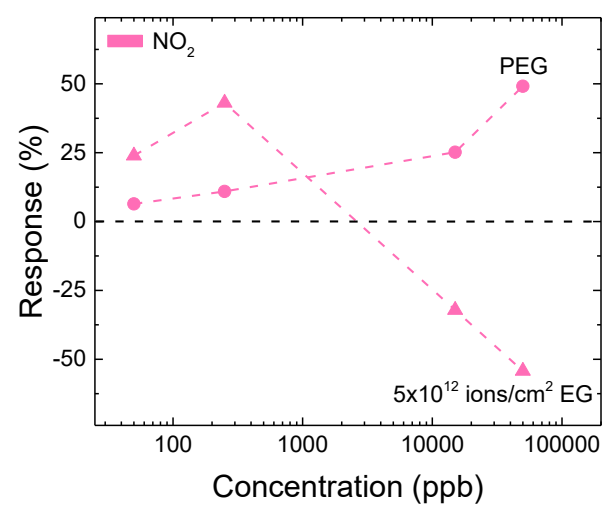

Figure 4.12: Responses of PEG and $5 \times 10^{12}$ ions $/ \mathrm{cm}^{2}$ irradiated $\mathrm{EG}$ for $\mathrm{NO}_{2}$ exposures at $150{ }^{\circ} \mathrm{C}$ at $0 \% \mathrm{RH}$. Based on [Paper C].

position of the Fermi level, which can change the response direction if the Dirac point is passed from below to above or vice versa (compare section 2.3.2).

\subsubsection{Target analyte detection}

One of the main findings of this work is the ability to detect concentrations of hazardous VOC, i.e., $\mathrm{C}_{6} \mathrm{H}_{6}$ and $\mathrm{CH}_{2} \mathrm{O}$, quantitatively down to single ppb and also over a large dynamic range of three orders of magnitude under lab conditions (compare Figure 4.13). This was first presented in [Paper 2] with the $\mathrm{Fe}_{3} \mathrm{O}_{4}$ NP DEG sensors. This measurement was repeated twice in the same environment and once more approximately one year later with the same sensor. The measured responses show some small deviations between the measurements but without a clear trend of decreasing response over time. This shows the long-term stability of the sensor. What decreases though is the SNR. More noise can be seen for a sensor if operated over a longer time compared to a 'fresh' one. $\mathrm{Fe}_{3} \mathrm{O}_{4}$ (4min) NP DEG was also tested to $\mathrm{C}_{6} \mathrm{H}_{6}$ in the lower ppb range at $150{ }^{\circ} \mathrm{C}$ at $0 \% \mathrm{RH}$, resulting in very similar response values as $\mathrm{Fe}_{3} \mathrm{O}_{4}$ (2min) NP DEG, e.g., $0.049 \%$ and $0.052 \%$ for $10 \mathrm{ppb}$ for $\mathrm{Fe}_{3} \mathrm{O}_{4}(2 \mathrm{~min})$ and (4min) NP DEG, respectively. This fits the observation that the NP coverage is similar for both samples, indicating a reproducible sensor performance. A systematic study of the influence of particle coverage on the sensor response was not done here, but it was already found that it can have a significant impact [131]. However, as 


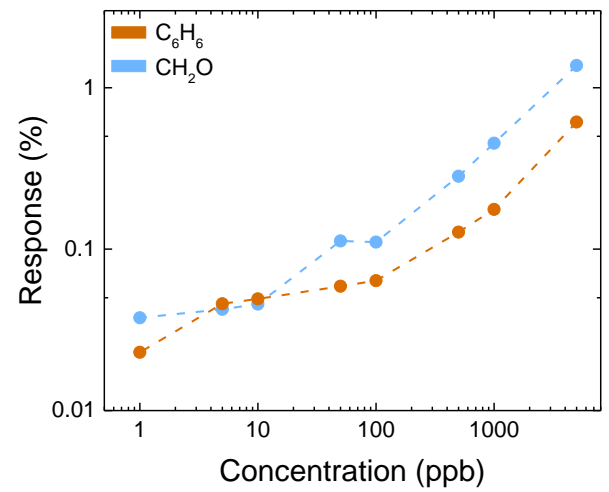

Figure 4.13: Response of $\mathrm{Fe}_{3} \mathrm{O}_{4}$ NP DEG for $\mathrm{C}_{6} \mathrm{H}_{6}$ and $\mathrm{CH}_{2} \mathrm{O}$ exposures at $150{ }^{\circ} \mathrm{C}$ at $0 \% \mathrm{RH}$. Adapted from [Paper 2].

mentioned in section 4.2.2, the sensors were able to detect both gases only in a dry environment.

Latest results show that it is possible to detect these VOCs at low concentrations in a humid environment as well. In Figure 4.14, the responses for Pt NP DEG and IEG sensors to $\mathrm{C}_{6} \mathrm{H}_{6}$ exposures at $150{ }^{\circ} \mathrm{C}$ are summarized. It can clearly be seen that the sensors react even with relative humidity present in the ambient. The response at $50 \% \mathrm{RH}$ is, however, smaller compared to the one in dry ambient, resulting in approximately half of the response compared to $0 \% \mathrm{RH}$. The response of the $\mathrm{Pt}$ NP DEG sensor is the highest of all observed responses (compare also Figure 4.15), but it is also approximately one order of magnitude higher than the only other sensor, i.e., IEG, able to detect $\mathrm{C}_{6} \mathrm{H}_{6}$ and $\mathrm{CH}_{2} \mathrm{O}$ at

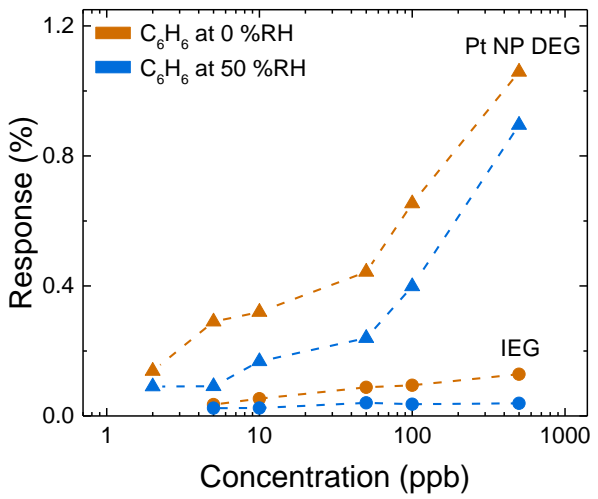

Figure 4.14: Responses of Pt NP DEG and IEG for $\mathrm{C}_{6} \mathrm{H}_{6}$ exposures at $150{ }^{\circ} \mathrm{C}$. 
$50 \% \mathrm{RH}$. This results in LODs of 0.05 and $0.09 \mathrm{ppb}$ for $\mathrm{C}_{6} \mathrm{H}_{6}$ at 0 and $50 \% \mathrm{RH}$ and 0.07 and $0.17 \mathrm{ppb}$ for $\mathrm{CH}_{2} \mathrm{O}$, respectively. It was already found in other studies that Pt doped sensors showed superior gas response to relative humidity compared to their undoped counterparts [132, 133]. However, also there, an increase in $\mathrm{RH}$ leads to a decrease in response.

The appearance of sensitivity for IEG compared to PEG is most probably due to the known increased defect density for IEG (compare [134] and section 4.2.4). Another possible explanation could be the difference in carrier density between the sensors [134]. The response of the IEG sensor is comparably small (see also Figure 4.15), but still has estimated LODs of 0.68 and $1.40 \mathrm{ppb}$ for $\mathrm{C}_{6} \mathrm{H}_{6}$ at 0 and $50 \% \mathrm{RH}$. Exposures to formaldehyde result in very similar responses, e.g., $0.04 \%$ vs $0.05 \%$ for 10 ppb $\mathrm{CH}_{2} \mathrm{O}$ and $\mathrm{C}_{6} \mathrm{H}_{6}$ at $0 \% \mathrm{RH}$, respectively. This leads to similar LODs for $\mathrm{CH}_{2} \mathrm{O}$ exposures of 0.97 and $1.74 \mathrm{ppb}$ at 0 and $50 \% \mathrm{RH}$, respectively. The promising outcome with this sensor surface is that it could additionally be decorated with other nanostructures, thus further enhancing its sensor properties.

For a better comparability, all sensors were exposed to $500 \mathrm{ppb} \mathrm{C}_{6} \mathrm{H}_{6}$ and $\mathrm{CH}_{2} \mathrm{O}$, respectively, at $150{ }^{\circ} \mathrm{C}$ and $0 \% \mathrm{RH}$. The results are shown in Figure 4.15. As expected from theoretical calculations (see section 4.1.3), the PEG sensor did not exhibit any response for both gases and also $\mathrm{ZrO}_{2}$ NL DEG did not react discernibly. Both $\mathrm{Fe}_{3} \mathrm{O}_{4}$ DEG sensors have similar responses with a small increase with the NL compared to the NP DEG sensor to $\mathrm{C}_{6} \mathrm{H}_{6}$ but vice versa for $\mathrm{CH}_{2} \mathrm{O}$. This would support the claim that the reaction mainly takes place at the $\mathrm{Fe}_{3} \mathrm{O}_{4}$ sites as the NL DEG sensor is completely covered with an ultra-thin layer, whereby no direct graphene-gas interaction can occur. Both $\mathrm{CuO}$ and $\mathrm{V}_{2} \mathrm{O}_{5}$ NL DEG sensors outperform the $\mathrm{Fe}_{3} \mathrm{O}_{4}$ DEG in regards to their responses. The highest response of all sensors was exhibited by the Pt NP DEG sensor, which was more than twice as high as the second highest response observed with the CuO NL DEG sensor. The IEG sensor showed a comparably low response, but as it is without any additional metal oxide decoration and also operable in a humid environment (compare also Figure 4.14), this is especially interesting as both techniques, i.e., hydrogen intercalation and metal oxide decoration, could be combined in the future to obtain even better sensors. 


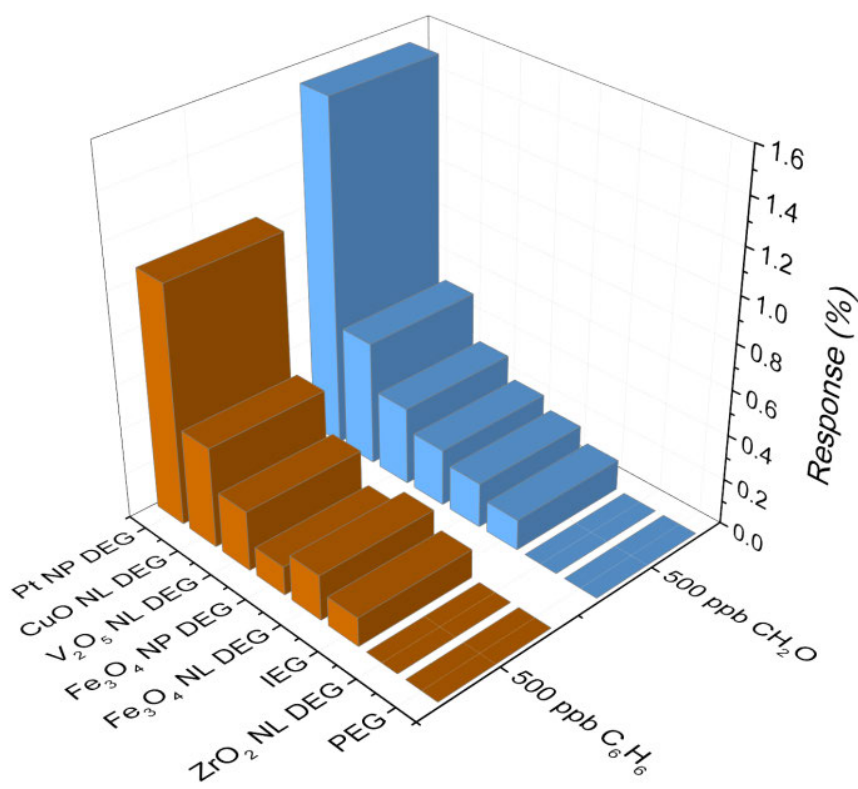

Figure 4.15: Responses of all sensors for 500 ppb $\mathrm{C}_{6} \mathrm{H}_{6}$ and $\mathrm{CH}_{2} \mathrm{O}$ exposures at $150{ }^{\circ} \mathrm{C}$ at $0 \% \mathrm{RH}$. Partly based on [Paper 2, 4].

Furthermore, the responses towards $\mathrm{CH}_{2} \mathrm{O}$ compared to $\mathrm{C}_{6} \mathrm{H}_{6}$ were higher for all sensors except for the $\mathrm{Fe}_{3} \mathrm{O}_{4}$ NL DEG one, where the response was approximately the same (compare also section 4.1.3). An overview about LOD and SNR values is given at the end of this section.

As already mentioned, the main focus was the detection of VOCs down to as low concentrations as possible. Nevertheless, experiments with other gases can highly contribute to the understanding of sensor properties, especially when it comes to selectivity or even cross-sensitivity. For example, $\mathrm{NH}_{3}$ was used as either a common interference gas or common reducing agent. All tested sensors in this work have exhibited a response to $\mathrm{NH}_{3}$. In general, PEG showed the smallest response compared to all modified sensors. Some more in-depth results regarding ammonia detection are included in [Paper 4, C]. $\mathrm{NH}_{3}$ is an interesting gas also at low concentration for example as analyte in breath analysis applications. Hibbard and Killard state that there is a need of simple, non-invasive detection methods that can detect ammonia with a limit of detection of at least $50 \mathrm{ppb}$ at high levels of relative humidity [135]. This was not evaluated in this work, but could be investigated with some of the sensors in the future due to their promising detection behaviors. 
Other very common gases in the ambient are $\mathrm{CO}$ and $\mathrm{NO}_{2}$. The responses are summarized in Table 6 for 30 min exposures to 500 ppb of $\mathrm{CO}$ and $\mathrm{NO}_{2}$, respectively, at $150{ }^{\circ} \mathrm{C}$ at $0 \% \mathrm{RH}$. For all tested sensors, the response to $\mathrm{CO}$ was smallest. Interestingly, the IEG sensor has an almost 10-times larger response compared to most other sensors. The only sensors not reacting to $\mathrm{CO}$ at all were the $\mathrm{Pt} \mathrm{NP}$ and $\mathrm{ZrO}_{2} \mathrm{NL}$ DEG sensor. The $\mathrm{Fe}_{3} \mathrm{O}_{4} \mathrm{NP}$ DEG sensor was not tested with $\mathrm{CO}$. To $\mathrm{NO}_{2}$, the $\mathrm{Fe}_{3} \mathrm{O}_{4} \mathrm{NL}$ DEG sensor exhibited the highest and the untreated PEG sensor the second highest response. The strong gas response towards $\mathrm{NO}_{2}$ with PEG could be due to the fact that $\mathrm{NO}_{2}$ sensing is highly dependent on the substrate and has a known high binding energy with EG [136]. The $\mathrm{Fe}_{3} \mathrm{O}_{4} \mathrm{NP}$ DEG sensor (not shown in Table 6) exhibited one of the lowest responses of all sensors, which can partly be explained with the lower exposure time (see section 4.3.1 for influence of exposure time on response magnitude). But a high SNR (64 dB) at $400 \mathrm{ppb}$ hints to a much lower detection limit of approximately $0.15 \mathrm{ppb}$. However, the time constant $\tau$ is rather long with approximately $500 \mathrm{~s}$ for a 100 ppb exposure.

In summary, the investigated EG sensors react with many different gases and not only the desired VOC targets. A method to obtain faster time constants and proper selectivity nevertheless is discussed in section 4.3.

Table 6: Summary of responses for $500 \mathrm{ppb} \mathrm{CO}$ and $\mathrm{NO}_{2}$ exposures at $150{ }^{\circ} \mathrm{C}$ at $0 \% \mathrm{RH}$ partly based on [Paper 4]. $\mathrm{Fe}_{3} \mathrm{O}_{4} \mathrm{NP}$ DEG is not shown here due to different experimental conditions.

Response (\%)

\begin{tabular}{|c|c|c|c|c|c|c|c|}
\hline & PEG & $\begin{array}{c}\mathrm{Pt} \\
\mathrm{NP} \\
\mathrm{DEG}\end{array}$ & $\begin{array}{c}\mathrm{CuO} \\
\mathrm{NL} \\
\mathrm{DEG}\end{array}$ & $\begin{array}{c}\mathrm{Fe}_{3} \mathrm{O}_{4} \\
\mathrm{NL} \\
\mathrm{DEG}\end{array}$ & $\begin{array}{c}\mathrm{V}_{2} \mathrm{O}_{5} \\
\mathrm{NL} \\
\mathrm{DEG}\end{array}$ & $\begin{array}{c}\mathrm{ZrO}_{2} \\
\mathrm{NL} \\
\mathrm{DEG}\end{array}$ & IEG \\
\hline $\begin{array}{l}\text { CO } \\
500 \mathrm{ppb}\end{array}$ & -0.06 & 0 & 0.12 & 0.09 & 0.14 & 0 & 0.98 \\
\hline $\begin{array}{l}\mathrm{NO}_{2} \\
500 \mathrm{ppb}\end{array}$ & 42.50 & -8.65 & 14.60 & 65.82 & -8.93 & -17.10 & -5.42 \\
\hline
\end{tabular}


Table 7 gives an overview of SNR and LOD values for all different sensors and various gases. The SNR values are based on $500 \mathrm{ppb}$ exposures at $150{ }^{\circ} \mathrm{C}$ at $0 \% \mathrm{RH}$ similar to Figure 4.15 and Table 6 , and LOD values are based on $10 \mathrm{ppb}$ for $\mathrm{C}_{6} \mathrm{H}_{6}$ and $\mathrm{CH}_{2} \mathrm{O}$, and $100 \mathrm{ppb}$ for $\mathrm{CO}$ and $\mathrm{NO}_{2}$, respectively. $\mathrm{NH}_{3}$ is not included as not all sensors were exposed to ppb level concentrations, thus limiting the comparability with the other gases. It can be seen that the highest SNR and lowest LOD values occur for $\mathrm{NO}_{2}$ exposures, which is expected as also the relative responses towards $\mathrm{NO}_{2}$ are highest compared to other gases. In general, the SNR values are rather high indicating that $500 \mathrm{ppb}$ exposures are easily detectable with all sensors for all gases. The LOD values however range from about 0.01 up to $16 \mathrm{ppb}$ spanning approximately three orders of magnitude. This demonstrates that the $21 \mathrm{ppb} \mathrm{NO}_{2}$ exposure limit for AQM could easily be detected and could even outperform state of the art commercial sensors, such as $\mathrm{NO}_{2}$-A1 from Alphasense (Essex, United Kingdom [137]) with a resolution of $20 \mathrm{ppb}$. Moreover, the detection of $\mathrm{NO}_{2}$ at these very low concentrations is of interest as a marker for the production of ultra-fine particles [138]. Buckley et al. give a comprehensive overview about the sensor performances of graphene based chemiresistors and, depending on the functionalization, LODs ranging from single ppt up to tens of ppm are observed for $\mathrm{NO}_{2}$ [139].

For both VOCs, the detection limit is always below $4 \mathrm{ppb}$ and theoretically reaches even down to $0.05 \mathrm{ppb}$ for the Pt NP DEG sensor. However, the SNR and LOD highly depend on the amount of baseline noise, which increases over time. This is most probably due to a slow degradation of the contacts. For example, the $\mathrm{Fe}_{3} \mathrm{O}_{4}$ NP DEG sensor has today, i.e., after 4 years of repeated operation, values of $16 \mathrm{~dB}$ and $3.97 \mathrm{ppb}$ but it had $58 \mathrm{~dB}$ and $0.03 \mathrm{ppb}$ when the sensor was new. Knowing that the Pt NP DEG sensor is relatively new, this might lead to a decreased detection limit of approximately 100 times more, i.e., 5 ppb for $\mathrm{C}_{6} \mathrm{H}_{6}$, if operated for 4 years. Nevertheless, assuming an increase in baseline noise, thus a decrease in SNR and an increase in LOD, detection of hazardous VOCs would still be possible down to $\sim 10 \mathrm{ppb}$ with all sensors ${ }^{12}$. Furthermore, the SNR highly depends on the used readout electronics (compare section 4.4). Since measurements could be performed with the same sensor over a period of several

${ }_{12} \mathrm{Fe}_{3} \mathrm{O}_{4}$ NP DEG sensors were operated for more than a period of 4 years, NL DEG sensors for over 3 years, and PEG, Pt NP DEG and IEG only for about 1 year. 
years including two different laboratories (compare section 4.4), the longtime stability is still promising.

One of the main drawbacks are the slow ad- and desorption times. Comparing the investigated epitaxial graphene sensors in this thesis with commercially available sensors on the market, they nevertheless perform rather well. According to Spinelle et al. [8], the VOC sensors with the lowest detection limit and best accuracy are still chromatographic instruments. In a slightly more user-friendly portable system, these gas chromatographs reach LODs between 0.01-10 ppb with time constants between 30$900 \mathrm{~s}$, but are neither handheld nor cheap. Sensors with LODs comparable to the investigated EG sensors are based on photo-ionization detectors (PID). Their LODs are in the range between 1 ppb (Honeywell ppbRAE 3000+ from Geotech Environmental Equipment Inc., Denver, Colorado, USA [140]) and 10 ppb (X-am 8000 from Dräger, Lübeck, Germany [141]). Their big advantage is the fast sampling time of only a few seconds and good selectivity. However, such handheld devices are still not small and cheap enough for a versatile device integration. Commercially available VOC sensors based on metal oxides are usually not selective to one gas and give a TVOC (total VOC) level as output, which would also be a valid option for the EG sensors investigated here (compare section 4.3.2). However, the operation range of available sensors is in the 0.1-100 ppm range with best detection limits of around 50-100 ppb (AS-MLV-P2 from Sciosense, former AMS, Eindhoven, the Netherlands [142], SGPC3 from Sensirion, Zürich, Switzerland [143], VOC/CO 2 Sensor from UST, Geschwenda, Germany [144] and MiCS-VZ-89TE from SGX Sensortech, Corcelles-Cormondreche, Switzerland [145]). Note that it is not easy to define reliable detection limits as the sensor response highly depends on the operation environment and specific applications. Nevertheless, these sensors are comparably fast with time constants of about $10 \mathrm{~s}$ and are all very small, cheap and ready for device integration. 
Table 7: Comparison of the LOD and SNR values for different EG sensors and test gases at $150{ }^{\circ} \mathrm{C}$ at $0 \% \mathrm{RH}$. The $\mathrm{SNR}$ was calculated based on $500 \mathrm{ppb}$ exposures for all gases and the LOD was calculated based on $10 \mathrm{ppb}$ for $\mathrm{C}_{6} \mathrm{H}_{6}$ and $\mathrm{CH}_{2} \mathrm{O}$, and $100 \mathrm{ppb}$ for $\mathrm{CO}$ and $\mathrm{NO}_{2}$, respectively.

SNR (dB)

LOD (ppb)

\begin{tabular}{|c|c|c|c|c|}
\hline & $\mathrm{C}_{6} \mathrm{H}_{6}$ & $\mathrm{CH}_{2} \mathrm{O}$ & $\mathrm{CO}$ & $\mathrm{NO}_{2}$ \\
\hline PEG & $\begin{array}{l}0 \\
0\end{array}$ & $\begin{array}{l}0 \\
0\end{array}$ & $\begin{array}{c}32 \\
3.80\end{array}$ & $\begin{array}{c}88 \\
0.01\end{array}$ \\
\hline $\begin{array}{l}\mathrm{Fe}_{3} \mathrm{O}_{4} \\
\mathrm{NP} \text { DEG }\end{array}$ & $\begin{array}{c}16 \\
3.97\end{array}$ & $\begin{array}{c}22 \\
2.71\end{array}$ & $\begin{array}{l}1 \\
1\end{array}$ & $\begin{array}{l}64^{13} \\
0.15\end{array}$ \\
\hline $\begin{array}{l}\mathrm{Pt} \\
\mathrm{NP} \text { DEG }\end{array}$ & $\begin{array}{c}56 \\
0.05\end{array}$ & $\begin{array}{c}58 \\
0.07\end{array}$ & $\begin{array}{l}0 \\
0\end{array}$ & $\begin{array}{c}74 \\
0.04\end{array}$ \\
\hline $\begin{array}{l}\mathrm{CuO} \\
\mathrm{NL} \mathrm{DEG}\end{array}$ & $\begin{array}{c}31 \\
0.86\end{array}$ & $\begin{array}{c}33 \\
0.90\end{array}$ & $\begin{array}{c}20 \\
14.34\end{array}$ & $\begin{array}{c}61 \\
0.23\end{array}$ \\
\hline $\begin{array}{l}\mathrm{Fe}_{3} \mathrm{O}_{4} \\
\mathrm{NL} \mathrm{DEG}\end{array}$ & $\begin{array}{c}26 \\
1.54\end{array}$ & $\begin{array}{c}26 \\
1.42\end{array}$ & $\begin{array}{c}19 \\
12.29\end{array}$ & $\begin{array}{c}77 \\
0.03\end{array}$ \\
\hline $\begin{array}{l}\mathrm{V}_{2} \mathrm{O}_{5} \\
\mathrm{NL} \text { DEG }\end{array}$ & $\begin{array}{c}25 \\
3.90\end{array}$ & $\begin{array}{c}27 \\
2.73\end{array}$ & $\begin{array}{c}19 \\
16.73\end{array}$ & $\begin{array}{c}56 \\
0.46\end{array}$ \\
\hline $\begin{array}{l}\mathrm{ZrO}_{2} \\
\mathrm{NL} \text { DEG }\end{array}$ & $\begin{array}{l}0 \\
0\end{array}$ & $\begin{array}{l}0 \\
0\end{array}$ & $\begin{array}{l}0 \\
0\end{array}$ & $\begin{array}{c}78 \\
0.02\end{array}$ \\
\hline IEG & $\begin{array}{c}31 \\
0.68\end{array}$ & $\begin{array}{c}31 \\
0.97\end{array}$ & $\begin{array}{l}50 \\
1.5814\end{array}$ & $\begin{array}{c}63 \\
0.16\end{array}$ \\
\hline
\end{tabular}

13 Based on 15 min and 400 ppb exposure instead of 30 min and $500 \mathrm{ppb}$.

14 Based on 500 ppb exposure instead of 10 ppb. 


\subsection{Advanced data evaluation}

As mentioned earlier, a sensor with only good sensitivity is not sufficient and properties like stability, selectivity and speed of response need to be addressed as well. In this section, different methods are discussed on how to improve these parameters with smart sensor operation modes and enhanced data treatment.

\subsubsection{First-order time-derivative signal}

One method to achieve faster time constants is the use of the sensor signal's first-order time-derivative [21, 146]. In this section, the sensor response is evaluated based on the first-order time-derivative to introduce an alternative sensor signal. The response is calculated as

$$
r_{d t}=R_{d t}-R_{0, d t}
$$

where $R_{d t}$ is the highest absolute derivative signal during a gas pulse and $R_{0, d t}$ is the derivative baseline value before gas exposure. For most sensors, smoothening is necessary to eliminate the rapid fluctuations in the resistance value due to background noise. Here, a moving average filter with 10 points smoothening was used if not specified otherwise ${ }^{15}$.

Figure 4.16 shows the resistance over time of a $\mathrm{Fe}_{3} \mathrm{O}_{4}$ NP DEG sensor (upper black line) when exposed for 15 min to different $\mathrm{NO}_{2}$ concentrations similar to what is presented in [Paper 3]. It can be clearly seen that $15 \mathrm{~min}$ of exposure is not enough for the sensor to reach an equilibrated response. During the recovery time of $60 \mathrm{~min}$, it was also not possible for the sensor to fully relax back to its initial baseline. This is a common problem for rather slow reacting sensors. If the signal is far from reaching an equilibrated response level during the exposure, it is not very reliable to calculate the real maximum response and the common time constants, such as $\tau_{63}$ or $\tau_{90}$. Therefore, a direct comparison with sensor performances reported in literature and product specification sheets is not possible. To overcome these issues without adding more exposure or relaxation time, the first-order time-derivative of the sensor resistance is introduced as an additional sensor signal (see lower brown line in Figure 4.16).

\footnotetext{
${ }^{15}$ For more considerations regarding signal smoothening, confer the supplementary material of [Paper 3].
} 


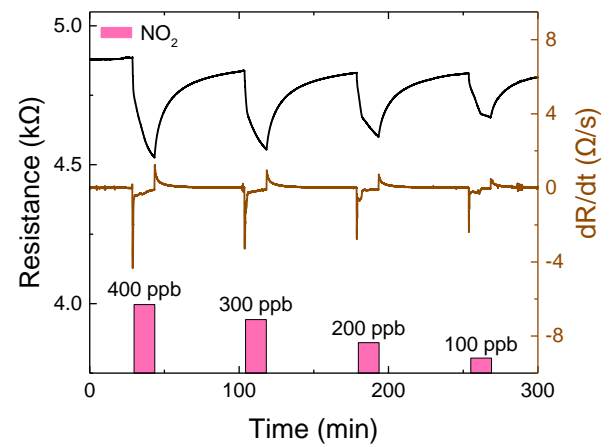

Figure 4.16: Resistance over time of $\mathrm{Fe}_{3} \mathrm{O}_{4}$ NP DEG (black, upper) with its corresponding time-derivative (brown, lower) for $\mathrm{NO}_{2}$ exposures at $150{ }^{\circ} \mathrm{C}$ at $0 \% \mathrm{RH}$. Adapted from [Paper 3].

The peaks of the first-order time-derivative signal arise much faster and are also concentration-dependent, which is in good agreement with $\mathrm{Wu}$ et al., stating that $r_{d t}$ is directly proportional to the applied gas concentration [21]. This behavior is here exemplarily shown with the $\mathrm{Fe}_{3} \mathrm{O}_{4}$ NP DEG sensor, but was also observed, for example, with the NL DEG or 2D Pt sensors. The desorption peak is concentration-dependent as well. However, the desorption response is normally not utilized as a standard indicator as it occurs after the adsorption, but it might be useful as a feature in multivariate statistics for selectivity enhancement [67, 147].

Because the peak of $d R / d t$ is reached much faster, it is also more robust against not sufficiently long exposure or relaxation times. If the exposure time is not long enough for the sensor to reach an equilibrated response, the maximum response increases with increasing exposure time, potentially leading to a misquantification. As the first-order time-derivative of the resistance signal is the slope of the change, it should be independent of the exposure time (if the exposure time is long enough for $d R / d t$ to reach its peak). Exactly this phenomenon can be seen in Figure 4.17 (a). The sensor response to $50 \mathrm{ppb} \mathrm{NO} 2$ increases from $-1.2 \%$ after 5 min to $-2.8 \%$ after $20 \mathrm{~min}$. On the other hand, $r_{d t}$ remains at approximately $2.5 \Omega / \mathrm{s}$, with a slight increase after the third exposure, regardless of the exposure time. The constant time-derivative response is due to $r_{d t}$ being determined by the initial adsorption/desorption phase during which the change in resistance is the highest. After this, further adsorption/desorption proceeds at a slower speed. Figure 4.17 (b) shows the sensor behavior with 


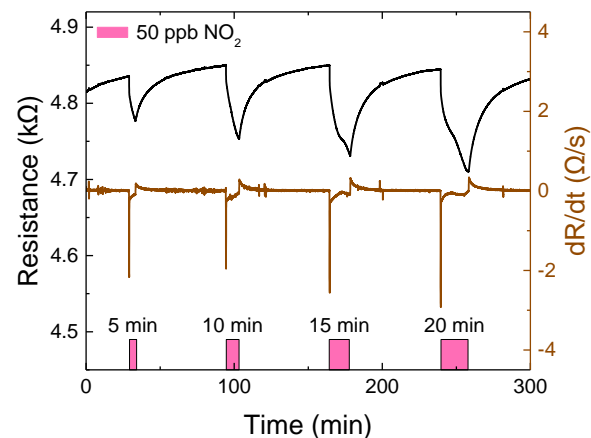

(a)

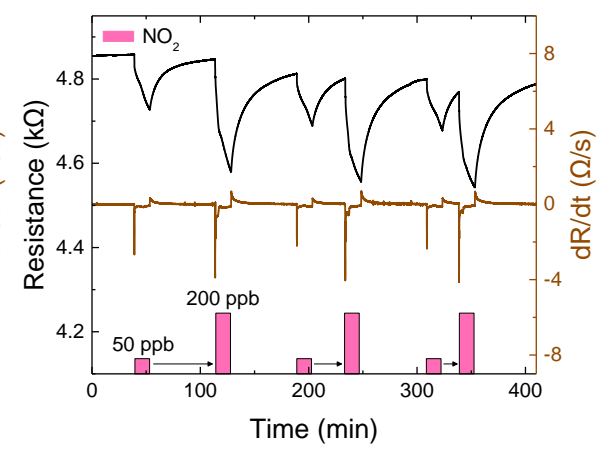

(b)

Figure 4.17: Resistance over time of $\mathrm{Fe}_{3} \mathrm{O}_{4}$ NP DEG (black, upper) with its corresponding time-derivative (brown, lower) for $\mathrm{NO}_{2}$ exposures at $150{ }^{\circ} \mathrm{C}$ at $0 \% \mathrm{RH}$ with different (a) exposure and (b) relaxation times. Adapted from [Paper 3].

decreasing relaxation times in between two gas exposures. Here, the sensor was repeatedly exposed for $15 \mathrm{~min}$ to 50 and $200 \mathrm{ppb} \mathrm{NO}_{2}$ while altering the relaxation time from initially 60 down to $15 \mathrm{~min}$ after the $50 \mathrm{ppb}$ exposure. If the sensor is not able to fully relax to its initial baseline between gas exposures, a drift is induced which could lead to a possible misquantification of the measured gas concentration. Using the standard sensor signal, the sensor is still able to distinguish between 50 and $200 \mathrm{ppb}$ of $\mathrm{NO}_{2}$ for all relaxation times. However, while the response to $50 \mathrm{ppb}$ stays approximately constant $(-2.6 \%)$, the response to $200 \mathrm{ppb}$ decreases from -5.5 to $-4.7 \%$ for 60 and 15 min relaxation time, respectively. This reduction in response is mainly due to the fact that the resistance does not return back to its initial baseline level with decreasing relaxation time. Therefore, the ratio between the responses at 200 and 50 ppb continuously decreases with a decrease in relaxation time. This is a clear sign that the sensor surface is not fully recovered, and, thus, not the same amount of adsorption sites is available for a reaction with $\mathrm{NO}_{2}$ molecules at the second exposure. For the time-derivative signal, the ratio between the responses at 200 and $50 \mathrm{ppb}$ stays approximately the same. This could be due to the baseline of the derivative signal relaxing much faster after the initial adsorption/desorption phase, while the change in the raw sensor signal occurs very slowly. Furthermore, the standard deviation of the responses to a given concentration changes drastically for the relative sensor responses. For the relative response to $50 \mathrm{ppb}$ exposures it is only 
about $-2.6 \pm 0.08 \%$, but it is with $-5.1 \pm 0.38 \%$ almost five times higher for $200 \mathrm{ppb}$. For the time-derivative signal, the response changes for $-2.4 \pm 0.20 \Omega / \mathrm{s}$ and $-4.0 \pm 0.13 \Omega / \mathrm{s}$ for 50 and $200 \mathrm{ppb}$, respectively. This is a slightly larger relative fluctuation for the time-derivative signal, but without a large difference between the two concentrations. Therefore, it can be assumed that the time-derivative readout has a slightly worse uncertainty in general, but at least it is not negatively affected by sensor relaxation times.

It is known that not only the sensor response but also the speed of response heavily depends on the sensor temperature [20]. Also the first-order time-derivative signal was found to vary with a change in temperature. Moreover, it was found that the time-derivative response follows the same pattern as the standard response when adding UV irradiation or varying the amount of relative humidity between gas measurements. More interesting is the time needed to reach $r_{d t}$. For changes in operating temperature or additional UV irradiation $\tau_{d t}$ stayed approximately constant but as shown in Figure 4.18, $\tau_{d t}$ increases if more humidity is introduced (compare also [Paper 3]). This could be due to water molecules occupying possible reaction sites, i.e., a competition between $\mathrm{H}_{2} \mathrm{O}$ and $\mathrm{NH}_{3}$ over available sites, or reactions between the two molecules to form ammonium and hydroxyl groups on the sensor surface, thus increasing the reaction time [65].

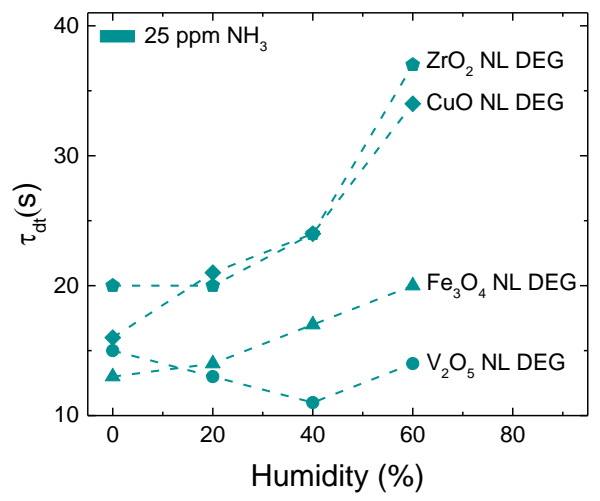

Figure 4.18: $\tau_{\mathrm{d} t}$ of first-order time-derivative responses of NL DEG sensors for $25 \mathrm{ppm} \mathrm{NH}_{3}$ exposures at $75^{\circ} \mathrm{C}$ (except $\mathrm{ZrO}_{2}$ at $125^{\circ} \mathrm{C}$ ) at different RH based on [Paper 3]. ${ }^{16}$

${ }_{16} \mathrm{Here}, \mathrm{Fe}_{3} \mathrm{O}_{4}$ (0.05) is used as the measurement with $\mathrm{Fe}_{3} \mathrm{O}_{4}$ (0.1) was flawed. 
Especially for indoor air quality monitoring, the sampling period should be rather fast, but at least within the range of a few minutes to allow realtime monitoring [17]. As already mentioned above, the peaks of the derivative signal reach their highest points already after a short period of time. Similar to Table 7, Table 8 gives an overview of the regular $(\tau)$ and derivative $\left(\tau_{d t}\right)$ time constants for different EG sensors and test gases at $150{ }^{\circ} \mathrm{C}$ at $0 \% \mathrm{RH}$ calculated from $500 \mathrm{ppb}$ exposures. In case a sensor did not exhibit a response towards a specific gas, this is specified as n.a. (not applicable). $\mathrm{NH}_{3}$ is not included as not all sensors were exposed to ppb level concentrations, thus limiting the comparability with the other gases. In general, $\tau_{d t}$ did not vary much between the different sensors and gases but stayed between 5 and $10 \pm 5 \mathrm{~s}$. This, and the fact that it also did not vary for changes in operating temperature or UV irradiation, but only for variations in $\mathrm{RH}$, is rather unexpected. It would fit the assumption that the initial material/gas-reaction takes place within the first 10 seconds of exposure and that the time-resolution, especially after signal smoothening, is not good enough to reveal occurring differences. Looking at the regular $\tau$, this does not apply and the different sensors have very different time constants, thus reaction behaviors, for specific gases. For example, all NL DEG sensors exhibit a faster response towards $\mathrm{C}_{6} \mathrm{H}_{6}$ and $\mathrm{CH}_{2} \mathrm{O}$ compared to $\mathrm{CO}$ and $\mathrm{NO}_{2}$, with $\mathrm{NO}_{2}$ exhibiting the largest $\tau$, but PEG has a higher $\tau$ for $\mathrm{CO}$ compared to $\mathrm{NO}_{2}$. Comparing the differences between $\tau$ and $\tau_{d t}$, for example, the $\mathrm{Fe}_{3} \mathrm{O}_{4} \mathrm{NP}$ DEG sensor to a $\mathrm{NO}_{2}$ exposure has a $\tau_{d t}$ of about $10 \mathrm{~s}$ (Figure 4.16) which is 25 times faster compared to $\tau$. Other measurements suggest a decrease of time constants from approximately $350 \mathrm{~s}$ down to $10 \mathrm{~s}$ for measurements with the same sensor to $\mathrm{C}_{6} \mathrm{H}_{6}$ and $\mathrm{CH}_{2} \mathrm{O}$ [Paper 2] ${ }^{17}$. For a $\mathrm{TiO}_{2}$ NP DEG sample (not shown in Table 8), the time constants with oxygen measurements could be decreased from $1500 \mathrm{~s}$ down to $25 \mathrm{~s}$ [Paper 1] ${ }^{18}$. This is an improvement by a factor of 60 in response time compared to the standard resistance signal. In general, even the smallest observed improvement is already 15 times lower/faster.

17 In [Paper 2], $\tau_{d t}$ is specified with $50 \mathrm{~s}$ and smoothening was performed with 500 points. This was necessary, as the baseline signal exhibited strong noise.

18 In [Paper 1], $\tau_{d t}$ is specified with $60 \mathrm{~s}$ as smoothening was performed with 100 points. 
Table 8: Comparison of the regular $(\tau)$ and derivative $\left(\tau_{d t}\right)$ time constants for different EG sensors and test gases at $150{ }^{\circ} \mathrm{C}$ at $0 \% \mathrm{RH}$ calculated from 500 ppb exposures. In case a sensor did not exhibit a response towards a specific gas, this is denoted as n.a. (not applicable).

$$
\begin{gathered}
\tau(\mathrm{s}) \pm 60 \\
\tau_{d t}(\mathrm{~s}) \pm 5
\end{gathered}
$$

\begin{tabular}{|c|c|c|c|c|}
\hline & $\mathrm{C}_{6} \mathrm{H}_{6}$ & $\mathrm{CH}_{2} \mathrm{O}$ & $\mathrm{CO}$ & $\mathrm{NO}_{2}$ \\
\hline PEG & n.a. & n.a. & $\begin{array}{c}1500 \\
10\end{array}$ & $\begin{array}{c}425 \\
5\end{array}$ \\
\hline $\begin{array}{l}\mathrm{Fe}_{3} \mathrm{O}_{4} \\
\mathrm{NP} \text { DEG }\end{array}$ & $\begin{array}{c}350 \\
10\end{array}$ & $\begin{array}{c}350 \\
10\end{array}$ & n.a. & $\begin{array}{l}400 \\
10^{19}\end{array}$ \\
\hline $\begin{array}{l}\mathrm{Pt} \\
\mathrm{NP} \text { DEG }\end{array}$ & $\begin{array}{c}425 \\
5\end{array}$ & $\begin{array}{c}475 \\
5\end{array}$ & n.a. & $\begin{array}{c}750 \\
10\end{array}$ \\
\hline $\begin{array}{l}\mathrm{CuO} \\
\mathrm{NL} \text { DEG }\end{array}$ & $\begin{array}{c}150 \\
10\end{array}$ & $\begin{array}{c}175 \\
5\end{array}$ & $\begin{array}{c}250 \\
5\end{array}$ & $\begin{array}{c}300 \\
5\end{array}$ \\
\hline $\begin{array}{l}\mathrm{Fe}_{3} \mathrm{O}_{4} \\
\mathrm{NL} \text { DEG }\end{array}$ & $\begin{array}{c}175 \\
10\end{array}$ & $\begin{array}{c}175 \\
5\end{array}$ & $\begin{array}{c}200 \\
5\end{array}$ & $\begin{array}{c}375 \\
5\end{array}$ \\
\hline $\begin{array}{l}\mathrm{V}_{2} \mathrm{O}_{5} \\
\mathrm{NL} \text { DEG }\end{array}$ & $\begin{array}{c}425 \\
10\end{array}$ & $\begin{array}{c}375 \\
5\end{array}$ & $\begin{array}{c}700 \\
10\end{array}$ & $\begin{array}{c}800 \\
10\end{array}$ \\
\hline $\begin{array}{l}\mathrm{ZrO}_{2} \\
\mathrm{NL} \text { DEG }\end{array}$ & n.a. & n.a. & n.a. & $\begin{array}{c}650 \\
10\end{array}$ \\
\hline IEG & $\begin{array}{c}475 \\
5\end{array}$ & $\begin{array}{c}200 \\
5\end{array}$ & $\begin{array}{l}475 \\
20\end{array}$ & $\begin{array}{c}475 \\
5\end{array}$ \\
\hline
\end{tabular}

${ }_{19}$ Based on 15 min and 400 ppb exposure instead of 30 min and 500 ppb. 
It should be noted that in practical applications of gas sensors, the change in the gas concentration in the environment is usually a slowchanging process and does not occur by leaps and bounds. Therefore, the first-order time-derivative signal might not give useful information for processes where the concentration change to be measured occurs slowly over time. To still apply this method, an option could be a sensor setup where an abrupt change in concentration is actively induced. This could, for example, be realized by changing between a reference and test gas flow. In stand-alone systems, this would require extra costs and space, as a defined reference flow would need to be established, for example through a reference gas reservoir and a pump. Nonetheless, there are still applications where this approach might be used even if an abrupt switch needs to be implemented either passively, e.g., for leak testing or battery system fault detection [148], or actively, e.g., with a valve switch between two existing gas streams. Another example would be the use of pre-concentrators, where the test gas is not continuously measured, but rather collected first and only released under defined conditions, e.g., degassing through heating [149]. Other possible applications where abrupt changes are monitored are, for example, measuring the gaseous by-product of biological processes or breath-analysis [150]. Furthermore, this method could also be used as an additional signal to create more transient data for multivariate statistical analysis [67, 147].

\subsubsection{Multivariate analysis}

As explained in section 3.4.2, one sensor alone is usually not able to distinguish between different gases very effectively, a sensor array can lead to a better classification [151]. However, when sensor arrays, physical or virtual, are used, more complex analysis methods are necessary to obtain useful results.

A very rudimentary example of an evaluation of a non-cyclic sensor response using LDA is shown in Figure 4.19. The evaluation was performed with the help of Tobias Baur at Saarland University. There, a sensor array of the four different NL DEG sensors was used at a constant temperature. Therefore, each measurement point is used as a feature as this is how it would be in a real setup, where the resistance over time is measured and gas exposures need to be determined. It is easily possible to distinguish between a strong-reacting gas and a weak-reacting one, $\mathrm{NO}_{2}$ and VOCs in 


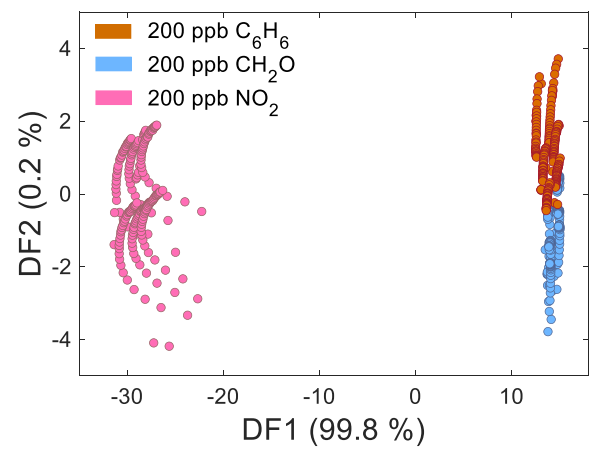

Figure 4.19: LDA based on all four NL DEG sensors for 200 ppb $\mathrm{C}_{6} \mathrm{H}_{6}, \mathrm{CH}_{2} \mathrm{O}$ and $\mathrm{NO}_{2}$ exposures at $150{ }^{\circ} \mathrm{C}$ at $0 \% \mathrm{RH}$. Adapted from [Paper 4].

this case. But a similar response could still be achieved with different concentrations of different gases, leading to a not very meaningful sensor system. More details are discussed in [Paper 4].

One way to obtain additional transient data from a single sensor for evaluation is the application of cycled methods such as TCO [59, 151]. To study if the IEG sensor in TCO mode is able to distinguish between different, but similarly reacting gases and different $\mathrm{RH}$ levels, the sensor was exposed to 1000 and 500 ppb of $\mathrm{C}_{6} \mathrm{H}_{6}, \mathrm{CH}_{2} \mathrm{O}, \mathrm{CO}$ and $\mathrm{H}_{2}$ at $0,15,30$ and $40 \% \mathrm{RH}$. The temperature was changed in plateaus from $30 \mathrm{~s}$ at $175^{\circ} \mathrm{C}$ to $30 \mathrm{~s}$ at $150{ }^{\circ} \mathrm{C}$ to $40 \mathrm{~s}$ at $125^{\circ} \mathrm{C}$. The central temperature of the cycle was $150^{\circ} \mathrm{C}$ because this was the main operating temperature of comparable measurements in this thesis. $175^{\circ} \mathrm{C}$ was included to have a slightly higher temperature with expected stronger gas interaction, which was also observed to be operational without stability issues (compare section 3.3.2). To maximize the temperature interval $125^{\circ} \mathrm{C}$ was chosen as the lowest temperature as temperatures below or around $100{ }^{\circ} \mathrm{C}$ with $\mathrm{RH}$ lead to additional slow sensor drift (compare section 4.2.2). Figure 4.20 (a) and (b) show the normalized and standardized temperature cycles, respectively, for all four gases and RH levels. The data treatment and evaluation was performed with the help of Guillem Domenèch Gil at Linköping University. As one can see, the normalized cycles exhibit differences for different gas exposures and RH levels (compare inset in Figure 4.20 (a)). The top three cycles of the $125{ }^{\circ} \mathrm{C}$ plateau correspond to air at the three non-zero $\mathrm{RH}$ levels studied, i.e., 15, 30 and $40 \% \mathrm{RH}$, the lowest to dry air and the four in the middle to the four gases. For the four different gases, both VOCs 


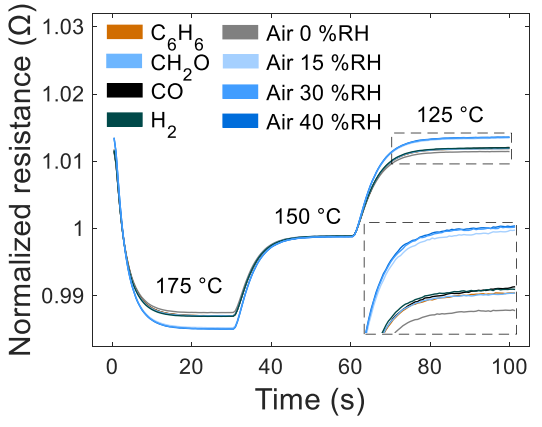

(a)

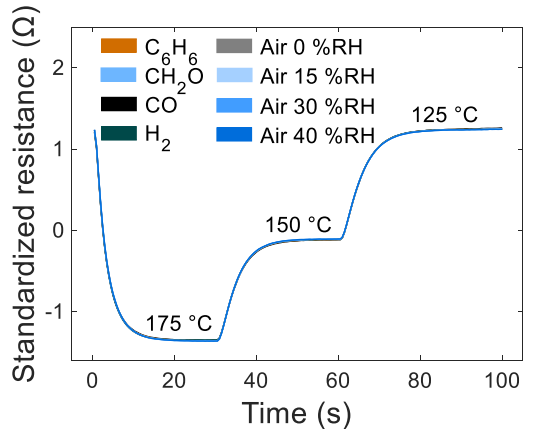

(b)

Figure 4.20: (a) Normalized and (b) standardized temperature cycles of IEG for $\mathrm{C}_{6} \mathrm{H}_{6}, \mathrm{CH}_{2} \mathrm{O}$, $\mathrm{CO}$ and $\mathrm{H}_{2}$ exposures and $\mathrm{RH}$ levels with temperature plateaus of 175,150 and $125^{\circ} \mathrm{C}$. The inset in in the lower right corner in (a) shows the enlarged normalized resistances of the $125^{\circ} \mathrm{C}$ temperature plateau.

have almost exactly the same cycle shape, i.e., resistance value for the given temperature, whereas $\mathrm{CO}$ and $\mathrm{H}_{2}$ have both distinguishably higher and lower resistances at the 125 and $175{ }^{\circ} \mathrm{C}$ temperature plateaus, respectively. If the cycles are standardized (Figure 4.20 (b)), only small differences can be appreciated between cycles, which only become visible if zooming in enough. The reason for this difference between normalization and standardization is because normalization divides the whole cycle by its own mean, thus centering all middle temperature plateaus at 1 and opening up the differences between the different cycles at the ends, i.e. lower and higher temperature plateaus. The standardization, however, centers the middle temperature plateau at 0 and, therefore, each plateau exhibits differences between the cycles but they are all comparably small. For further evaluation with LDA or PCA, this does not matter much as the used features will also be standardized, hence both preprocessing steps can lead to the same result. Here, only LDA and PCA results based on normalized cycles are shown. Similar measurements have been performed with PEG, but since it did not exhibit any response to both VOCs, the results are not discussed here.

To start with, it is worth looking at the different quasistatic plots. A quasistatic plot is obtained by plotting all points of all cycles at one given position in the temperature cycle. Here, one position was chosen at each 
temperature plateau. Figure 4.21 (a), (b) and (c) show the untreated quasistatic plots, the normalized quasistatic plots and a zoom-in of the exposures at $0 \% \mathrm{RH}$ for the untreated quasistatic plots, respectively. The untreated quasistatic plots show changes in resistance, that correspond to the applied gas exposures and changes of $\mathrm{RH}$. This could give valuable information about which temperature should be included in the cycle in general, in case strong difference would be observed. Here, since the temperatures are very close to each other, no strong differences between the three quasistatic plots can be seen. After normalization (Figure 4.21 (b)), the highest change observed is due to the increase of humidity, from 0 to $15 \% \mathrm{RH}$, while an additional increase in $\mathrm{RH}$ and the gas exposures induce smaller changes. A similar distinct change can be seen at the end of the

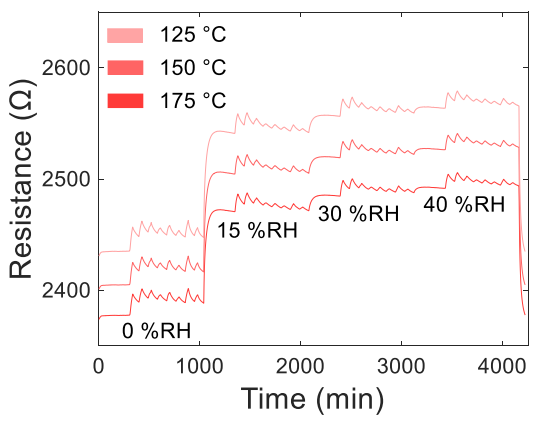

(a)

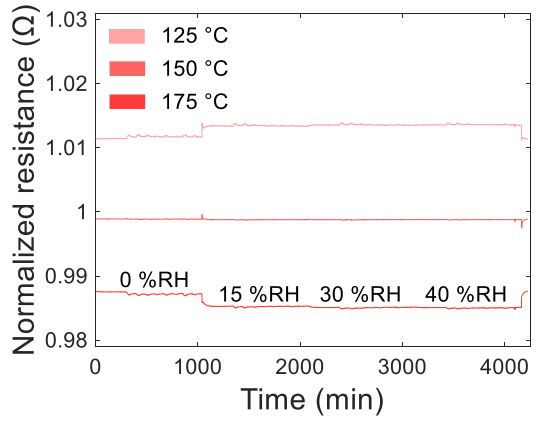

(b)

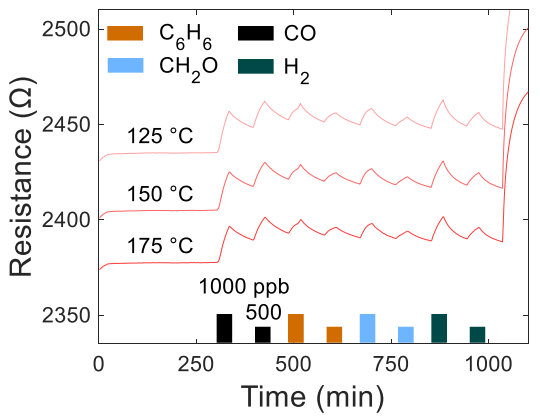

(c)

Figure 4.21: (a) Quasistatic and (b) normalized quasistatic plots of IEG for $\mathrm{C}_{6} \mathrm{H}_{6}$, $\mathrm{CH}_{2} \mathrm{O}, \mathrm{CO}$ and $\mathrm{H}_{2}$ exposures at $0,15,30$ and $40 \% \mathrm{RH}$ at 175,150 and $125^{\circ} \mathrm{C}$ with (c) as zoom-in of the quasistatic plots for gas exposures at $0 \% \mathrm{RH}$. 
measurement, when the $\mathrm{RH}$ level is changed back from 40 to $0 \% \mathrm{RH}$. This is in agreement with the findings in section 4.2.2. In case that the standardized quasistatic plot would only be a flat line without any distinct features, then the TCO mode would not give additional information compared to the operation at a constant temperature.

After the first measurement evaluations through quasistatic plots, further multivariate statistic algorithms, i.e., LDA and PCA, were implemented to differentiate between the different gases. For the gases, the points corresponding to $500 \mathrm{ppb}$ exposures at $0 \% \mathrm{RH}$ were used. As features, part of the slopes between the three temperature plateaus and the lifting, i.e., absolute difference in resistance between the 125 and $175{ }^{\circ} \mathrm{C}$ plateaus, were utilized (compare Figure 4.22).

Figure 4.23 shows the results of LDA and PCA evaluations. Both methods can cluster the four gases, with LDA reaching a better cluster separation. However, both VOC clusters are very close to each other and not always distinguishable. Therefore, a TVOC indicator, i.e., the total amount of VOCs present, instead of single gas determinations, might be a more feasible application. Furthermore, since a steady state in the sensor response was never reached during the gas exposure, it is expected that the points corresponding to the same gas do not group very closely, forming widespread clusters. These results are a first approximation, as a proof-ofconcept, similar to Figure 4.19, showing that this kind of EG sensors could potentially discriminate among different gases with further optimization.

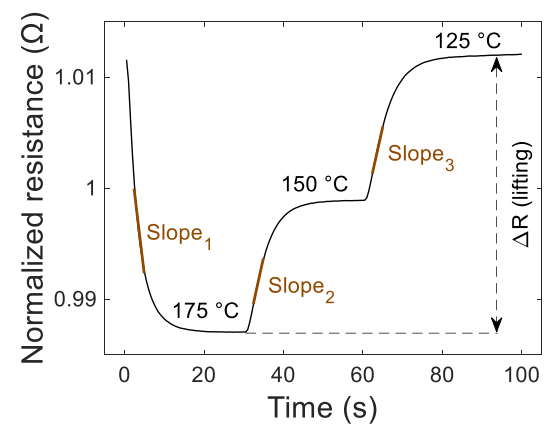

Figure 4.22: Exemplary normalized temperature cycle for $\mathrm{CO}$ exposure together with the used features. 


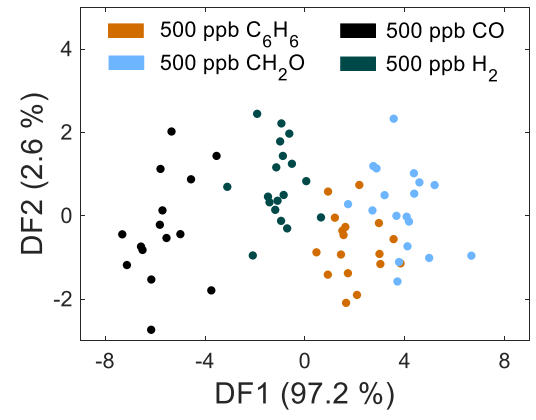

(a)

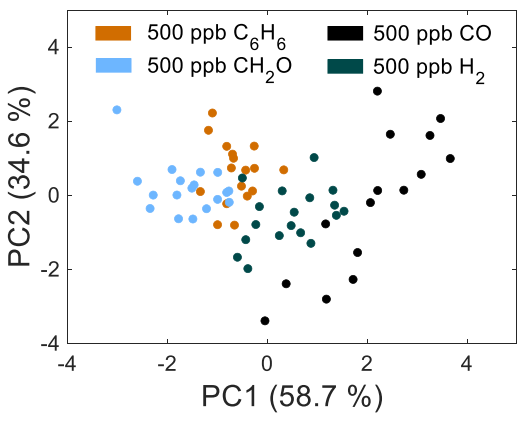

(b)

Figure 4.23: (a) LDA and (b) PCA of IEG to 500 ppb $\mathrm{C}_{6} \mathrm{H}_{6}, \mathrm{CH}_{2} \mathrm{O}, \mathrm{CO}$ and $\mathrm{H}_{2}$ exposures at $0 \% \mathrm{RH}$.

Besides classification, i.e., determination of the specific gas, quantification of the gas concentration was studied. Therefore, a PLSR was performed with the IEG sensor data for $\mathrm{C}_{6} \mathrm{H}_{6}$ and $\mathrm{CH}_{2} \mathrm{O}$ exposures with concentrations ranging from $2\left(1\right.$ for $\left.\mathrm{CH}_{2} \mathrm{O}\right)$ to $1000 \mathrm{ppb}$ at $0 \% \mathrm{RH}$. However, since the sensor response is rather slow and, consequently, does not reach a steady state even after 30 min exposure, the cycled operation mode does not help as only the last cycle of each exposure could be used for a concentration calibration. Another reason is very likely the chosen narrow temperature range as the physical and/or chemical surface reactions with the specific gases do not differ strongly at the different temperatures. Therefore, PLSR did not conclude in a meaningful evaluation, thus not giving an advantage compared to a static measurement (compare for example Figure 4.14).

In summary, applying TCO mode and multivariate statistics analysis methods lead to a differentiation between different gases. To fully exploit these methods, a broader operating temperature range would possibly improve the results, and also speed up the sensor response at higher temperatures to some extent. 


\subsection{Inter-lab studies}

It is very important to conduct inter-lab studies to independently verify sensor performances as a specific setup itself can have a strong influence on the sensor behavior and, therefore, the obtained results may only be valid under given circumstances. In-depth studies have shown that even for measurements performed in certified labs, unexpected deviations can occur, which opens the possibility for more insight into sensor behavior in general $[152,153]$. Unfortunately, round-robin testing, which is the standard in analytical chemistry to ensure that experimental procedures are correct, is still not applied in the field of chemical sensor research [154, $155]$.

To verify that the observed results are valid regardless of the lab-setting in this work, some measurements were first performed in the gas sensing lab at Linköping University $(\mathrm{LiU})$ and then repeated in another lab at Saarland University (UdS) or vice versa. All measurements were performed at $150{ }^{\circ} \mathrm{C}$ operating temperature, but the tested gas concentrations and levels of relative humidity were not always exactly the same due to some restrictions of the respective systems. A summary of several different gas measurements with the NL DEG sensors at both laboratories is discussed in detail in [Paper 4].

In general, it was found that exposures to $\mathrm{C}_{6} \mathrm{H}_{6}$ and $\mathrm{CH}_{2} \mathrm{O}$ resulted in a systematically lower response if measured at UdS except for $\mathrm{V}_{2} \mathrm{O}_{5}$. Exposures to $\mathrm{NO}_{2}$ also showed the same trend in response for three of the four sensors, i.e., an increase with increased gas concentration and a decrease with the introduction of relative humidity, indicating that the sensors have very similar performances at both laboratories. Only the $\mathrm{CuO}$ NL DEG resulted in a rather peculiar change in response direction if exposed to $200 \mathrm{ppb} \mathrm{NO}_{2}$ at $25 \% \mathrm{RH}$ at $\mathrm{LiU}$, compared to the exposure at $0 \%$ $\mathrm{RH}$. This change could be due to the competing effects of $\mathrm{NO}_{2}$ and $\mathrm{RH}$ on the sensor surface.

In a different investigation, the $\mathrm{Fe}_{3} \mathrm{O}_{4}$ NP DEG sensor was evaluated first with one setup at UdS and then one year later with another setup in the same laboratory ${ }^{20}$. At both times, the sensor was exposed for $30 \mathrm{~min}$ to $5 \mathrm{ppb}$ of $\mathrm{C}_{6} \mathrm{H}_{6}$ at $150{ }^{\circ} \mathrm{C}$ and $0 \% \mathrm{RH}$ (compare section 4.2.4 and [Paper 2]). The response varied between $0.05 \%$ and $0.08 \%$. This might seem like a

${ }^{20}$ Note that this measurement was rather an intra-lab than an inter-lab study. 
large difference, but taking into account that the sensor was not calibrated for one system and was operated over a long time, the repeatability is rather good.

Additional differences in sensor response could arise from the uncertainties in concentration of the gas bottles. Even with a purity of 6.0, each gas bottle has an approximate error range in concentration of up to $\pm 10 \%$. Moreover, the background gas (purity of 6.0) used for mixing of test gases also still contains approximately $1 \mathrm{ppm}$ of contaminants. Therefore, a higher target analyte concentration in a gas cylinder results in a lower relative error as a smaller concentration if both are diluted in the gas mixing system to reach the same concentration. This uncertainty in gas concentrations is believed to be the main impact on the observed responses here. Different background gases could also lead to differences between both labs. The background gas at LiU is mixed from $80 \% \mathrm{~N}_{2}$ (liquid source) and $20 \% \mathrm{O}_{2}$, while the background gas at UdS comes from a zero air generator ( $79 \% \mathrm{~N}_{2}$ and $21 \% \mathrm{O}_{2}$ ), but these differences are not believed to have a major impact here (compare section 3.5.1). A difference in response due to a different background gas flow, i.e., $100 \mathrm{ml} / \mathrm{min}$ at $\mathrm{LiU}$ and $200 \mathrm{ml} / \mathrm{min}$ at UdS, is not expected. However, the systems could be contaminated by prior gas exposures [156] ${ }^{21}$. Another problem could come from the applied flows from the MFCs, although this is rather unlikely as only calibrated MFCs were used and frequently reassessed. A variation due to the very small difference in background humidity is also not expected (compare section 3.5). Another very important aspect is the electric noise of the laboratory environment and the resolution of the readout hardware. In early measurements at UdS the resistance-readout was done with the 3S-board, while the measurements at LiU were always carried out with a Sourcemeter. The SNR for a 5 ppb $\mathrm{C}_{6} \mathrm{H}_{6}$ exposure varied for the $\mathrm{Fe}_{3} \mathrm{O}_{4} \mathrm{NP}$ DEG from $1.6 \mathrm{~dB}$ to $35 \mathrm{~dB}$, depending on the setup, with the Sourcemeter hardware being the superior solution. Looking only at the single standard deviation of the baseline resistance as indicator of noise when a Sourcemeter is used in both laboratories, there was no distinct difference in noise level anymore and it stayed below $0.1 \Omega$ for all four NL DEG sensors for example, which corresponds to a worst-case relative noise level of approximately $0.007 \%$ in terms of sensor response.

21 The gas mixing system at LiU was entirely cleaned and calibrated before low concentration measurements with VOCs have been performed as a contamination of the system was previously determined. 


\subsection{More EG sensor applications}

Even if the main focus of this work was to investigate EG on SiC as versatile gas sensing platform, sensing with this material is not limited to gaseous analytes. In this section, a short outlook to other sensing fields is given that were investigated with $\mathrm{EG}$ on $\mathrm{SiC}$.

In its pristine form, EG is rather inert, but it does not need to chemically bind to an analyte to be able to detect its presence. When an ion, e.g., a dissolved heavy metal ion, is in physical contact with the graphene lattice, the local doping changes and thus a change in resistance can be measured. For example, when pumping a solution with diluted heavy metal ions through a lab-on-chip device over the graphene lattice, the resistance of graphene changes as soon as the dissolved ions come in contact with the exposed graphene surface in the detection chamber, resembling a reaction to specific heavy metal ions [157]. With this approach, heavy metals like lead can be detected at very low concentration, i.e., $95 \mathrm{nM}$ for $\mathrm{Pb}^{2+}$ ions, and, as the response is geometry dependent, a larger relative EG exposure area is expected to further increase the sensitivity, thus further decreasing the detection limit [158]. Note that the required recommended limit for lead ions in drinking water by the WHO is $180 \mathrm{nM}$ [159], so about twice as high as the achieved LOD here.

Another advancement is the use of epitaxial graphene in bio-inspired applications, such as the detection of certain proteins. It was demonstrated that when exposed to HSA (human serum albumin) diluted in PBS (Phosphate-buffered saline) buffer, the sensor reacts rather fast to the analyte exposure with a stable baseline and the response is repeatable [160]. The idea is to eventually substitute HSA with other proteins that are important for medical applications where the exact determination of analytes reflects the health status. A similar approach is used for a rather new study, where EG is used to detect toxic dioxins in a buffer solution, but instead of a simple dilution process, electrophoresis is used additionally to separate molecules and isolate the target analyte.

As already mentioned, EG can also be used as the transducer and not the primary sensing material. Another side-project investigated the possible detection of bark beetle pheromones, in the perspective of a sensor for early detection of bark beetle infestation in spruce forests. Fresh bark beetle antennas should detect the pheromones and transfer this detection via an ionic gel onto the graphene surface. There, the change in resistance 
between two contacts should then resemble the difference between ambient air and ambient air with pheromones present. More can be found in [161].

All these projects are examples of what might be possible when detecting low concentrations of specific analytes with $\mathrm{EG}$ on $\mathrm{SiC}$ as the transducer or even sensing material. There will be a paper giving an overview about all these different EG sensors, but it was not published by the time of printing of this thesis. 



\section{Conclusions and outlook}

In summary, the work presented in this thesis focused on how to utilize epitaxially grown graphene on $\mathrm{SiC}$ as an ultra-sensitive gas sensor platform for gases of interest for air quality monitoring. Three main approaches have been tested and evaluated to their impacts on sensitivity, selectivity, speed of response and stability of the graphene based sensors.

First, the graphene surface was modified with several different methods. It was decorated with different metal oxide nanoparticles and nanolayers, intercalated with hydrogen, or defects have been introduced with Ag-ion bombardment. With most of the decorated sensors, it was easily possible to detect and quantitatively measure concentrations down to single ppb of benzene and formaldehyde and their limits of detection can be even in the ppt range. VOC detection was possible with relative humidity in the ambient only after platinum decoration or hydrogen intercalation though, making these materials very promising for air quality monitoring applications. The integrity of the graphene lattice was maintained after surface decoration, which was verified for each sample using characterization methods like atomic force microscopy and Raman spectroscopy.

The second approach is the optimization of the sensing environment. Here, the influence of operating temperature, relative humidity and additional UV irradiation during the measurement was evaluated. All three parameters are well known to have a strong impact on the sensor sensitivity and speed of response for some material/gas combinations.

As a last step, generation of richer data and extended data evaluation led to a better sensor performance. The first-order time-derivative was investigated as an additional sensor signal. With this approach, the time constants could be drastically reduced as the peak of slope reaches its maximum much faster compared to the resistance value, which opens an opportunity for rather slow gas sensors in areas where a fast sensor readout is compulsory. Moreover, reduced time constants can save lab testing time, thus saving time, resources and money during research activities. This peak is concentration dependent and almost independent of exposure and relaxation times. If operated in temperature cycled operation mode, it was possible to distinguish between different gases, thus increasing selectivity.

Furthermore, some sensors have been evaluated at two independent laboratories to ensure the reliability of the obtained results. 


\section{Conclusions and outlook}

All three investigated methods show very promising results to improve sensing performance and a combination of them opens new fields of possible applications. To fully exploit the potential of these epitaxial graphene based sensors, more work in terms of production optimization, method combination and application-specific testing would need to be done. For example, to stay within the idea of AQM, measurements with normal air, i.e., air with various contaminants, as background and not zero air should be investigated, higher temperature ranges for cycled operation established and sensors processed with a glue-less contact mechanism. 


\section{References}

[1] World Health Organisation, Ambient air pollution: A global assessment of exposure and burden of disease. Geneva, 2016.

[2] World Health Organisation, "Ambient air pollution - a major threat to health and climate," 2020. https://www.who.int/airpollution/ambient/en/ (accessed Mar. 28, 2021).

[3] World Health Organisation, "WHO Social media toolkit for Air pollution and Child Health: Prescribing Clean Air Launch," Geneva, 2018.2 [Online]. Available: https://www.who.int/ceh/publications/air-pollution-childhealth/en/.

[4] P. S. Burge, "Sick building syndrome," Occup. Environ. Med., vol. 61, no. 2, 2004, doi: 10.1136/oem.2003.008813.

[5] The World Bank, "The Cost of Air Pollution: Strengthening the Economic Case for Action," Washington, 2016.

[6] A. Farrow, K. A. Miller, and L. Myllyvirta, "Toxic air: The price of fossil fuels," Seoul, 2020.

[7] B. Szulczyński and J. Gębicki, "Currently Commercially Available Chemical Sensors Employed for Detection of Volatile Organic Compounds in Outdoor and Indoor Air," Environments, vol. 4, no. 1, p. 21, 2017, doi: 10.3390/environments4010021.

[8] L. Spinelle, M. Gerboles, G. Kok, S. Persijn, and T. Sauerwald, "Review of portable and low-cost sensors for the ambient air monitoring of benzene and other volatile organic compounds," Sensors (Switzerland), vol. 17, no. 7. 2017, doi: 10.3390/s17071520.

[9] L. Jiang, "Environmental Gas Sensors 2020-2030: Technologies, manufacturers, forecasts," 2020.

[10] R. Pearce, J. Eriksson, T. Iakimov, L. Hultman, A. Lloyd Spetz, and R. Yakimova, "On the differing sensitivity to chemical gating of single and double layer epitaxial graphene explored using scanning kelvin probe microscopy," ACS Nano, vol. 7, no. 5, pp. 4647-4656, 2013, doi: 10.1021/nn3052633.

[11] C. Anichini, W. Czepa, D. Pakulski, A. Aliprandi, A. Ciesielski, and P. Samorì, "Chemical sensing with 2D materials," Chem. Soc. Rev., vol. 47, no. 13, pp. 4860-4908, 2018, doi: 10.1039/c8cs00417j.

[12] M. Kodu, A. Berholts, T. Kahro, J. Eriksson, R. Yakimova, T. Avarmaa, I. Renge, H. Alles, and R. Jaaniso, "Graphene-Based Ammonia Sensors Functionalised with Sub-Monolayer V2O5: A Comparative Study of Chemical Vapour Deposited and Epitaxial Graphene," Sensors, vol. 19, no. 4, pp. 1-17, 2019, doi: 10.3390/s19040951. 
[13] R. Malik, V. K. Tomer, Y. K. Mishra, and L. Lin, "Functional gas sensing nanomaterials: A panoramic view," Appl. Phys. Rev., vol. 7, no. 2, 2020, doi: 10.1063/1.5123479.

[14] F. L. Meng, Z. Guo, and X. J. Huang, "Graphene-based hybrids for chemiresistive gas sensors," TrAC - Trends Anal. Chem., vol. 68, pp. 37-47, 2015, doi: 10.1016/j.trac.2015.02.008.

[15] S. Gupta Chatterjee, S. Chatterjee, A. K. Ray, and A. K. Chakraborty, "Graphene-metal oxide nanohybrids for toxic gas sensor: A review," Sensors Actuators, B Chem., vol. 221, no. 2, pp. 1170-1181, 2015, doi: 10.1016/j.snb.2015.07.070.

[16] J. Eriksson, D. Puglisi, C. Strandqvist, R. Gunnarsson, S. Ekeroth, I. G. Ivanov, U. Helmersson, K. Uvdal, R. Yakimova, and A. Lloyd Spetz, "Modified epitaxial graphene on $\mathrm{SiC}$ for extremely sensitive and selective gas sensors," Mater. Sci. Forum, vol. 858, pp. 11451148, 2016, doi: 10.4028/www.scientific.net/MSF.858.1145.

[17] B. Timmer, W. Olthuis, and A. Van Den Berg, "Ammonia sensors and their applications - A review," Sensors Actuators, B Chem., vol. 107, no. 2, pp. 666-677, 2005, doi: 10.1016/j.snb.2004.11.054.

[18] S. Batterman, S. Chambliss, and V. Isakov, "Spatial resolution requirements for traffic-related air pollutant exposure evaluations," Atmos. Environ., vol. 94, pp. 518-528, 2014, doi: 10.1016/j.atmosenv.2014.05.065.

[19] E. Espid and F. Taghipour, "UV-LED Photo-activated Chemical Gas Sensors: A Review," Crit. Rev. Solid State Mater. Sci., vol. 42, no. 5, pp. 416-432, 2017, doi: 10.1080/10408436.2016.1226161.

[20] C. Schultealbert, T. Baur, A. Schütze, S. Böttcher, and T. Sauerwald, "A novel approach towards calibrated measurement of trace gases using metal oxide semiconductor sensors," Sensors Actuators B Chem., vol. 239, pp. 390-396, 2017, doi: http://dx.doi.org/10.1016/j.snb.2016.08.002.

[21] C. H. Wu, G. J. Jiang, C. C. Chiu, P. Chong, C. C. Jeng, R. J. Wu, and J. H. Chen, "Fast gas concentration sensing by analyzing the rate of resistance change," Sensors Actuators, B Chem., vol. 209, pp. 906-910, 2015, doi: 10.1016/j.snb.2014.12.066.

[22] A. P. Lee and B. J. Reedy, "Temperature modulation in semiconductor gas sensing," Sensors Actuators, B Chem., vol. 60, no. 1, pp. 35-42, 1999, doi: 10.1016/S0925-4005(99)00241-5.

[23] A. D'Amico, C. Di Natale, and P. M. Sarro, "Ingredients for sensors science," Sensors Actuators, B Chem., vol. 207, no. PB, pp. 10601068, 2015, doi: 10.1016/j.snb.2014.07.065.

[24] P. T. Mosely and B. C. Tofield, "Semiconductor gas sensors," Sensors and Actuators, vol. 1, no. July, pp. 505-509, 1985, doi: 10.1016/0250-6874(81)80054-6. 
[25] A. Dey, "Semiconductor metal oxide gas sensors: A review," Mater. Sci. Eng. B Solid-State Mater. Adv. Technol., vol. 229, no. November 2017, pp. 206-217, 2018, doi: 10.1016/j.mseb.2017.12.036.

[26] C. Wang, L. Yin, L. Zhang, D. Xiang, and R. Gao, "Metal oxide gas sensors: Sensitivity and influencing factors," Sensors, vol. 10, no. 3, pp. 2088-2106, 2010, doi: 10.3390/s100302088.

[27] M. J. Madou and S. R. Morrison, Chemical Sensing with Solid State Devices. San Diego: Academic Press, 1989.

[28] N. Barsan, D. Koziej, and U. Weimar, "Metal oxide-based gas sensor research: How to?," Sensors Actuators, B Chem., vol. 121, no. 1, pp. 18-35, 2007, doi: 10.1016/j.snb.2006.09.047.

[29] K. S. Novoselov, A. K. Geim, S. V. Morozov, D. Jiang, Y. Zhang, S. V. Dubonos, I. V. Grigorieva, and A. A. Firsov, "Electric Field Effect in Atomically Thin Carbon Films," Science (80-. )., vol. 306, pp. 666669, 2004, doi: 10.1126/science.1102896.

[30] F. Bonaccorso, Z. Sun, T. Hasan, and A. C. Ferrari, "Graphene photonics and optoelectronics," Nat. Photonics, vol. 4, no. 9, pp. 611-622, 2010, doi: 10.1038/nphoton.2010.186.

[31] A. H. Castro Neto, F. Guinea, N. M. R. Peres, K. S. Novoselov, and A. K. Geim, "The electronic properties of graphene," Rev. Mod. Phys., vol. 81, no. 1, pp. 109-162, 2009, doi: 10.1103/RevModPhys.81.109.

[32] J. Lloyd-Hughes and T. I. Jeon, "A review of the terahertz conductivity of bulk and nano-materials," J. Infrared, Millimeter, Terahertz Waves, vol. 33, no. 9, pp. 871-925, 2012, doi: 10.1007/s10762-012-9905-y.

[33] A. Nag, A. Mitra, and S. C. Mukhopadhyay, "Graphene and its sensor-based applications: A review," Sensors Actuators, A Phys., vol. 270, pp. 177-194, 2018, doi: 10.1016/j.sna.2017.12.028.

[34] J. Huang, J. A. Alexander-Webber, A. M. R. Baker, T. J. B. M. Janssen, A. Tzalenchuk, V. Antonov, T. Yager, S. Lara-Avila, S. Kubatkin, R. Yakimova, and R. J. Nicholas, "Disorder induced Dirac-point physics in epitaxial graphene from temperaturedependent magneto-transport measurements," Phys. Rev. B Condens. Matter Mater. Phys., vol. 92, no. 7, pp. 1-6, 2015, doi: 10.1103/PhysRevB.92.075407.

[35] E. Mostaani, N. D. Drummond, and V. I. Fal'ko, "Quantum Monte Carlo Calculation of the Binding Energy of Bilayer Graphene," Phys. Rev. Lett., vol. 115, no. 11, pp. 1-5, 2015, doi: 10.1103/PhysRevLett.115.115501.

[36] Yomach, "Graphene Brillouin Zone \& Linear Dispersion," 2014. https://commons.wikimedia.org/wiki/File:Graphene_Brillouin_Zon e_\%26_Linear_Dispersion.PNG (accessed Mar. 28, 2021). 
[37] G. R. Yazdi, R. Vasiliauskas, T. Iakimov, A. Zakharov, M. Syväjärvi, and R. Yakimova, "Growth of large area monolayer graphene on $3 \mathrm{C}-\mathrm{SiC}$ and a comparison with other $\mathrm{SiC}$ polytypes," Carbon N. Y., vol. 57, pp. 477-484, 2013, doi: 10.1016/j.carbon.2013.02.022.

[38] W. F. Knippenberg, "Growth Phenomena in Silicon Carbide," Philips Res. Reports, vol. 18, no. R480, pp. 161-274, 1963.

[39] C. Virojanadara, M. Syväjarvi, R. Yakimova, L. I. Johansson, A. A. Zakharov, and T. Balasubramanian, "Homogeneous large-area graphene layer growth on $6 \mathrm{H}-\mathrm{SiC}(0001)$," Phys. Rev. B - Condens. Matter Mater. Phys., vol. 78, no. 24, pp. 1-6, 2008, doi: 10.1103/PhysRevB.78.245403.

[40] U. Starke and C. Riedl, "Epitaxial graphene on $\mathrm{SiC}(0001)$ and $\mathrm{SiC}(000-1)$ : from surface reconstructions to carbon electronics," $J$. Phys. Condens. Matter, vol. 21, no. 13, 2009, doi: 10.1088/09538984/21/13/134016.

[41] K. von Klitzing, "The quantized Hall effect," Rev. Mod. Phys., vol. 58, no. 3, pp. 519-531, 1986, doi: 10.1103/RevModPhys.58.519.

[42] A. Tzalenchuk, S. Lara-Avila, A. Kalaboukhov, S. Paolillo, M. Syväjärvi, R. Yakimova, O. Kazakova, T. J. B. M. Janssen, V. Fal'Ko, and S. Kubatkin, "Towards a quantum resistance standard based on epitaxial graphene," Nat. Nanotechnol., vol. 5, no. 3, pp. 186-189, 2010, doi: 10.1038/nnano.2009.474.

[43] M. Beshkova, L. Hultman, and R. Yakimova, "Device applications of epitaxial graphene on silicon carbide," Vacuum, vol. 128, pp. 186197, 2016, doi: 10.1016/j.vacuum.2016.03.027.

[44] I. Razado-Colambo, J. Avila, D. Vignaud, S. Godey, X. Wallart, D. P. Woodruff, and M. C. Asensio, "Structural determination of bilayer graphene on $\mathrm{SiC}(0001)$ using synchrotron radiation photoelectron diffraction," Sci. Rep., vol. 8, no. 1, pp. 1-10, 2018, doi: 10.1038/s41598-018-28402-0.

[45] S. V. Kopylov, A. Tzalenchuk, S. Kubatkin, and V. I. Fal'ko, "Charge transfer between epitaxial graphene and silicon carbide," Appl. Phys. Lett., vol. 97, no. 11, pp. 11-14, 2010, doi: 10.1063/1.3487782.

[46] C. Riedl, C. Coletti, T. Iwasaki, A. A. Zakharov, and U. Starke, "Quasi-free-standing epitaxial graphene on $\mathrm{SiC}$ obtained by hydrogen intercalation," Phys. Rev. Lett., vol. 103, no. 24, pp. 1-4, 2009, doi: 10.1103/PhysRevLett.103.246804.

[47] I. Shtepliuk, I. G. Ivanov, T. Iakimov, R. Yakimova, A. Kakanakova-Georgieva, P. Fiorenza, and F. Giannazzo, "Raman probing of hydrogen-intercalated graphene on Si-face $4 \mathrm{H}$-SiC," Mater. Sci. Semicond. Process., vol. 96, pp. 145-152, 2019, doi: 10.1016/j.mssp.2019.02.039. 
[48] K. S. Novoselov, A. K. Geim, S. V. Morozov, D. Jiang, M. I. Katsnelson, I. V. Grigorieva, S. V. Dubonos, and A. A. Firsov, "Twodimensional gas of massless Dirac fermions in graphene," Nature, vol. 438, no. 7065, pp. 197-200, 2005, doi: 10.1038/nature04233.

[49] G. Liu, W. Stillman, S. Rumyantsev, Q. Shao, M. Shur, and A. A. Balandin, "Low-frequency electronic noise in the double-gate single-layer graphene transistors," Appl. Phys. Lett., vol. 95, no. 3, pp. 1-4, 2009, doi: 10.1063/1.3180707.

[50] M. Pumera, A. Ambrosi, A. Bonanni, E. L. K. Chng, and H. L. Poh, "Graphene for electrochemical sensing and biosensing," $\operatorname{Tr} A C$ Trends Anal. Chem., vol. 29, no. 9, pp. 954-965, 2010, doi: 10.1016/j.trac.2010.05.011.

[51] F. Schedin, A. K. Geim, S. V. Morozov, E. W. Hill, P. Blake, M. I. Katsnelson, and K. S. Novoselov, "Detection of individual gas molecules adsorbed on graphene," Nat. Mater., vol. 6, no. 9, pp. 652655, 2007, doi: 10.1038/nmat1967.

[52] F. Yavari, E. Castillo, H. Gullapalli, P. M. Ajayan, and N. Koratkar, "High sensitivity detection of NO2 and NH3 in air using chemical vapor deposition grown graphene," Appl. Phys. Lett., vol. 100, no. 20, 2012, doi: 10.1063/1.4720074.

[53] S. S. Varghese, S. Lonkar, K. K. Singh, S. Swaminathan, and A. Abdala, "Recent advances in graphene based gas sensors," Sensors Actuators, B Chem., vol. 218, pp. 160-183, 2015, doi: 10.1016/j.snb.2015.04.062.

[54] N. Briggs, Z. M. Gebeyehu, A. Vera, T. Zhao, K. Wang, A. De La Fuente Duran, B. Bersch, T. Bowen, K. L. Knappenberger, and J. A. Robinson, "Epitaxial graphene/silicon carbide intercalation: A minireview on graphene modulation and unique 2D materials," Nanoscale, vol. 11, no. 33, pp. 15440-15447, 2019, doi: 10.1039/c9nr03721g.

[55] Y. You, J. Deng, X. Tan, N. Gorjizadeh, M. Yoshimura, S. C. Smith, V. Sahajwalla, and R. K. Joshi, "On the mechanism of gas adsorption for pristine, defective and functionalized graphene," Phys. Chem. Chem. Phys., vol. 19, no. 8, pp. 6051-6056, 2017, doi: 10.1039/c6cp07654h.

[56] Y. H. Zhang, Y. Bin Chen, K. G. Zhou, C. H. Liu, J. Zeng, H. L. Zhang, and Y. Peng, "Improving gas sensing properties of graphene by introducing dopants and defects: A first-principles study," Nanotechnology, vol. 20, no. 18, 2009, doi: 10.1088/09574484/20/18/185504.

[57] A. Berholts, T. Kahro, A. Floren, H. Alles, and R. Jaaniso, "Photoactivated oxygen sensitivity of graphene at room temperature," Appl. Phys. Lett., vol. 105, no. 16, 2014, doi: 10.1063/1.4899276. 
[58] C. Bur, "Selectivity Enhancement of Gas Sensitive Field Effect Transistors by Dynamic Operation," Saarland University, Saarbrücken, 2015.

[59] C. Bur, M. Bastuck, D. Puglisi, A. Schütze, A. Lloyd Spetz, and M. Andersson, "Discrimination and quantification of volatile organic compounds in the ppb-range with gas sensitive SiC-FETs using multivariate statistics," in Sensors and Actuators, B: Chemical, 2015, vol. 214, pp. 225-233, doi: 10.1016/j.snb.2015.03.016.

[60] M. Rodner, M. Bastuck, A. Schütze, M. Andersson, J. Huotari, J. Puustinen, J. Lappalainen, and T. Sauerwald, "Enabling a new method of dynamic field-effect gas sensor operation through lithium-doped tungsten oxide," J. Sensors Sens. Syst., vol. 8, no. 2, pp. 261-267, 2019, doi: 10.5194/jsss-8-261-2019.

[61] E. Gonzalez, E. Llobet, A. Romero, and X. Vilanova, "A New Approach to NO2 Gas Sensing Based on Pulsed UV Light and FFT Analysis Using MOX Sensors," IEEE Sens. J., vol. 20, no. 1, pp. 397-404, 2020, doi: 10.1109/JSEN.2019.2942490.

[62] F. Yavari and N. Koratkar, "Graphene-based chemical sensors," J. Phys. Chem. Lett., vol. 3, no. 13, pp. 1746-1753, 2012, doi: 10.1021/jz300358t.

[63] A. Di Bartolomeo, "Graphene Schottky diodes: An experimental review of the rectifying graphene/semiconductor heterojunction," Phys. Rep., vol. 606, pp. 1-58, 2016, doi: 10.1016/j.physrep.2015.10.003.

[64] S. Y. Zhou, G. H. Gweon, A. V. Fedorov, P. N. First, W. A. De Heer, D. H. Lee, F. Guinea, A. H. Castro Neto, and A. Lanzara, "Substrate-induced bandgap opening in epitaxial graphene," Nat. Mater., vol. 6, no. 10, pp. 770-775, 2007, doi: 10.1038/nmat2003.

[65] N. Barsan and U. Weimar, "Conduction model of metal oxide gas sensors," J. Electroceramics, vol. 7, pp. 143-167, 2001, doi: 10.1023/A:1014405811371.

[66] Y. F. Sun, S. B. Liu, F. L. Meng, J. Y. Liu, Z. Jin, L. T. Kong, and J. H. Liu, "Metal oxide nanostructures and their gas sensing properties: A review,” Sensors, vol. 12, no. 3, pp. 2610-2631, 2012, doi: 10.3390/s120302610.

[67] S. Marco and A. Gutierrez-Galvez, "Signal and data processing for machine olfaction and chemical sensing: A review," IEEE Sens. J., vol. 12, no. 11, pp. 3189-3214, 2012, doi: 10.1109/JSEN.2012.2192920.

[68] M. Bastuck, "Improving the Performance of Gas Sensor Systems with Advanced Data Evaluation, Operation, and Calibration Methods," Linköping University, 2019. 
[69] A. Gramm and A. Schütze, "High performance solvent vapor identification with a two sensor array using temperature cycling and pattern classification," Sensors Actuators B Chem., vol. 95, no. 1-3, pp. 58-65, 2003, doi: 10.1016/S0925-4005(03)00404-0.

[70] R. Gutierrez-Osuna, "Pattern analysis for machine olfaction: A review," IEEE Sens. J., vol. 2, no. 3, pp. 189-202, 2002, doi: 10.1109/JSEN.2002.800688.

[71] R. Duda, P. Hart, and D. Stork, Pattern Classification. John Wiley \& Sons, 2001.

[72] R. A. Fisher, "The Use of Multiple Measurements in Taxonomic Problems," Ann. Eugen., vol. 7, no. 2, pp. 179-188, 1936, doi: 10.1111/j.1469-1809.1936.tb02137.x.

[73] D. Depla, S. Mahieu, and J. E. Greene, "Sputter Deposition Processes," in Handbook of Deposition Technologies for Films and Coatings, Third., P. M. Martin, Ed. Elsevier, 2010, pp. 253-296.

[74] Y. Yamamura and H. Tawara, "Energy dependence of ion-induced sputtering yields from monatomic solids at normal incidence," At. Data Nucl. Data Tables, vol. 62, no. 2, pp. 149-253, 1996, doi: 10.1006/adnd.1996.0005.

[75] M. Ohring, Materials Science of Thin Films. Academic Press, 1992.

[76] I. Pilch, D. Söderström, N. Brenning, and U. Helmersson, "Sizecontrolled growth of nanoparticles in a highly ionized pulsed plasma," Appl. Phys. Lett., vol. 102, no. 3, 2013, doi: 10.1063/1.4788739.

[77] R. Gunnarsson, U. Helmersson, and I. Pilch, "Synthesis of titanium-oxide nanoparticles with size and stoichiometry control," J. Nanoparticle Res., vol. 17, no. 9, pp. 1-11, 2015, doi: 10.1007/s11051-015-3158-3.

[78] M. Rodner, "Lithium doped tungsten oxide films for gas sensor applications," Saarland University, 2016.

[79] G. S. Bumbrah and R. M. Sharma, "Raman spectroscopy - Basic principle, instrumentation and selected applications for the characterization of drugs of abuse," Egypt. J. Forensic Sci., vol. 6, no. 3, pp. 209-215, 2016, doi: 10.1016/j.ejfs.2015.06.001.

[80] L. M. Malard, M. A. Pimenta, G. Dresselhaus, and M. S. Dresselhaus, "Raman spectroscopy in graphene," Phys. Rep., vol. 473, no. 5-6, pp. 51-87, 2009, doi: 10.1016/j.physrep.2009.02.003.

[81] I. G. Ivanov, J. U. Hassan, T. Iakimov, A. A. Zakharov, R. Yakimova, and E. Janzén, "Layer-number determination in graphene on $\mathrm{SiC}$ by reflectance mapping," Carbon N. Y., vol. 77, pp. 492-500, 2014, doi: 10.1016/j.carbon.2014.05.054. 
[82] I. Shtepliuk, I. G. Ivanov, N. Pliatsikas, T. Iakimov, A. Jamnig, K. Sarakinos, and R. Yakimova, "Probing the uniformity of silverdoped epitaxial graphene by micro-Raman mapping," Phys. B Condens. Matter, p. 411751, 2019, doi: 10.1016/j.physb.2019.411751.

[83] P. Hohenberg and W. Kohn, "Inhomogeneous Electron Gas," Phys. Rev., vol. 136, no. 3B, pp. 864-871, 1964, doi: 10.1007/BF01198136.

[84] M. J. Frisch, G. W. Trucks, H. E. Schlegel, G. E. Scuseria, M. A. Robb, J. R. Cheeseman, G. Scalmani, V. Barone, G. A. Petersson, F. O., J. B. Foresman, and J. D. Fox, "Gaussian 16," Gaussian, Inc., Wallingford CT, . Gaussian Inc, Wallingford CT, 2016.

[85] Y. Zhao and D. G. Truhlar, "A new local density functional for maingroup thermochemistry, transition metal bonding, thermochemical kinetics, and noncovalent interactions," J. Chem. Phys., vol. 125, no. 19, 2006, doi: 10.1063/1.2370993.

[86] Y. Zhao and D. G. Truhlar, "The M06 suite of density functionals for main group thermochemistry, thermochemical kinetics, noncovalent interactions, excited states, and transition elements: Two new functionals and systematic testing of four M06-class functionals and 12 other function," Theor. Chem. Acc., vol. 120, no. 1-3, pp. 215-241, 2008, doi: 10.1007/s00214-007-0310-x.

[87] P. J. Hay and W. R. Wadt, "Ab initio effective core potentials for molecular calculations. Potentials for $\mathrm{K}$ to $\mathrm{Au}$ including the outermost core orbitale," J. Chem. Phys., vol. 82, no. 1, pp. 299-310, 1985, doi: 10.1063/1.448975.

[88] S. F. Boys and F. Bernardi, "The calculation of small molecular interactions by the differences of separate total energies. Some procedures with reduced errors," Mol. Phys., vol. 19, no. 4, pp. 553566, 1970, doi: 10.1080/00268977000101561.

[89] A. C. Ferrari et al., "Science and technology roadmap for graphene, related two-dimensional crystals, and hybrid systems," Nanoscale, vol. 7, no. 11, pp. 4598-4810, 2015, doi: 10.1039/c4nr01600a.

[90] B. Deng, Z. Liu, and H. Peng, "Toward Mass Production of CVD Graphene Films," Adv. Mater., vol. 31, no. 9, pp. 1-25, 2019, doi: 10.1002/adma.201800996.

[91] L. Lin, H. Peng, and Z. Liu, "Synthesis challenges for graphene industry," Nat. Mater., vol. 18, no. 6, pp. 520-524, 2019, doi: 10.1038/s41563-019-0341-4.

[92] G. R. Yazdi, T. Iakimov, and R. Yakimova, "Epitaxial graphene on SiC: A review of growth and characterization," Crystals, vol. 6, no. 5, 2016, doi: 10.3390/cryst6050053. 
[93] R. Yakimova, C. Virojanadara, D. Gogova, M. Syväjärvi, D. Siche, K. Larsson, and L. I. Johansson, "Analysis of the formation conditions for large area epitaxial graphene on $\mathrm{SiC}$ substrates," Mater. Sci. Forum, vol. 645-648, pp. 565-568, 2010, doi: 10.4028/www.scientific.net/MSF.645-648.565.

[94] F. Giannazzo, I. Shtepliuk, I. G. Ivanov, T. Iakimov, A. Kakanakova-Georgieva, E. Schiliro, P. Fiorenza, and R. Yakimova, "Probing the uniformity of hydrogen intercalation in quasi-freestanding epitaxial graphene on SiC by micro-Raman mapping and conductive atomic force microscopy," Nanotechnology, vol. 30, no. 28, 2019, doi: 10.1088/1361-6528/ab134e.

[95] C. Bur, "New method for selectivity enhancement of SiC field effect gas sensors for quantification of NOx," Saarland University, 2012.

[96] M. Bastuck, T. Baur, and A. Schütze, "DAV3E - a MATLAB toolbox for multivariate sensor data evaluation," Sensors, pp. 489-506, 2018.

[97] A. Lloyd Spetz and M. Andersson, "Technology and Application Opportunities for SiC-FET Gas Sensors," in Solid State Gas Sensors - Industrial Application, M. Fleischer and M. Lehmann, Eds. Berlin: Springer, 2011, pp. 189-214.

[98] M. Leidinger, C. Schultealbert, J. Neu, A. Schütze, and T. Sauerwald, "Characterization and calibration of gas sensor systems at ppb level - A versatile test gas generation system," Meas. Sci. Technol., vol. 29, no. 1, 2018, doi: 10.1088/1361-6501/aa91da.

[99] N. Helwig, M. Schüler, C. Bur, A. Schütze, and T. Sauerwald, "Gas mixing apparatus for automated gas sensor characterization," Meas. Sci. Technol., vol. 25, no. 5, p. 055903, 2014, doi: 10.1088/0957-0233/25/5/055903.

[100] World Health Organisation, "Guidelines for Indoor Air Quality: Selected Pollutants," WHO Guidel., vol. 9, p. 454, 2010.

[101] The European Parliament and the Council of the European Union, "DIRECTIVE 2008/50/EC OF THE EUROPEAN PARLIAMENT AND OF THE COUNCIL of 21 May 2008 on ambient air quality and cleaner air for Europe," Off. J. Eur. Communities, pp. 1-43, 2008 , doi: http://eurlex.europa.eu/LexUriServ/LexUriServ.do?uri=OJ:L:2008:152:0001: 0044:EN:PDF.

[102] The Commission of the European Communities, "EU exposure limit chemical agents at work, Comission Directive 2000/39/EC," Off. J. Eur. Communities, vol. L142, no. 47, 2001, [Online]. Available: https://eur-lex.europa.eu/legalcontent/en/ALL/?uri=CELEX\%3A32000L0039. 
[103] H. Jasuja, G. W. Peterson, J. B. Decoste, M. A. Browe, and K. S. Walton, "Evaluation of MOFs for air purification and air quality control applications: Ammonia removal from air," Chem. Eng. Sci., vol. 124, pp. 118-124, 2015, doi: 10.1016/j.ces.2014.08.050.

[104] S. N. Behera and M. Sharma, "Investigating the potential role of ammonia in ion chemistry of fine particulate matter formation for an urban environment," Sci. Total Environ., vol. 408, no. 17, pp. 3569-3575, 2010, doi: 10.1016/j.scitotenv.2010.04.017.

[105] D. Rüffer, F. Hoehne, and J. Bühler, "New digital metal-oxide (MOx) sensor platform," Sensors (Switzerland), vol. 18, no. 4, 2018, doi: 10.3390/s18041052.

[106] V. Palmisano, L. Boon-Brett, C. Bonato, F. Harskamp, W. J. Buttner, M. B. Post, R. Burgess, and C. Rivkin, "Evaluation of selectivity of commercial hydrogen sensors," Int. J. Hydrogen Energy, vol. 39, no. 35, pp. 20491-20496, 2014, doi: 10.1016/j.ijhydene.2014.03.251.

[107] European Environment Agency, "Nitrogen oxides (NOx) emissions," Copenhagen, 2014.

[108] The European Parliament and the Council of the European Union, "Directive 2004/42/CE on the limitation of emissions of volatile organic compounds due to the use of organic solvents in certain paints and varnishes and vehicle refinishing products and amending Directive 1999/13/EC," Off. J. Eur. Union, vol. L143, no. 47, pp. 87-96, 2004, [Online]. Available: https://eurlex.europa.eu/legalcontent/EN/TXT/PDF/?uri=CELEX:32004L0042\&from=EN.

[109] The Council of the European Union, "Council Directive 1999/13/EC of 11 March 1999 on the limitation of emissions of volatile organic compounds due to the use of organic solvents in certain activities and installations," Off. J. Eur. Communities, vol. L85, no. 42, pp. 1-22, 1999, doi: http://eurlex.europa.eu/LexUriServ/LexUriServ.do?uri=OJ:L:1999:085:0001: 0022:EN:PDF.

[110] US Environmental Protection Agency, "40 CFR Part 51, Subpart F - Procedural Requirements,” 2018. [Online]. Available: https://www.govinfo.gov/content/pkg/CFR-2018-title40vol2/xml/CFR-2018-title40-vol2-part51.xml\#seqnum51.100.

[111] L. Zhong, S. Batterman, and C. W. Milando, "VOC sources and exposures in nail salons: a pilot study in Michigan, USA," Int. Arch. Occup. Environ. Health, vol. 92, no. 1, pp. 141-153, 2019, doi: 10.1007/s00420-018-1353-0. 
[112] OEHHA California Office of Environmental Health Hazard Assessmen, "OEHHA Acute, 8-hour and Chronic Reference Exposure Level (REL) Summary,” 2020. https://oehha.ca.gov/air/general-info/oehha-acute-8-hour-andchronic-reference-exposure-level-rel-summary (accessed Mar. 28, 2021).

[113] Ministère de l'Ecologie du Développement Durable des Transports et du Logement, "Décret no 2011-1727 du 2 décembre 2011 relatif aux valeurs-guides pour l'air intérieur pour le formaldéhyde et le benzène," $2011 . \quad$ [Online]. Available: https://www.legifrance.gouv.fr/affichTexte.do?cidTexte=JORFTEX T000024909119\&categorieLien=id.

[114] M. Schiavon, M. Redivo, G. Antonacci, E. C. Rada, M. Ragazzi, D. Zardi, and L. Giovannini, "Assessing the air quality impact of nitrogen oxides and benzene from road traffic and domestic heating and the associated cancer risk in an urban area of Verona (Italy)," Atmos. Environ., vol. 120, pp. 234-243, 2015, doi: 10.1016/j.atmosenv.2015.08.054.

[115] G. D. Nielsen, S. T. Larsen, and P. Wolkoff, "Re-evaluation of the WHO (2010) formaldehyde indoor air quality guideline for cancer risk assessment," Arch. Toxicol., vol. 91, no. 1, pp. 35-61, 2017, doi: 10.1007/s00204-016-1733-8.

[116] T. Yager, "Epitaxial Graphene Technology for Quantum Metrology," Chalmers University of Technology, 2015.

[117] Y. C. Lin, C. C. Lu, C. H. Yeh, C. Jin, K. Suenaga, and P. W. Chiu, "Graphene annealing: How clean can it be?," Nano Lett., vol. 12, no. 1, pp. 414-419, 2012, doi: 10.1021/nl203733r.

[118] K. H. Kim, H. He, M. Rodner, R. Yakimova, K. Larsson, M. Piantek, D. Serrate, A. Zakharov, S. Kubatkin, J. Eriksson, and S. LaraAvila, "Chemical sensing with atomically-thin metals templated by a two- dimensional insulator," Adv. Mater. Interfaces, vol. 1902104, pp. 1-7, 2020, doi: 10.1002/admi.201902104.

[119] D. S. Lee, C. Riedl, B. Krauss, K. Von Klitzing, U. Starke, and J. H. Smet, "Raman spectra of epitaxial graphene on $\mathrm{SiC}$ and of epitaxial graphene transferred to SiO2," Nano Lett., vol. 8, no. 12, pp. 43204325, 2008, doi: 10.1021/nl802156w.

[120] A. C. Ferrari, "Raman spectroscopy of graphene and graphite: Disorder, electron-phonon coupling, doping and nonadiabatic effects," Solid State Commun., vol. 143, no. 1-2, pp. 47-57, 2007, doi: 10.1016/j.ssc.2007.03.052. 
[121] C. Bouhafs, A. A. Zakharov, I. G. Ivanov, F. Giannazzo, J. Eriksson, V. Stanishev, P. Kühne, T. Iakimov, T. Hofmann, M. Schubert, F. Roccaforte, R. Yakimova, and V. Darakchieva, "Multi-scale investigation of interface properties, stacking order and decoupling of few layer graphene on C-face $4 \mathrm{H}-\mathrm{SiC}$," Carbon N. Y., vol. 116, pp. 722-732, 2017, doi: 10.1016/j.carbon.2017.02.026.

[122] A. Zandiatashbar, G. H. Lee, S. J. An, S. Lee, N. Mathew, M. Terrones, T. Hayashi, C. R. Picu, J. Hone, and N. Koratkar, "Effect of defects on the intrinsic strength and stiffness of graphene," Nat. Commun., vol. 5, pp. 1-9, 2014, doi: 10.1038/ncomms4186.

[123] E. Del Corro, M. Taravillo, and V. G. Baonza, "Nonlinear strain effects in double-resonance Raman bands of graphite, graphene, and related materials," Phys. Rev. B - Condens. Matter Mater. Phys., vol. 85, no. 3, pp. 1-5, 2012, doi: 10.1103/PhysRevB.85.033407.

[124] C. Melios, C. E. Giusca, V. Panchal, and O. Kazakova, "Water on graphene: Review of recent progress," 2D Mater., vol. 5, no. 2, 2018, doi: 10.1088/2053-1583/aa9ea9.

[125] N. Barsan and U. Weimar, "Understanding the fundamental principles of metal oxide based gas sensors; the example of $\mathrm{CO}$ sensing with $\mathrm{SnO} 2$ sensors in the presence of humidity," J. Phys. Condens. Matter, vol. 15, no. 20, 2003, doi: 10.1088/0953$8984 / 15 / 20 / 201$.

[126] E. C. Dickey, O. K. Varghese, K. G. Ong, D. Gong, M. Paulose, and C. A. Grimes, "Room Temperature Ammonia and Humidity Sensing Using Highly Ordered Nanoporous Alumina Films," Sensors, vol. 2, pp. 91-110, 2002, doi: 10.3390/s20300091.

[127] E. H. Hwang, S. Adam, and S. Das Sarma, "Transport in chemically doped graphene in the presence of adsorbed molecules," Phys. Rev. B - Condens. Matter Mater. Phys., vol. 76, no. 19, pp. 1-6, 2007, doi: 10.1103/PhysRevB.76.195421.

[128] G. Chen, T. M. Paronyan, and A. R. Harutyunyan, "Sub-ppt gas detection with pristine graphene," Appl. Phys. Lett., vol. 101, no. 5, 2012, doi: $10.1063 / 1.4742327$.

[129] A. Cagliani, D. M. A. Mackenzie, L. K. Tschammer, F. Pizzocchero, K. Almdal, and P. Bøggild, "Large-area nanopatterned graphene for ultrasensitive gas sensing," Nano Res., vol. 7, no. 5, pp. 743-754, 2014, doi: 10.1007/s12274-014-0435-x.

[130] G. Lee, G. Yang, A. Cho, J. W. Han, and J. Kim, "Defect-engineered graphene chemical sensors with ultrahigh sensitivity," Phys. Chem. Chem. Phys., vol. 18, no. 21, pp. 14198-14204, 2016, doi: 10.1039/c5cp04422g. 
[131] J. H. Lee, A. Mirzaei, J. Y. Kim, J. H. Kim, H. W. Kim, and S. S. Kim, "Optimization of the surface coverage of metal nanoparticles on nanowires gas sensors to achieve the optimal sensing performance," Sensors Actuators, B Chem., vol. 302, no. September 2019, p. 127196, 2020, doi: 10.1016/j.snb.2019.127196.

[132] K. Großmann, S. Wicker, U. Weimar, and N. Barsan, "Impact of Pt additives on the surface reactions between $\mathrm{SnO} 2$, water vapour, $\mathrm{CO}$ and H2; An operando investigation," Phys. Chem. Chem. Phys., vol. 15, no. 44, pp. 19151-19158, 2013, doi: 10.1039/c3cp52782d.

[133] S. Steinhauer, E. Lackner, F. Sosada-Ludwikowska, V. Singh, J. Krainer, R. Wimmer-Teubenbacher, P. Grammatikopoulos, A. Köck, and M. Sowwan, "Atomic-scale structure and chemical sensing application of ultrasmall size-selected Pt nanoparticles supported on SnO 2 ," Mater. Adv., vol. 1, no. 9, pp. 3200-3207, 2020, doi: 10.1039/d0ma00244e.

[134] N. Armakavicius, P. Kühne, J. Eriksson, C. Bouhafs, V. Stanishev, I. G. Ivanov, R. Yakimova, A. A. Zakharov, A. Al-Temimy, C. Coletti, M. Schubert, and V. Darakchieva, "Resolving mobility anisotropy in quasi-free-standing epitaxial graphene by terahertz optical Hall effect," Carbon N. Y., vol. 172, pp. 248-259, 2021, doi: 10.1016/j.carbon.2020.09.035.

[135] T. Hibbard and A. J. Killard, "Breath ammonia analysis: Clinical application and measurement," Crit. Rev. Anal. Chem., vol. 41, no. 1, pp. 21-35, 2011, doi: 10.1080/10408347.2011.521729.

[136] N. M. Caffrey, R. Armiento, R. Yakimova, and I. A. Abrikosov, "Changes in work function due to NO2 adsorption on monolayer and bilayer epitaxial graphene on $\mathrm{SiC}(0001)$," Phys. Rev. B, vol. 94, no. 20, pp. 1-7, 2016, doi: 10.1103/PhysRevB.94.205411.

[137] Alphasense, "NO2-A1 Nitrogen Dioxide Sensor Data Sheet," Essex, $2015 . \quad$ [Online]. Available: http://www.alphasense.com/WEB1213/wpcontent/uploads/2015/09/NO2-A1.pdf.

[138] K. Wolf, J. Cyrys, T. Harciníková, J. Gu, T. Kusch, R. Hampel, A. Schneider, and A. Peters, "Land use regression modeling of ultrafine particles, ozone, nitrogen oxides and markers of particulate matter pollution in Augsburg, Germany," Sci. Total Environ., vol. 579, pp. 1531-1540, 2017, doi: 10.1016/j.scitotenv.2016.11.160.

[139] D. J. Buckley, N. C. G. Black, E. G. Castanon, C. Melios, M. Hardman, and O. Kazakova, "Frontiers of graphene and 2D material-based gas sensors for environmental monitoring," $2 D$ Mater., vol. 7, no. 3, 2020, doi: 10.1088/2053-1583/ab7bc5. 
[140] Geotech Environmental Equipment Inc., "Honeywell ppbRAE 3000+ Data Sheet," Denver, Colorado, 2019. [Online]. Available: http://www.geotechenv.com/pdf/air_quality/minirae_ppbrae_3000. pdf.

[141] Dräger, "X-am 8000 Multi-Gas Detector Data Sheet," Lübeck, 2020. [Online]. Available: https://www.draeger.com/Products/Content/xam-8000-pi-9104484-en-master.pdf.

[142] AMS, "AS-MLV-P2 Air Quality Sensor Data Sheet," Eindhoven, 2015. [Online]. Available: https://www.sciosense.com/wpcontent/uploads/documents/AS-MLV-P2-Datasheet.pdf.

[143] Sensirion, "SGPC3 Data Sheet," Zürich, 2020. [Online]. Available: https://www.sensirion.com/fileadmin/user_upload/customers/sensi rion/Dokumente/9_Gas_Sensors/Datasheets/Sensirion_Gas_Senso rs_Datasheet_SGPC3.pdf.

[144] UST, "VOC/CO2 Sensor Data Sheet," Geschwenda, 2017. [Online]. Available:

https://www.umweltsensortechnik.de/fileadmin/assets/downloads/ gassensoren/module/Datasheet_VOC-CO2-Sensor_Rev1700.pdf.

[145] SGX Sensortech, "MiCS-VZ-89TE Data sheet," CorcellesCormondreche. [Online]. Available: https://www.sgxsensortech.com/content/uploads/2016/07/MiCS-VZ89TE-V1.0.pdf.

[146] R. Muller and E. Lange, "Multidimensional Sensor for Gas Analysis," Sensors and Actuators, vol. 9, pp. 39-48, 1986.

[147] T. Eklöv, P. Mårtensson, and I. Lundström, "Enhanced selectivity of MOSFET gas sensors by systematical analysis of transient parameters," Anal. Chim. Acta, vol. 353, no. 2-3, pp. 291-300, 1997, doi: 10.1016/S0003-2670(97)87788-4.

[148] M. Wenger, R. Waller, V. R. H. Lorentz, M. Marz, and M. Herold, "Investigation of gas sensing in large lithium-ion battery systems for early fault detection and safety improvement," IECON Proc. (Industrial Electron. Conf., pp. 5654-5659, 2014, doi: 10.1109/IECON.2014.7049366.

[149] M. Leidinger, M. Rieger, T. Sauerwald, C. Alépée, and A. Schütze, "Integrated pre-concentrator gas sensor microsystem for ppb level benzene detection," Sensors Actuators, B Chem., vol. 236, pp. 988996, 2016, doi: 10.1016/j.snb.2016.04.064.

[150] N. A. Rakow and K. S. Suslick, "A colorimetric sensor array for odour visualization," Nature, vol. 406, no. 6797, pp. 710-713, 2000, doi: 10.1038/35021028.

[151] P. Reimann and A. Schütze, "Sensor Arrays, Virtual Multisensors, Data Fusion, and Gas Sensor Data Evaluation," in Springer Series on Chemical Sensors and Biosensors, Volume 15 2014, Springer Berlin Heidelberg, 2014, pp. 67-107. 
[152] M. Bastuck, T. Baur, M. Richter, B. Mull, A. Schütze, and T. Sauerwald, "Comparison of ppb-level gas measurements with a metal-oxide semiconductor gas sensor in two independent laboratories," Sensors Actuators, B Chem., vol. 273, no. March, pp. 1037-1046, 2018, doi: 10.1016/j.snb.2018.06.097.

[153] T. Sauerwald, T. Baur, M. Leidinger, W. Reimringer, L. Spinelle, M. Gerboles, G. Kok, and A. Schütze, "Highly sensitive benzene detection with metal oxide semiconductor gas sensors - an interlaboratory comparison," J. Sensors Sens. Syst., vol. 7, no. 1, pp. 235243, 2018, doi: 10.5194/jsss-7-235-2018.

[154] W. Buttner, R. Burgess, C. Rivkin, M. Post, L. Boon-Brett, G. Black, F. Harskamp, and P. Moretto, "Round Robin Testing of Commercial Hydrogen Sensor Performance - Observations and Results: Preprint," 2010, [Online]. Available: http://www.osti.gov/bridge.

[155] A. Moritz and D. Breuer, "Production of test gases in the ppb range for round-robin tests and quality assurance measures during the measurement of VOCs," J. Environ. Monit., vol. 10, no. 12, pp. 1454-1459, 2008, doi: 10.1039/b810557j.

[156] A. Schütze, T. Baur, M. Leidinger, W. Reimringer, R. Jung, T. Conrad, and T. Sauerwald, "Highly Sensitive and Selective VOC Sensor Systems Based on Semiconductor Gas Sensors: How to?," Environments, vol. 4, no. 1, p. 20, Mar. 2017, doi: 10.3390/environments4010020.

[157] M. F. Santangelo, I. Shtepliuk, D. Filippini, D. Puglisi, M. Vagin, R. Yakimova, and J. Eriksson, "Epitaxial graphene sensors combined with 3D-printed microfluidic chip for heavy metals detection," Sensors (Switzerland), vol. 19, no. 10, pp. 1-13, 2019, doi: $10.3390 / \mathrm{s} 19102393$.

[158] M. F. Santangelo, I. Shtepliuk, D. Filippini, I. G. Ivanov, R. Yakimova, and J. Eriksson, "Real-time sensing of lead with epitaxial graphene-integrated microfluidic devices," Sensors Actuators, B Chem., vol. 288, no. February, pp. 425-431, 2019, doi: 10.1016/j.snb.2019.03.021.

[159] World Health Organisation, "Lead in Drinking-water," Geneva, 2011.

[Online]. Available: https://www.who.int/water_sanitation_health/dwq/chemicals/lead. pdf.

[160] A. Zilli, "Design and test of a graphene-based sensor towards detection of cancer biomarkers," Linköping University, 2020.

[161] I. Cederquist, "Bioinspired smell sensor to trace pheromone released by the European spruce bark beetle," Linköping University, 2020. 
References

[162] R. M. McCormick and B. L. Karger, "Guidelines For Data Acquisition And Data Quality Evaluation In Environmental Chemistry," Anal. Chem., vol. 52, no. 14, pp. 2242-2249, 1980, doi: 10.1021/ac50064a004. 


\section{Abbreviations}

$\begin{array}{ll}\text { AFM } & \text { Atomic Force Microscopy } \\ \text { AQM } & \text { Air Quality Monitoring } \\ \text { BSSE } & \text { Basis Set Superposition Error } \\ \text { BZ } & \text { Brillouin Zone } \\ \text { CNT } & \text { Carbonanotube } \\ \text { CCD } & \text { Charge-Coupled Device } \\ \text { CDA } & \text { Canonical Discriminant Analysis } \\ \text { CVD } & \text { Chemical Vapor Deposition } \\ \text { DEG } & \text { Decorated Epitaxial Graphene } \\ \text { DFT } & \text { Density Functional Theory } \\ \text { DOS } & \text { Density Of States } \\ \text { EG } & \text { Epitaxial Graphene } \\ \text { FET } & \text { Field Effect Transistor } \\ \text { FWHM } & \text { Full Width at Half Maximum } \\ \text { GMA } & \text { Gas Mixing Apparatus } \\ \text { IEG } & \text { Intercalated Epitaxial Graphene } \\ \text { LANL2DZ } & \text { Los Alamos National Laboratory 2 Double-Zeta } \\ \text { LDA } & \text { Linear Discriminant Analysis } \\ \text { LED } & \text { Light Emitting Diode } \\ \text { LOD } & \text { Limit Of Detection } \\ \text { MFC } & \text { Mass Flow Controller } \\ \text { MOS } & \text { Metal Oxide Semiconductor } \\ \text { NL } & \text { Nanolayer } \\ \text { NP } & \text { Nanoparticle } \\ \text { PBS } & \text { Phosphate-Buffered Saline } \\ \text { PCA } & \text { Principal Component Analysis } \\ \text { PEG } & \text { Pristine Epitaxial Graphene } \\ \text { PFA } & \text { Perfluoroalkoxy Alkane } \\ \text { PID } & \text { Photo-Ionization Detector } \\ \text { PLD } & \text { Pulsed Laser Deposition } \\ \text { PVD } & \text { Physical Vapor Deposition } \\ \text { QHE } & \text { Quantum Hall Effect } \\ \text { REL } & \text { chronic Reference Exposure Level } \\ \text { RH } & \text { Relative Humidity } \\ \text { SNR } & \text { Signal-to-Noise-Ratio } \\ & \end{array}$


Abbreviations

$\begin{array}{ll}\text { TVOC } & \text { Total Volatile Organic Compounds } \\ \text { UV } & \text { Ultraviolet } \\ \text { VOC } & \text { Volatile Organic Compound } \\ \text { WHO } & \text { World Health Organization }\end{array}$




\section{Papers}

The papers associated with this thesis have been removed for copyright reasons. For more details about these see:

http://urn.kb.se/resolve?urn=urn:nbn:se:liu:diva-174680 


\section{FACULTY OF SCIENCE AND ENGINEERING}

Linköping Studies in Science and Technology, Dissertation Thesis No. 2134, 2021 Department of Physics, Chemistry and Biology

Linköping University

SE-581 83 Linköping, Sweden

www.liu.se

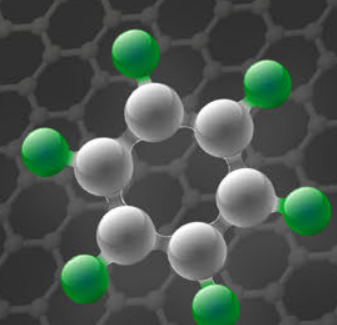

